University of Redlands

\title{
A GIS for Balboa Park’s Desert Garden in San Diego, California
}

A Major Individual Project submitted in partial satisfaction of the requirements for the degree of Master of Science in Geographic Information Systems

\author{
by \\ Gina Seiko Durizzi
}

Mark Kumler, Ph.D., Chair

James A. Ciarrocca, M.S.

Paul Sirois

August 2007 
A GIS for Balboa Park’s Desert Garden in San Diego, California

Copyright (C) 2007

by

Gina Seiko Durizzi 
The report of Gina Seiko Durizzi is approved.

Mark Kumler, Ph.D.

James A. Ciarrocca, M.S.

Paul Sirois

August 2007 



\section{ACKNOWLEDGEMENTS}

I would like to thank my kind mother, Seiko Durizzi, and understanding boyfriend, Mark Herbst, for making it possible for me to journey to Redlands and spend a year away from them, my dogs and work. Thanks Chisa, Mike, Mark, Tom, Tim, and Ruth for letting me twist your arms in joining my relentless food marathon and trying to keep up with me! Thank you Chisa for your friendship and good influence on my study habits! I appreciate all the support and help that I received from my client, Paul Sirois, MIP advisor and program director, Dr. Mark Kumler, and adjunct professor, Jim Ciarrocca, for their wisdom, honesty, and encouragement. My thanks to the Fox and Stell's Coffee House for letting me hang out to study all day with the purchase of an iced tea... and, finally, thank you Holy Name of Jesus Catholic Church, Ruth, and Tom for the rockin’ Sundays! 

ABSTRACT

\title{
A GIS for Balboa Park's Desert Garden in San Diego, California
}

\author{
by \\ Gina Seiko Durizzi
}

Balboa Park's Desert Garden in San Diego, California, contains a collection of desert plants from around the world that attracts a growing number of park enthusiasts each year. The park's staff desires a GIS inventory of the garden's assets and spatial tools to aid in querying, reporting, analyzing, and mapping. A quality garden inventory made available to the public for educational purposes will fulfill one of the criteria for future accreditation provided by the American Association of Museums. This project provides: (a) a geodatabase of the plant inventory and garden infrastructure, (b) georeferenced digital photographs of garden features, (c) a digital elevation model compiled from lidar data and a related 3-D land surface map, (d) a map and brochure for the garden's information kiosk and Balboa Park visitor center, (e) an interactive web mapping service for the public to explore the garden via the internet, and (f) a project workflow poster. 



\section{Table of Contents}

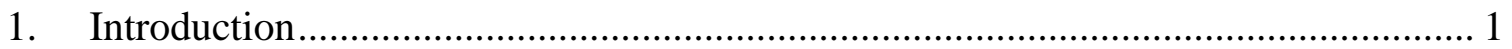

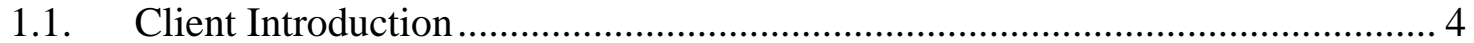

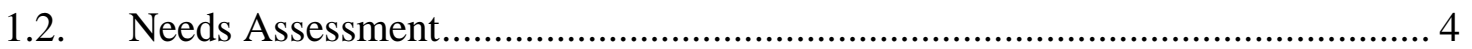

2. Background and Literature Search.............................................................. 7

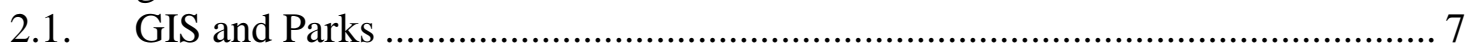

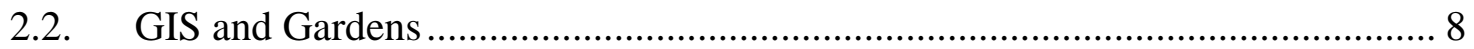

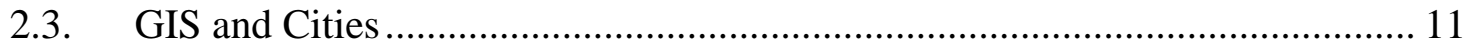

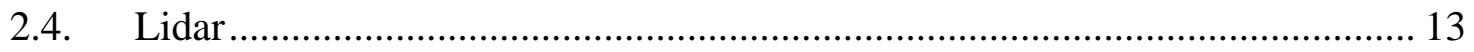

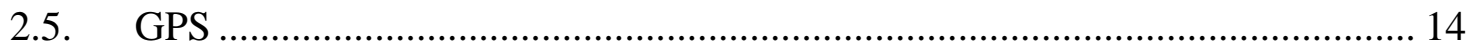

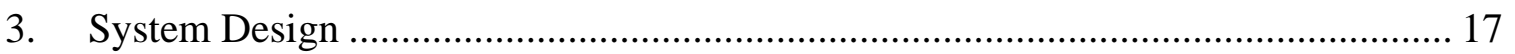

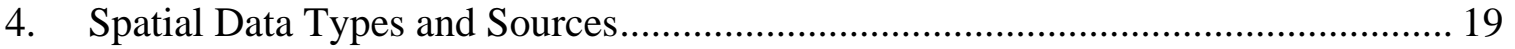

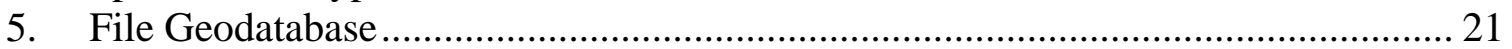

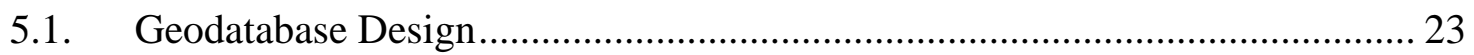

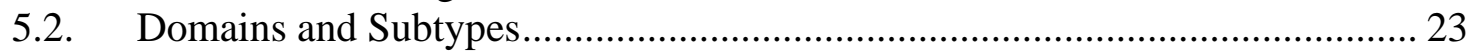

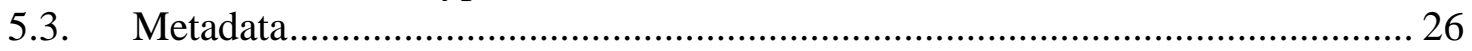

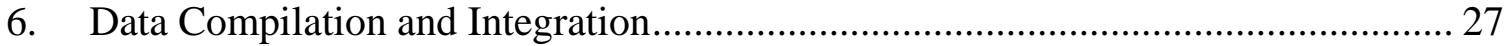

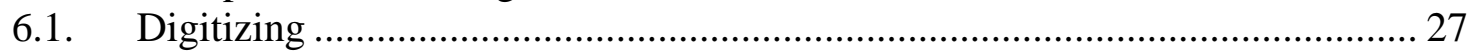

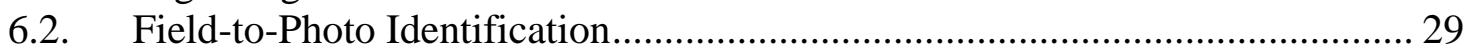

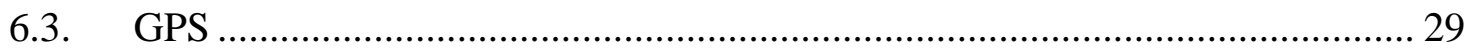

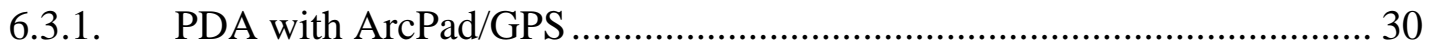

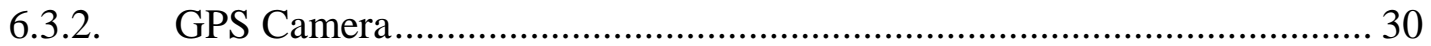

6.3.3. Digital Camera with Hand-held GPS ................................................... 31

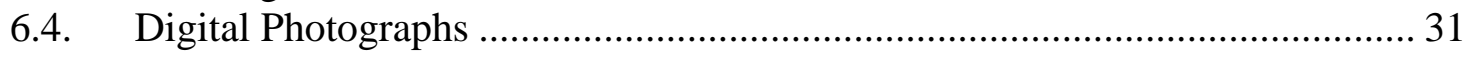

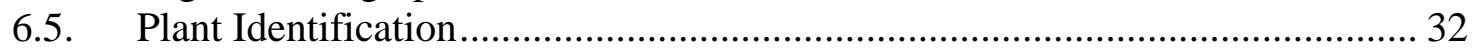

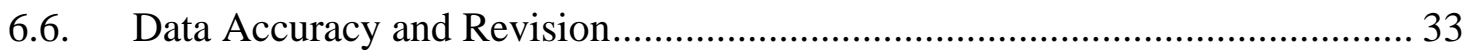

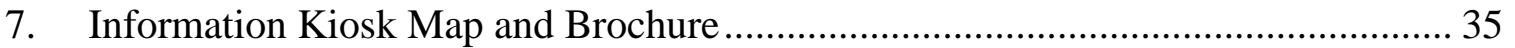

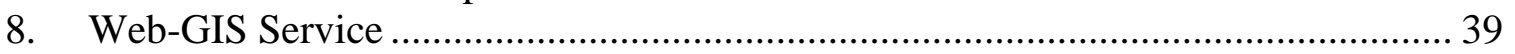

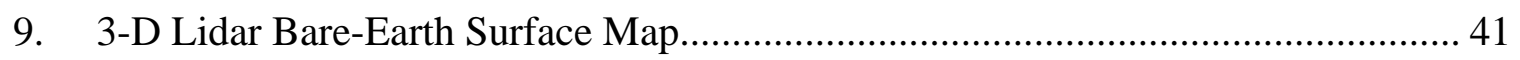

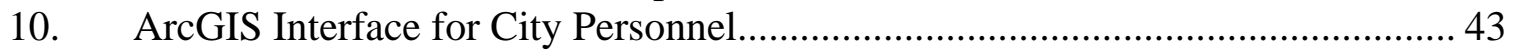

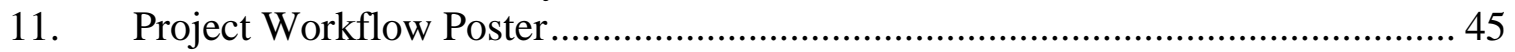

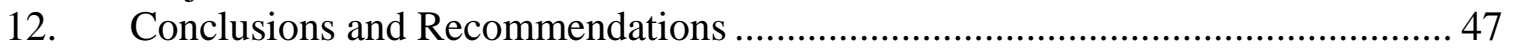

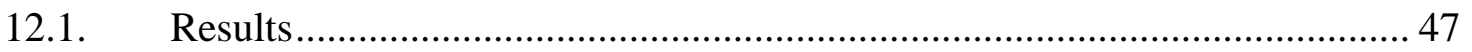

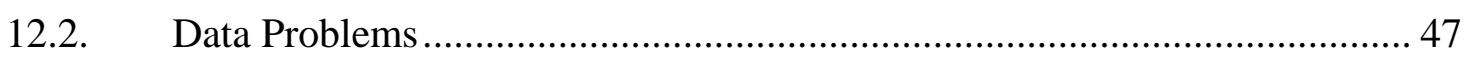

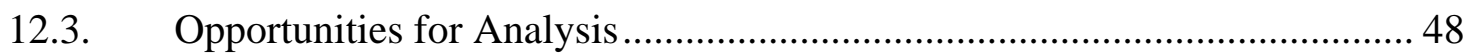

12.4. Future Recommendations for the Desert Garden........................................ 49

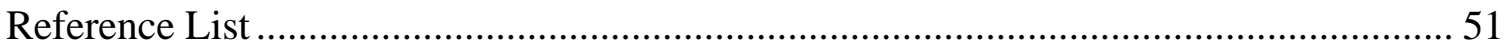

Appendix A: Web Application Set-up Instructions .................................................. 53 


\section{Table of Figures}

Figure 1. Vicinity map of San Diego and location of Balboa Park. .................................. 1

Figure 2. Aerial map of Balboa Park's Desert Garden in San Diego, California............... 2

Figure 3. Examples of plants found in the Desert Garden............................................... 3

Figure 4. La Tuque's mountain bike trail map . ....................................................... 8

Figure 5. The general map of the Mounts Botanical Garden.......................................... 9

Figure 6. A result from identifying a plant from the Mount Botanical Garden website... 10

Figure 7. The main map of the Royal Botanical Garden. .............................................. 11

Figure 8. The interactive mapping website for the City of San Diego's CityWorks. ....... 12

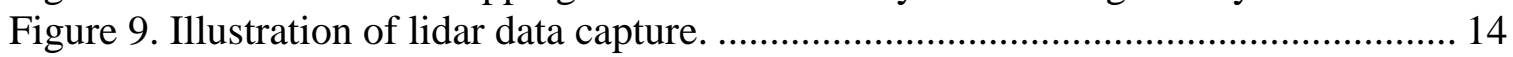

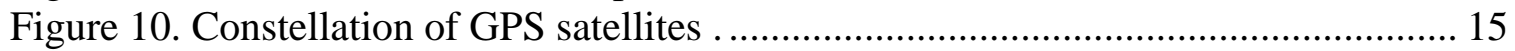

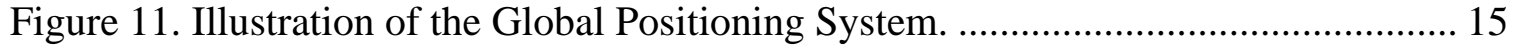

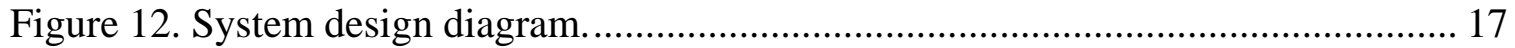

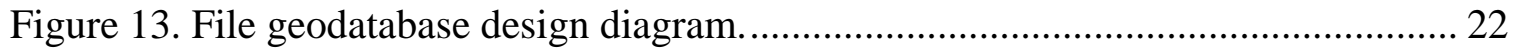

Figure 14. Example of a predefined attribute selection. .............................................. 25

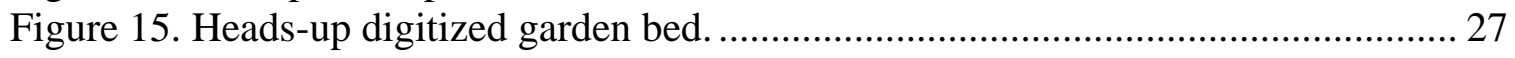

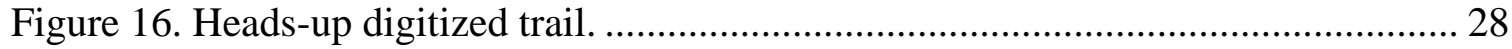

Figure 17. Irrigation components created by field-to-photo identification...................... 29

Figure 18. Visitor points of interest captured using a GPS camera............................... 30

Figure 19. Digital photograph of a garden plant.................................................... 31

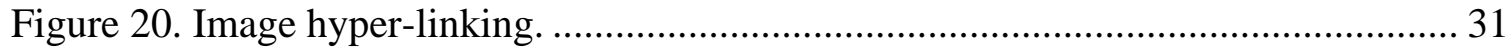

Figure 21. Plant feature captured using a hand-held GPS receiver. ............................... 32

Figure 22. Example of a regular grid-like pattern of overlapping points. ....................... 33

Figure 23. Example after manually dispersing overlapping points. .............................. 34

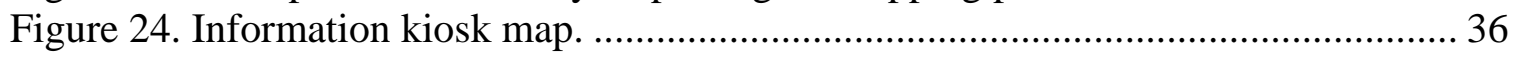

Figure 25. Legend for the information kiosk map and brochure. .................................. 37

Figure 26. Brochure for the Balboa Park’s visitor center. ........................................... 38

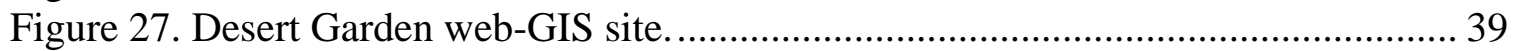

Figure 28. Hyper-link to the Desert Garden website. ................................................... 40

Figure 29. 3-D bare-earth surface map generated from lidar DEM............................... 42

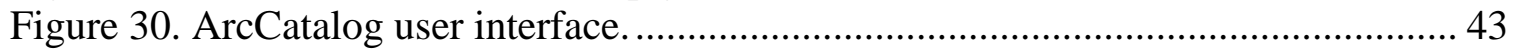

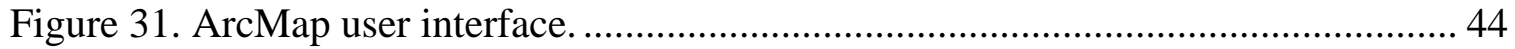

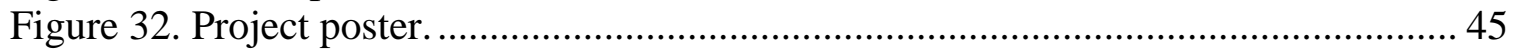

\section{List of Tables}

Table 1. Attribute table sample of the plant feature class............................................ 23

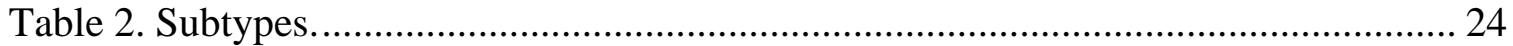

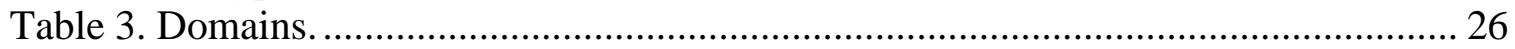




\section{List of Acronyms}

$\begin{array}{ll}\text { AAM } & \text { American Association of Museums } \\ \text { ArcIMS } & \text { ESRI’s Internet Map Server } \\ \text { DEM } & \text { Digital Elevation Model } \\ \text { DTM } & \text { Digital Terrain Model } \\ \text { ESRI } & \text { Environmental Systems Research Institute } \\ \text { FGDB } & \text { File Geodatabase } \\ \text { GIS } & \text { Geographic Information Systems } \\ \text { GPS } & \text { Global Positioning Systems } \\ \text { INS } & \text { Inertial Navigation System } \\ \text { IR } & \text { Infrared } \\ \text { Lidar } & \text { Light Detection and Ranging } \\ \text { MIP } & \text { Major Individual Project } \\ \text { NAD83 } & \text { North American Datum of 1983 } \\ \text { PDA } & \text { Personal Data Assistant } \\ \text { SDE } & \text { Spatial Data Engine } \\ \text { TIN } & \text { Triangulated Irregular network } \\ \text { WGS84 } & \text { World Geodetic System of 1984 }\end{array}$





\section{Introduction}

As early as 1862, a 1,400 acre parcel of land was dedicated for the development of what is known today as Balboa Park (Figure 1), but remained undeveloped until 1892, when Kate Sessions, the park's earliest landscape designer donated and planted trees. The park's first master plan was created in 1903, taxes were levied to support the plan in 1905, and by 1910, water systems and roads were built. The park began shaping into what it looks like today, and was named to honor the famous Spanish explorer, Vasco Nunez de Balboa. The park continued to transform through the development of two world fairs, the Panama-California Exposition of 1915-16, and the California Pacific International Exposition of 1935-36.

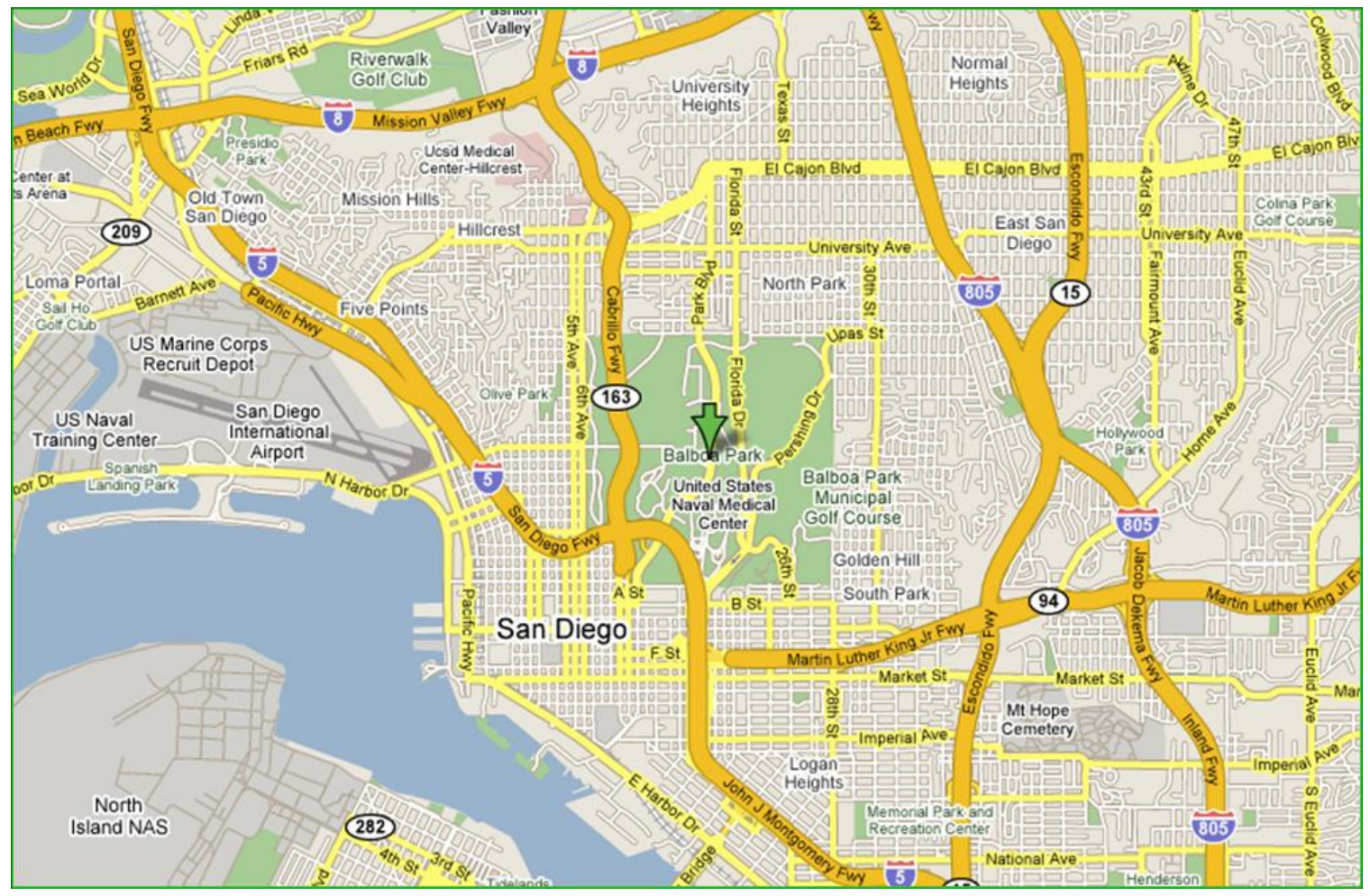

Figure 1. Vicinity map of San Diego and location of Balboa Park

\footnotetext{
${ }^{1}$ This map was created from http://maps.google.com, entering “Balboa Park, San Diego, California” in the map search. Copyright 2007 Google. Map Data Copyright 2007 NAVTEQ $^{\mathrm{TM}}$.
} 
Balboa Park's Desert Garden in San Diego, California (Figure 2), represents a mature and worldly collection of succulents and drought-resistant plants (Figure 3). The 2.5 acre garden was established along the east side of Park Boulevard, in 1976, and is maintained by the City of San Diego's Park and Recreation Department. The garden is open to the public all year round and admission is free. The park staff and volunteers assist over 500,000 visitors each year, as San Diego continues to be one of the most popular tourist destinations in the country (Balboa Park, 2007).

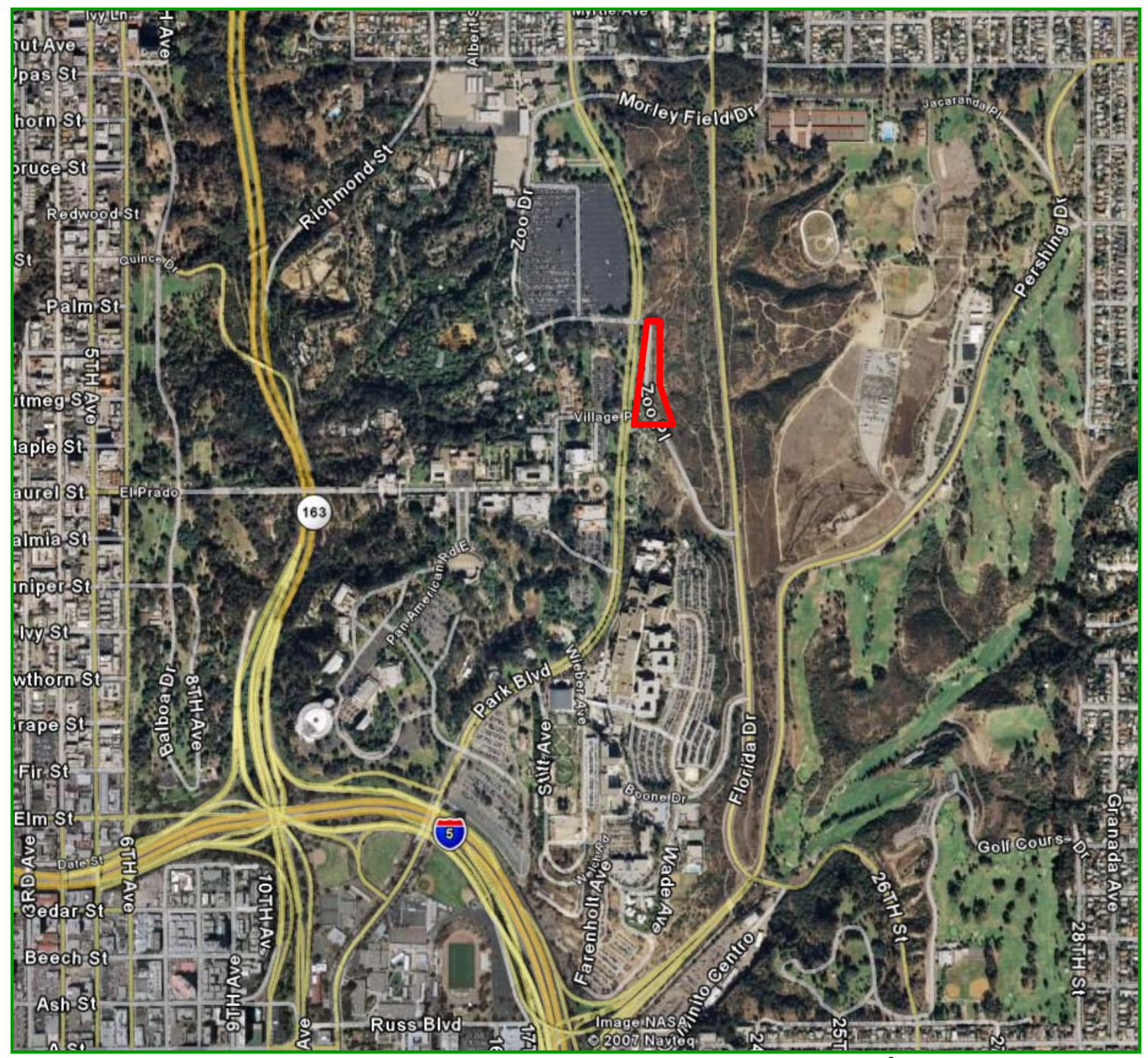

Figure 2. Aerial map of Balboa Park’s Desert Garden in San Diego, California².

\footnotetext{
${ }^{2}$ This map was created by using the free downloadable Google Earth application available at http://earth.google.com and entering "Balboa Park, San Diego, California” in the Fly To search. Copyright Google 2006. Copyright 2007 Europa Technologies. Copyright 2007 Navteq. Image provided by NASA.
} 


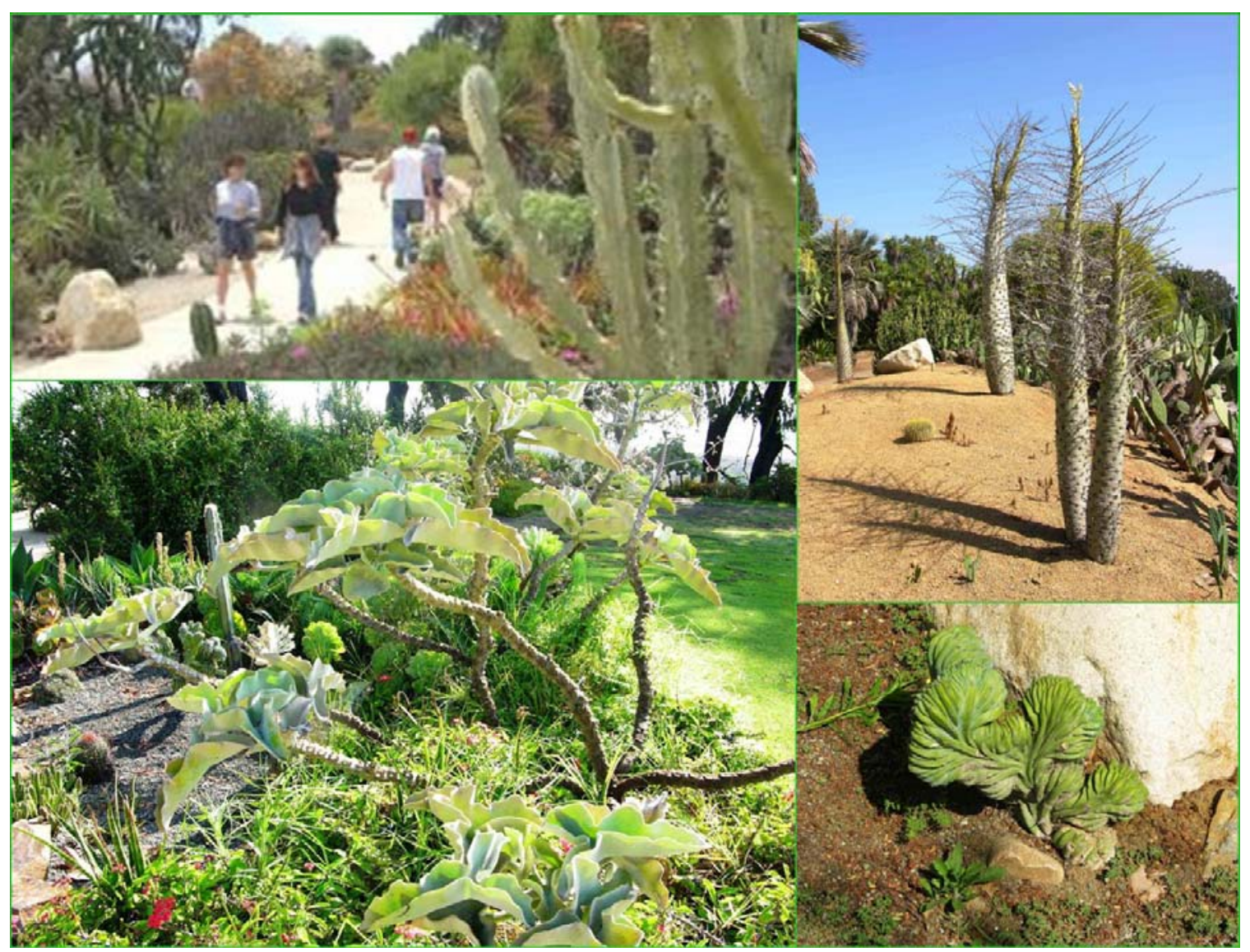

Figure 3. Examples of plants found in the Desert Garden ${ }^{3}$.

Facilities management is an important and growing practice for park systems worldwide. The integration of geographic information systems (GIS) technologies into park management has revolutionized the interaction between the park staff and the park environment, and has improved the quality of resource management and services provided to the public. Many park systems today benefit from information-rich inventories that manage spatial, temporal, and character attributes, including those of plants, wildlife, terrain, atmosphere, emergency, disaster, staff, visitor, and infrastructure. GIS implementation (with proper training and necessary hardware, software and peripherals) and data acquisition enable the park staff to standardize, centralize, update, manage and store valuable resource information. In turn, the system tools allow for the tracking, management, displaying, querying, analyzing, reporting, and mapping of park assets (Armstrong \& Henry, 2004).

This project introduced ArcGIS 9.2 and ArcServer 9.2, Environmental Systems Research Institute, Inc. (ESRI) commercial off-the-shelf software. A foundational file geodatabase (FGDB) was created using the software's out-of-the-box functionality. The Park and Recreation Department was already using ESRI ArcGIS 9.2 but not at the garden level. A web-GIS service was created using ArcServer 9.2 for the public to interact with the garden's features. A complete inventory was not captured, but by prioritized garden beds

\footnotetext{
${ }^{3}$ This is a photo collage of three pictures taken by Gina Durizzi 2007 and the upper left picture, which was retrieved from http://www.balboapark.org/in-the-park/detail.php?OrgID=44.
} 
only. A new data model was designed for this garden-level pilot project that can be utilized for other Balboa Park facilities in the future. The garden inventory includes features and attributes for the garden beds, plants, trails, irrigation components, boulders, benches, kiosks, trash cans, bus stops, entrances and exits, and georeferenced images. Once all of the garden features are captured by the garden staff, the completed garden inventory could help fulfill a criterion for an accreditation program offered by the American Association of Museums (AAM) which once achieved would provide funding for further GIS implementation within the park system (American Association of Museums, 2007).

This project utilized existing city data as a reference and as a base to create new data. Data was created by heads-up digitizing, a field-to-photo identification process, using a global positioning system (GPS) receiver, and a digital camera. The project deliverables include a FGDB of the garden inventory, web-GIS service of featured plants and visitor information sites, 3-D bare-earth surface map derived from a Light Detection and Ranging (lidar) generated digital elevation model (DEM), an information kiosk map, a brochure to inform and guide garden visitors, and reports based on system queries to aide in planning and designing exhibits, coordinating maintenance events, and making measurements to determine material assessment. These components provide a medium for the park staff to manage a dynamic inventory and for the public to interact with the garden's assets which, in turn, promote awareness and appreciation of the gardens assets.

The implementation and integration of GIS for the Desert Garden will provide the garden staff with spatially-enabled facility management tools for tracking the plants and the supporting garden infrastructure and enrich the GIS data repository for Balboa Park and the city. Promoting the standardized and practical applications of GIS to the different work groups within the Park and Recreation Department will improve services provided to the public and preserve the quality of the parks infrastructure and assets.

\subsection{Client Introduction}

The client for this project is Paul Sirois, the former Park Director for the City of San Diego, and the current Open Space Manager for the City of Chula Vista. Paul initiated a garden-level GIS pilot project to be implemented park-wide to enhance the management of park assets, and to fulfill a criterion for an accreditation program offered by the AAM. Mr. Sirois continued to advise and consult for this project even after his move from the City of San Diego to the City of Chula Vista. He referred three additional park staff members to assist with the project: (a) Michael Marika, Park Arborist, for identifying plant and infrastructure features, (b) Trent Robertson, GIS Coordinator, for project implementation, and (c) Kamal Scott, Web Coordinator, for web implementation.

\subsection{Needs Assessment}

The client and the City of San Diego’s GIS Manager, Lisa Lubely, discussed the following needs for the Park and Recreation Department, addressing both garden and park-level issues.

Prior to the initiation of this project, the client was limited to working with a non-digital, outdated, static and non-spatial inventory, including a hand sketch of the garden bed boundaries, to assist in managing the Desert Garden. Budget constraints within the Park 
and Recreation Department have postponed garden-level GIS implementation, leaving all project opportunities to be fulfilled by volunteers. Finding, disseminating, processing, and converting existing data into useful GIS data was the project's first priority. There was neither enough time nor budget allocated for this project to allow for creating redundant data. There was sufficient data compiled from the San Diego GIS data repository (SanGIS) to establish a base map. This data served as a foundation for creating new data. In addition, existing garden-level data was provided by the client. It was necessary to create new plant and infrastructure data by using GPS receivers, digital cameras, heads-up digitizing, and field-to-photo identification.

There was a departmental need for a current inventory of the Desert Garden to help the garden staff plan garden events, design and plan new garden bed exhibits, and budget for materials and staffing for garden upkeep. The client was in need of implementing GIS into their workflow to manage the dynamic inventory of garden plants and infrastructure. The planning, designing, and documenting of new garden exhibits was challenging without the help of spatial tools. For example, a GIS can query and display the distribution of plants by specific plant nomenclature and native origin. The garden staff was currently designing and planning a garden bed exhibit by including only plants from Baja California. That project could benefit from a simple GIS query displaying the locations of plants with a specific nativity. Garden maintenance could also benefit from using GIS to measure and assess where materials, such as fertilizer, water, sand and boulders are needed in the garden. A spatial inventory could further aid in the planning and scheduling for watering, planting, pruning, pest control, garden-to-nursery rotation, and path improvements. The garden staff understood the importance and practical applications that a GIS could provide to track each plant location and to monitor the condition of each plant. The success of Balboa Park is owed to the plant collections, museums, activities and the park's historical recognition. Although revenue is not generated from most of the plant collections due to free admission (donations are appreciated), the gardens are major attractions for the park's visitors.

Vandalism and theft are serious and prevalent issues for managing the Desert Garden. The garden staff makes special considerations when determining where to plant rare and endangered plants. As a precaution, plant labels are intentionally kept off of the rare and endangered plant species to deter the incidence of theft. Plants that are in well traveled areas or prone to vandalism were cabled-off or moved to less vulnerable areas. The garden staff needed to monitor plants affected by vandalism or theft by tracking the incidence details.

The client was also interested in initiating a quality inventory program, to enable the Park and Recreation Department to provide the necessary documentation needed to apply for an accreditation program offered by the AAM. The criteria include having a garden-level inventory and a means for sharing inventory information with the public. In order to meet the criteria, the park staff must produce a complete digital inventory of the park's Botanical Garden, which is considered a museum, and make the data available for the public though an educational medium such as a map, brochure, or web-service. The Botanical Garden is an intensive plant collection residing in a partially enclosed structure, not suitable for capturing data from a GPS receiver, but would require conventional surveying and the design of a data model. Unfortunately, there was no city budget 
available to order a survey and to design a data model. The client proposed a project plan to create a foundational GIS inventory and data model for an outdoor garden. The guidelines for the project include adhering to the city's GIS standards, utilizing existing GIS data resources, and accepting volunteer GIS services and GPS equipment from an external source. The Desert Garden was to serve as a pilot project to prepare for future inventory capture of the Botanical Garden, and to fulfill a criterion for an accreditation program.

The park was in need of applying surface change detection to their engineering, planning and design departments. The city's lidar data was scheduled to be acquired every year and would provide data for change detection analysis for the park's bare-earth surface. The results could help the park's engineers, surveyors, and planners determine areas with erosion problems, predict future problem areas, and apply preventative measures to those areas. Flood modeling and irrigation conservation can also be studied from the lidar data. This project produced a 3-D bare-earth surface map to benchmark the parks surface for 2005. The lidar data could be further processed and utilized by park staff to detect areas of change against existing 1991 and 1999 DEM to determine areas with usable slopes for garden bed expansion, extending the trail system, and adding components to the garden's irrigation system. The client requested that existing garden data be utilized as much as possible for this project.

The garden's information kiosk was under-utilized for many years due to a lack of funding to produce display materials. Admission for the garden was free, therefore generating no revenue for funding the design, printing and upkeep of maps and brochures. The garden required self-guiding, not many of the plants had identification tags, and those tagged were subject to vandalism and fading from the outdoor elements. The kiosk was in need of a useful map to assist and inform the visitors.

The Balboa Park visitor center also desired a Desert Garden map for display at their facility, and an accompanying brochure to be made available for the visitors to use as a guide and keep as a souvenir.

There is a need for monitoring and detecting change in the plants' physical condition, including the evidence of disease or vandalism. The location-based and time-stamped digital photographs will aid in tracking change. Each plant photograph was analyzed for the evidence of vandalism, and that information was tracked in the plant inventory.

Desert Garden was chosen as the pilot garden, and GIS services and supporting resources were volunteered to fulfill components for this Major Individual Project (MIP). The completed project was delivered to the Park and Recreation Department's GIS Coordinator, not the garden staff, due to a lack of a GIS workstation and funds for training the clients in GIS. 


\section{Background and Literature Search}

This section reviews the literature available on topics relating and supporting this project. The implementation and integration of GIS into facility management world-wide is the broader theme and focuses on the specific topics of parks and GIS, botanical gardens and GIS, municipalities and facility/asset management, and lidar and GPS.

\subsection{GIS and Parks}

In 2001, the client and a park arborist from Balboa Park collaborated to create a collection of photographs, illustrations and historical documentation of the park's trees and gardens. This beautiful guide was based on a prior tree survey and provided an index to the general locations of the referenced trees and the gardens (Paplava \& Sirois, 2001). This guidebook provided examples of standardized plant nomenclature used in plant descriptions and plant pictures to aid in identifying some of the garden's trees. The photographs were good examples of effective photographic styles.

Many national park systems have designed cartographically appropriate map displays and web-GIS services to promote park awareness, visitation and to assist park management practices. Kalaupapa National Park in Hawaii identified historic structures using a photo identification process and digitizing to create GIS layers for historical documentation and facility management purposes. They used high-resolution imagery for a small geographic extent to digitize the structures on the property (Armstrong \& Henry, 2004). The data creation techniques for this historical preservation project were similar to the strategy used in this MIP for capturing the garden beds and trails via heads-up digitizing. This rich compilation of data and GIS applications created for park systems provided many examples of project themes, data capturing techniques, and cartographic design styles.

National Parks use GIS for foot-path maintenance and improvements (Longley, Goodchild, Maguire \& Rhind, 2005). The trail feature class for the Desert Garden was created to help the park staff determine material assessment and maintenance for the concrete and decomposed granite surfaced trails. The staff could make geographic decisions based on visualization and query tools provided by GIS. For example, distance and volume measurements along the trails could be done remotely.

The Mauricycle La Tuque Department, a cycling tourism organization in Quebec, Canada, produced a mountain bike trail map of La Tuque, an area with 90 kilometers of mountain bike trails (Sappington, 2006). This map featured the various difficulty levels of the trails, informing novices and experts with safety signs and trail segment distances. This information was made available by the Mauricycle La Tuque Department at the La Tuque tourism office and via the Internet (Mauricycle La Tuque Department, 2007). Design considerations from this map were used for the garden kiosk map, including the use of number symbolization and referencing and the uncluttered simple approach to map design (Figure 4). 


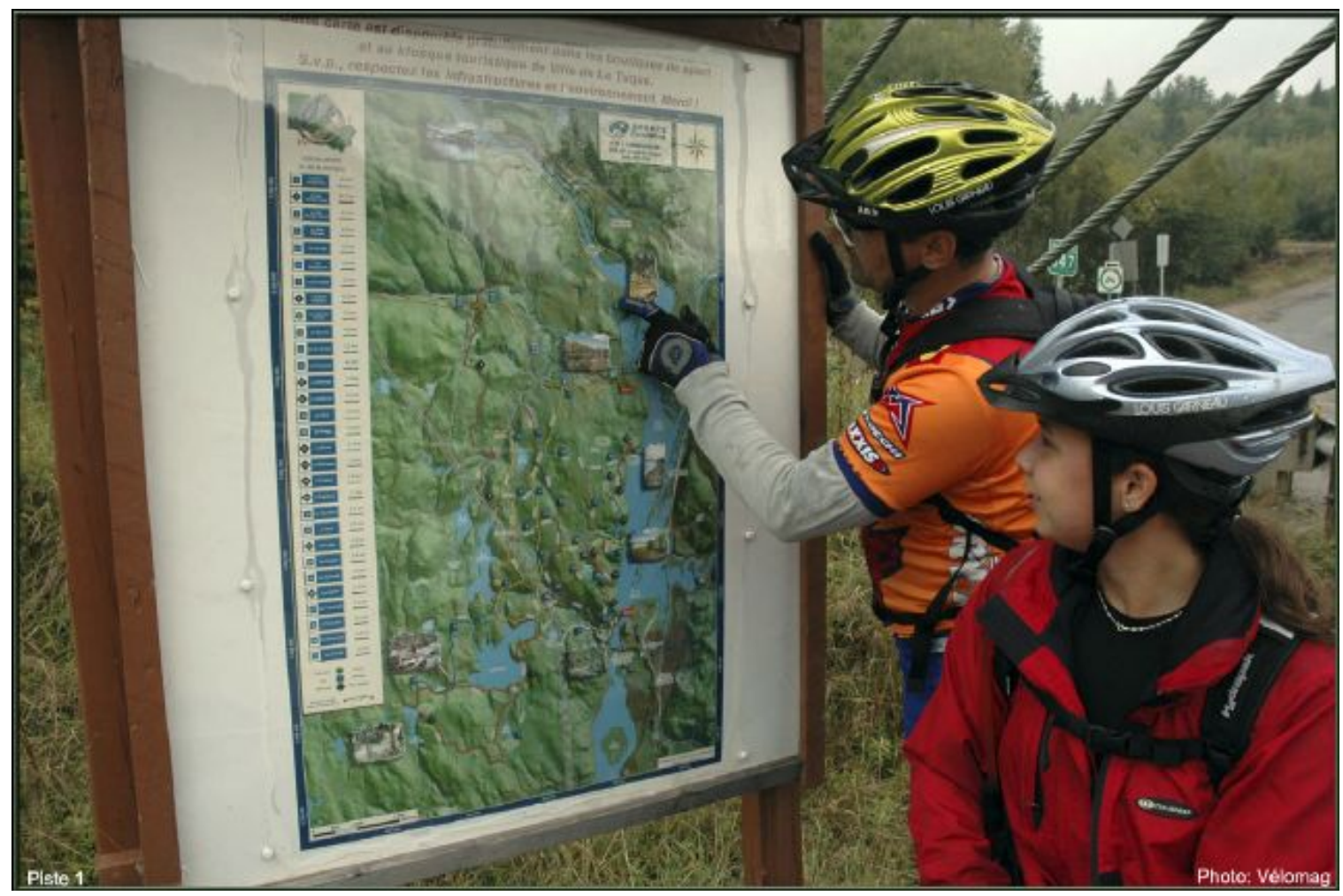

Figure 4. La Tuque's mountain bike trail map ${ }^{4}$.

\subsection{GIS and Gardens}

The Santa Barbara Botanical Garden created an informative visitor guide for the unique collections within the garden using a highly artistic design. The desert, meadow, island and canyon collections and integrated trails were well illustrated and provided detailed historical references. This guidebook provided a comprehensive self-guide to help the park enthusiasts get the most out their visit to the garden (Odion, 1988).

The Royal Botanical Gardens of Melbourne, Australia, captured data for over 50,000 plants and 12,000 different species using GPS receivers, and is storing and managing the data in a GIS. GIS has been an invaluable tool for managing their resources, monitoring changes and for decision making. Water conservation was an issue for this garden, so irrigation efficiency analysis was performed and used to regulate the watering practices within the garden, drastically cutting costs for water usage (Glissmann-Gough, 2005). Water conservation and cost savings were serious concerns for the City of San Diego, especially for the Park and Recreation Department, which managed all of the parks within the city and some even county-wide. This paper provided background on successful water conservation efforts and practices and helped design the irrigation feature class and attributes that were important in documenting the irrigation components.

\footnotetext{
${ }^{4}$ This map was retrieved from http://www.tourismehsm.qc.ca/mauricycle, by navigating to the photos section and selecting the thumbnail for the above photograph in the Dossier Cycliste collection. Copyright 2006 Mauricycle La Tuque. Site Developers: Philippe Huart, Claude Meunier and François Léonard.
} 
The Scott Arboretum of Swarthmore College, in Pennsylvania, had a mapping program in place to link plant locations with their campus facilities mapping. BG-Map, a botanical garden-specific data collection system, and GPS receivers were used to collect plant locations and their feature attributes throughout the college campus. The project goal was to map their 18,000 plants and integrate the data into a GIS to manage their resources (Scott Arboretum of Swathmore College, 2007). Budget permitting, Balboa Park could acquire and adopt the BG-Map and GPS data collection and documentation system for creating the park's Botanical Garden inventory in the future. This website provided industry standard data collection methods and plant nomenclature documentation examples for parks.

The Mounts Botanical Garden in Palm County, Florida, created a GIS database of their plants and attributes by integrating AutoCAD data and using BG-Map. An interactive web-site was developed using ESRI's Internet Map Server (ArcIMS) software. The botanical garden was made available to the public to tour and view information about the garden’s individual plants and visitor sites (Figure 5).

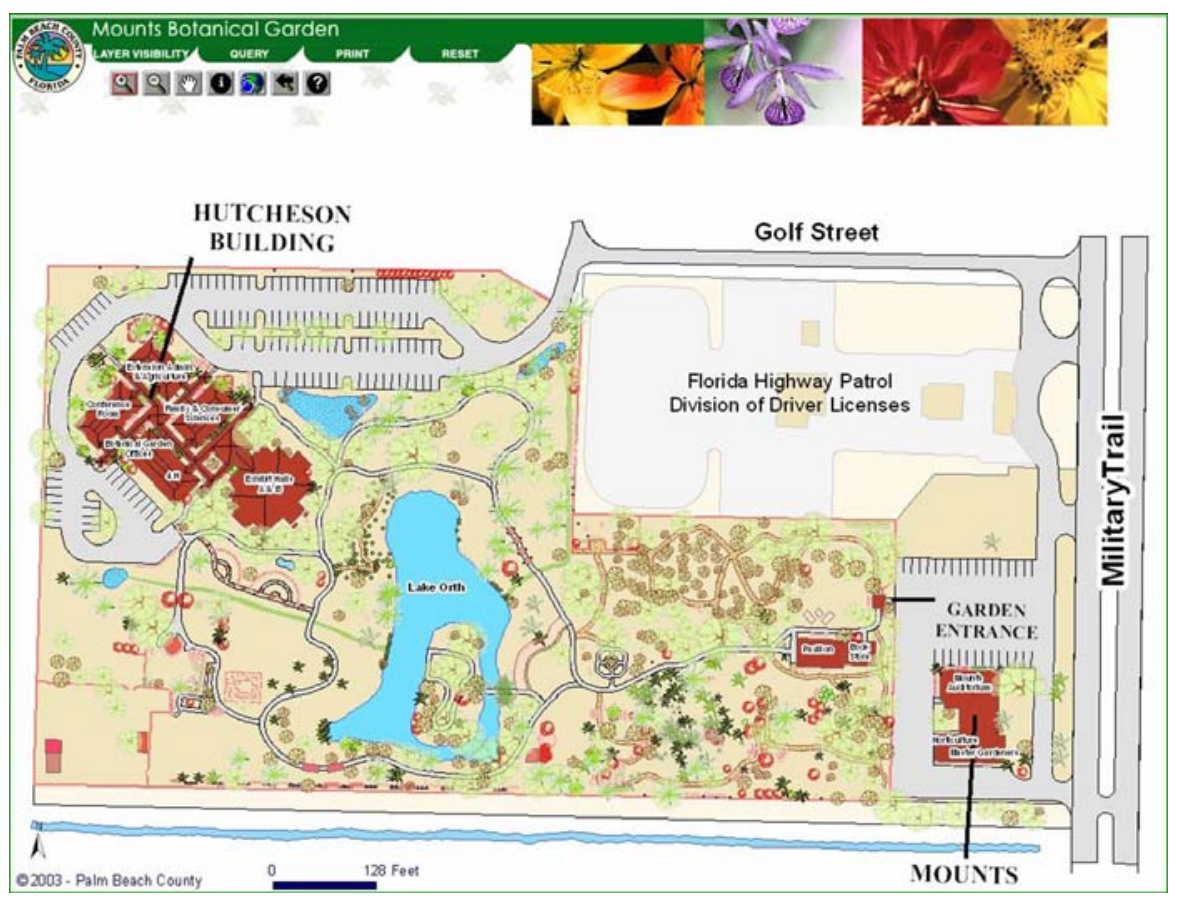

Figure 5. The general map of the Mounts Botanical Garden ${ }^{5}$.

The information available for individual plants included the botanical name, common name, accession name, grid number, and a link to additional sites and information (Figure 6). The symbology and artwork was landscape architecture grade with artistic detail. The website also provides portals to additional botanical related information (Jeter \& Ratchhinsky, 2007).

\footnotetext{
${ }^{5}$ This map was retrieved from http://gisweb.co.palm-beach.fl.us/mbggis/.
} 


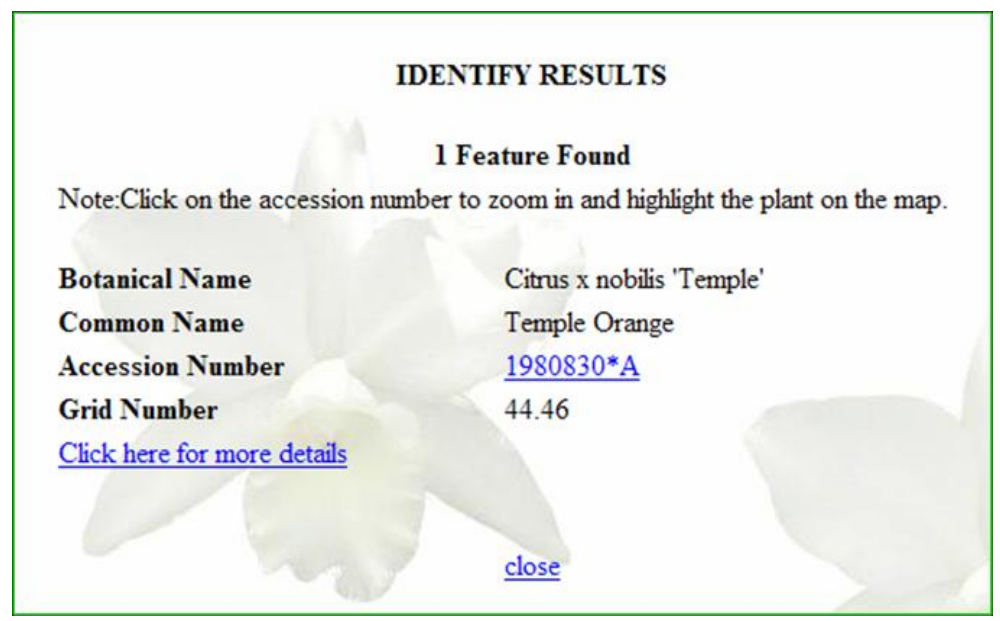

Figure 6. A result from identifying a plant from the Mount Botanical Garden website ${ }^{6}$.

The Royal Botanical Gardens (RBG) of Ontario, Canada, started a GIS program after conducting a feasibility study that revealed the success of GIS implementation for managing their garden's activities through the creation and maintenance of spatially referenced data.

It recognized that efficient organization and maintenance of historical and accumulating environmental data is essential if informed decisions are to be made with respect to the long-term management of the marsh (ArcNorth News, 2002, p.1).

GIS data was created using ArcView 3x, an earlier version of ESRI's GIS software, high resolution orthophotography, and GPS, and included base mapping the gardens trails, buildings, roads, and individual plant locations. The high resolution orthophotography was used by the field botanists to create plant attributes that tracked and monitored relative conditions to surrounding habitats. A database was created to track and manage the donor information and locations of memorialized trees, rocks and benches. Highly accurate and informative maps were created in ArcView to assist the RBG staff and garden visitors (Figure 7). ArcIMS was used to make garden maps available to the public. The garden's GIS department created a DEM to calculate slope and aspect for the design and redevelopment of a wheel-chair accessible boardwalk in the Morrison Woodland Garden, one of the many garden collections. The RBG staff planned on integrating ArcPad, ESRI's field data collector, into their data collection procedure, to make realtime updates to the garden's dynamic data (ArcNorth News, 2002). This article emphasized how GIS implementation has saved time, money and resources, and helped garden staffs make informed and efficient decisions.

\footnotetext{
6 This identify result window display was retrieved from http://gisweb.co.palm-beach.fl.us/mbggis.
} 


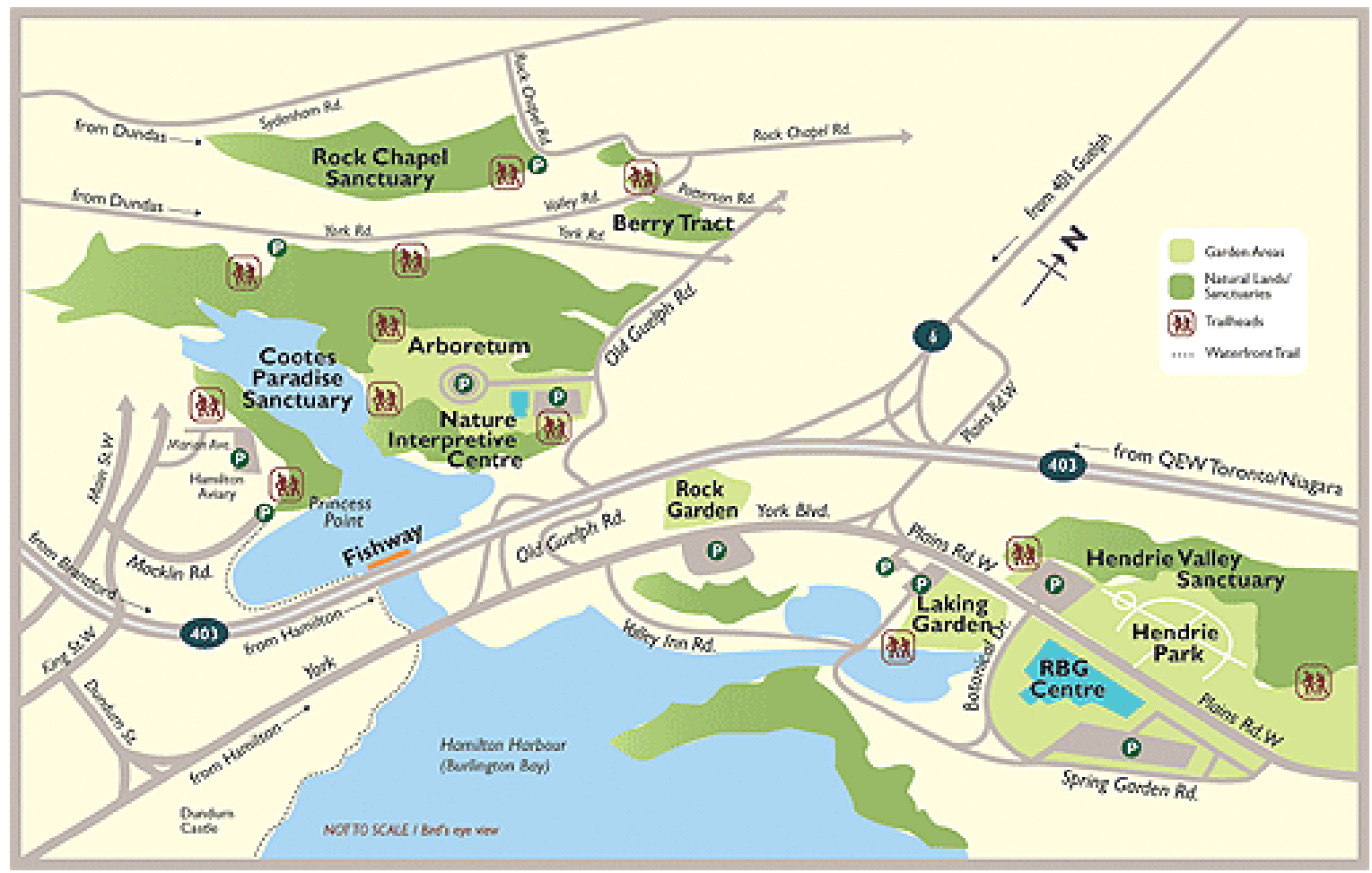

Figure 7. The main map of the Royal Botanical Garden?7.

\subsection{GIS and Cities}

The City of San Diego had a GIS Manager under the office of the Chief Information Officer (CIO). This position enforced the standardized practices city-wide and coordinated all efforts to create, share, and store GIS data within the city and make appropriate data available to the public. An ArcIMS-based interactive mapping website, called CityWorks, was created to allow the city staff and public to view, query, and identify attributes related to capital improvement projects within the city (CityWorks, 2007). This site assisted in researching the existing city GIS data that could be used for the Desert Garden, and provided a design example for a city GIS-website (Figure 8).

\footnotetext{
${ }^{7}$ This map was retrieved from http://www.rbg.ca/pages/visit_garden_areas.html.
} 


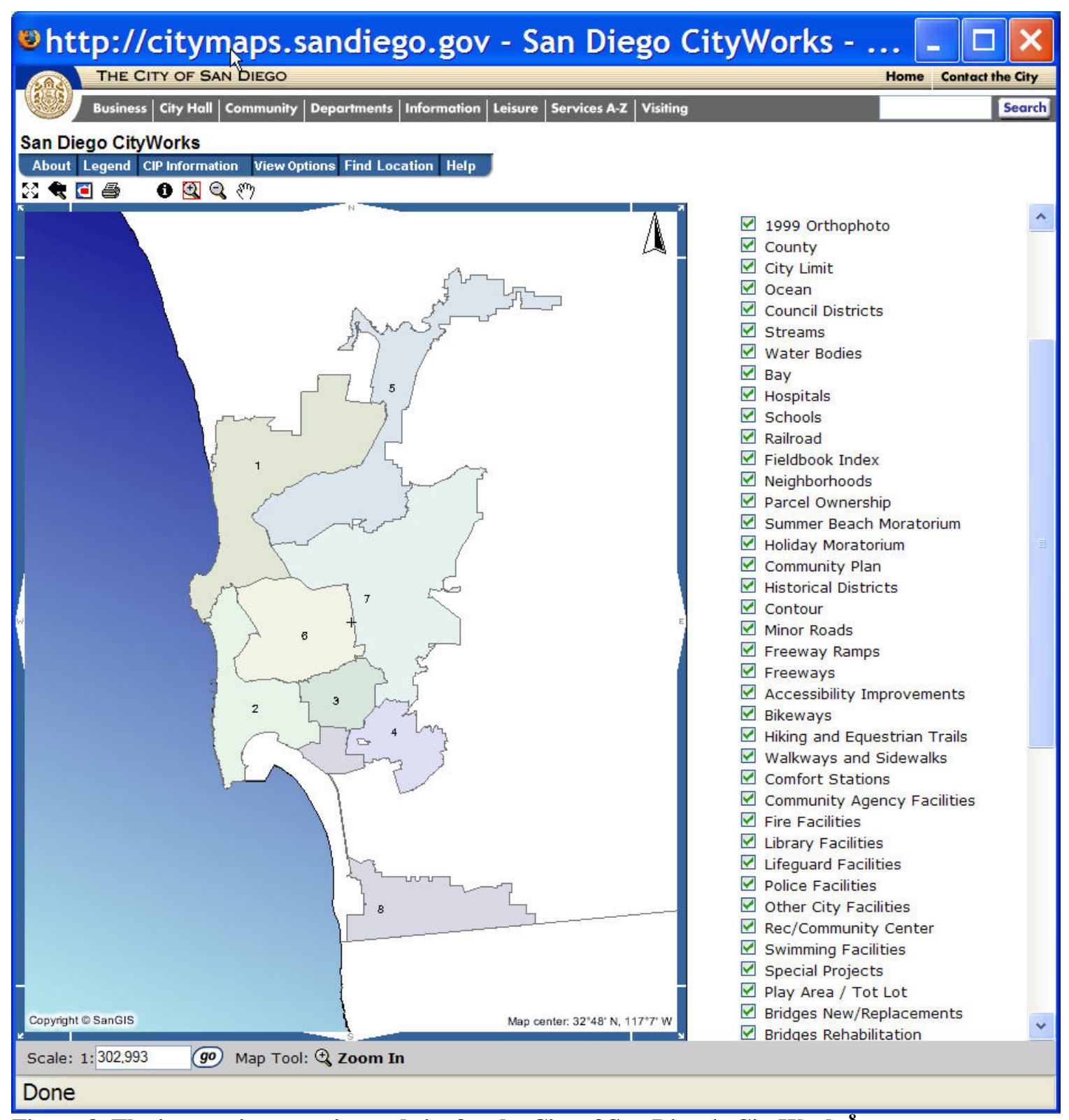

Figure 8. The interactive mapping website for the City of San Diego's CityWorks ${ }^{8}$.

The City of Greensboro, North Carolina, documented their GIS integration and implementation process to create a single enterprise-wide asset management system to manage and maintain their transportation, storm water, solid waste, park and building data. This system provided a powerful tool for work-order tracking, creating a GIS inventory of the municipality's data documents, and allowing for the spatial analysis of work order trends. This system included a customized map and document search interface resulting in a map display and descriptions. The city's supervisors were provided with tools to identify, select maintenance-related assets and identify the locations of active and past work orders. The city's call center improved their customer

${ }^{8}$ This map was retreived from http://citymaps.sandiego.gov. Copyright SanGIS. 
service and work order documentation, retrieval, and archiving processes (Sherman, 2005). This paper had useful examples of the data types and attributes that were collected and tracked for this municipality-wide GIS.

The City of Boulder, Colorado, built an integrated ArcIMS application to centralize, manage, and serve park data internally to the park staff. This project used ArcIMS and contains many relevant references for the Desert Garden project. Boulder had over ninety parks to manage and maintain, and a team was made up of representatives from the city's planning, maintenance and administration departments to build a park system GIS. The application concept included the city enterprise imaging, departmental database of the city parks land and assets, and the city enterprise Spatial Data Engine (SDE) GIS repository to be accessed and managed by the park staff through a Park Land and Asset Management System which utilized and integrated ESRI products, MS Access and IBM Content Manager. This paper provided an example of a successful project management workflow that resulted in a system that enables park staff to centralize, share and access vital park assets via an integrated GIS. There was a helpful example of the system's identify result, which included a hyperlinked image with feature descriptions similar to the Desert Garden’s identify result (Jensen \& Stonich, 2005).

\subsection{Lidar}

Light Detection and Ranging (lidar) became a popular form of acquiring remote-sensed location and elevation data and was used for small- and large-scale projects worldwide. Lidar data had many applications, and included geomorphic mapping, flood modeling and change detection. The following is a definition and illustration of lidar technology (Figure 9):

A lidar collection system uses a powerful laser sensor comprised of a transmitter and a receiver, a geodetic-quality GPS receiver, and an Inertial Navigation System (INS) unit. The technology resembles that used by radar sensors by which a device emits energy (focused light) and then measures the time it takes to travel to a target and return to a collector and at the time compensates for the movement of the aircraft and the sensor. The laser sensor is precision-mounted to the underside of an aircraft (helicopter or plane) similar to the mounting of a precision aerial mapping camera. Once airborne, the sensor emits rapid pulses of infrared (IR) laser light that are used to determine ranges to points on the terrain below as shown in the accompanying illustration (Cannistra \& Raber, 2005, p. 9). 


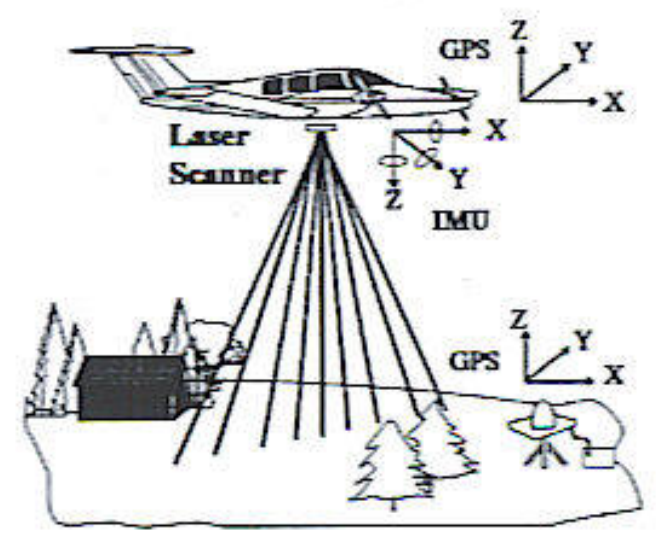

Figure 9. Illustration of lidar data capture 9

Lidar data generated extremely accurate terrain models that supported the City of San Diego's infrastructure mapping projects, including those for the Park and Recreation Department. In 2005, the city acquired city-wide lidar and orthophoto data from Merrick and Company, to create a new DEM for change detection against the existing 1999 DEM and future DEMs. Once the areas of change were determined, the city's existing digital terrain models (DTM) for those areas of change were updated. The DTM represented vector points, lines and break lines where elevation changes occurred on the terrain. This saved the city time and money to update their data without procuring new city-wide DTMs, which required an expensive and laborious photogrammetric process.

The bare-earth data was a lidar data product that represents the ground surface with manmade features and vegetation removed. The Park and Recreation Department could use bare-earth surface representations of the garden to determine usable slopes for garden expansion and trail extension. Lidar data could be represented in many ways, including a point cloud, contour, DEM, and TIN. Working with lidar can be intimidating and challenging due to the vast number of points or point cloud, resulting in large file sizes (Hewett, 2005).

\subsection{GPS}

GPS data capture is another popular way of measuring geographic positions and creating GIS data. There are many different models of GPS receivers with varying accuracies and costs. The hand-held GPS units used for collecting this project's data offered accuracies of approximately +/- 10 feet.

GPS data is acquired by receiving GPS signals that are transmitted by satellites (Figures $10 \& 11$ ) along a "line of site", therefore capable of passing through the atmosphere, materials such as glass and plastic, but not through buildings, mountains, or most solid objects (Garmin, 2000). Accuracies can degrade and signals can be lost when collecting data in urban areas with tall structures, steep slopes, and vegetation (Longley, Goodchild, Maguire \& Rhind, 2005). The following is a definition of the GPS:

\footnotetext{
${ }^{9}$ This illustration was taken from "LIDAR Guidbook: Concepts, Project Design and Practical Applications”, by J. Cannistra and B.R. Raber, 2005, p. 9. Copyright 2005 by URISA.
} 
The GPS consists of a system of 24 satellites (plus some spares), each orbiting the Earth every 12 hours on distinct orbits at a height of 20,200 $\mathrm{km}$ and transmitting radio pulses at very precisely timed intervals. To determine position, a receiver must make precise calculations from the signals, the known positions of the satellites, and the velocity of light. Positioning in three dimensions (latitude, longitude, and elevation) requires at least four satellites are above the horizon, and accuracy depends on the number of such satellites and their positions (if elevation is not needed then only three satellites need to be above the horizon) (Longley, Goodchild, Maguire \& Rhind, 2005, p. 122).

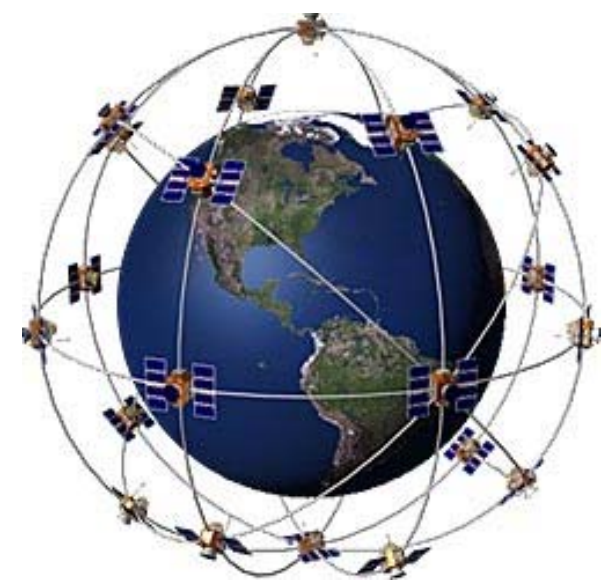

Figure 10. Constellation of GPS satellites ${ }^{10}$.

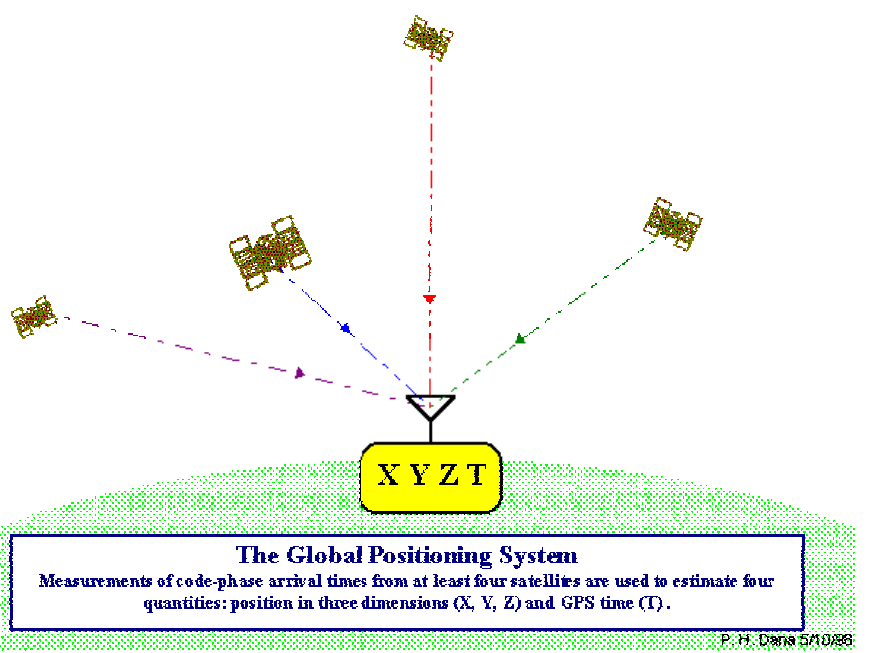

Figure 11. Illustration of the Global Positioning System ${ }^{11}$.

\footnotetext{
${ }^{10}$ This illustration was retrieved from the Garmin GPS Guide for Beginners available at http://ww8.garmin.com/aboutGPS/maual.html, p. 1. Copyright 2000 Garmin Corporation.

${ }^{11}$ This illustration was retrieved from http://www.colorado.edu/geography/gcraft/notes/gps/gps f.html, P.H. Dana 1998.
} 


\section{System Design}

Figure 12 illustrates the project's system design. There are three major components to this system design; (a) the project data to be ingested into the system, (b) the application where geoprocessing is performed, and (c) the project deliverables and data outputs.

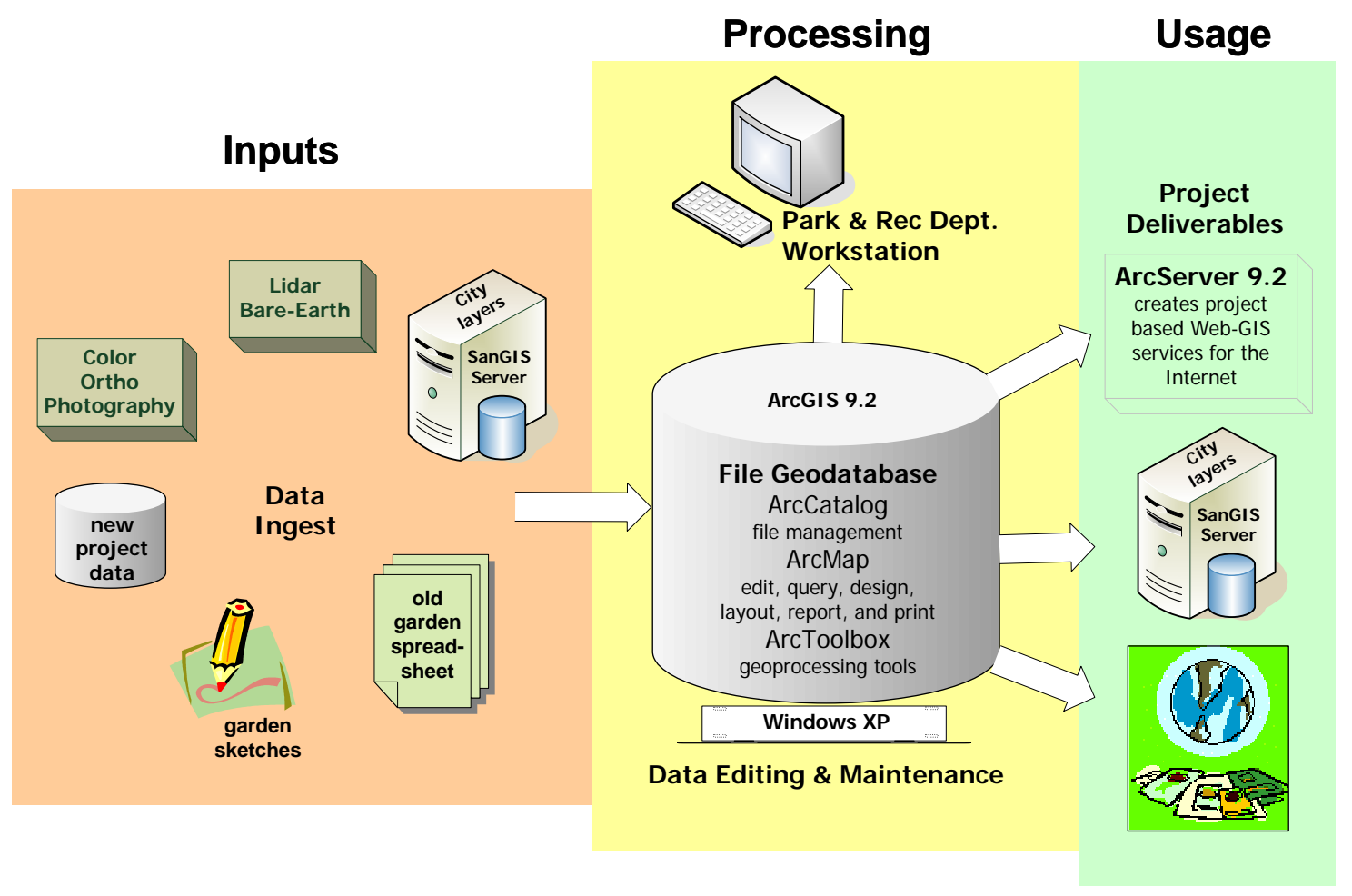

Figure 12. System design diagram.

The data ingested by the ArcGIS 9.2 FGDB was comprised of existing garden-level data and city-wide data, and newly created data from digitizing, field identification, GPS and a digital camera. The ArcCatalog interface was used to setup, integrate, and manage the GIS data for this project. This data was available for editing and processing and included maintaining and processing existing data, creating new data, querying and analyzing data, documenting data via metadata and designing maps. The ArcMap interface was used to create, edit, display, query, report and map project data. The ArcToolbox interface was used for geoprocessing project data.

The following products are the results of the GIS:

- A pre-designed MXD (ArcMap Map Document) file was published using ArcServer 9.2 to create an interactive web-GIS mapping service for the public to view the garden via the Internet.

- A 3-D bare-earth surface map was designed for displaying a digital elevation model compiled from bare-earth lidar data.

- Garden feature classes from the FGDB were added to the SanGIS server for citywide access, and updated are made as needed. The features include plants, visitor 
points of interest (boulder resting sites, benches, kiosks, entrances/exits, bus stops, and trash cans), garden bed boundaries, signs, and trails.

- Preformatted reports were created from client defined queries.

- A map was designed for display in the garden's kiosk which shows the locations, descriptions, and images of 20 plants that were recommended by the park staff for visitors to see.

- A complete garden inventory map including all of the feature classes was created for the project.

- A brochure based on the garden kiosk map was designed for distribution at the garden kiosk and the Balboa Park Visitor Center.

- A project workflow poster was created for the client and the University of Redlands. 


\section{Spatial Data Types and Sources}

Many data types were used for this project and included existing and newly created GIS data. All project GIS data adhered to the city's GIS standards which were in the State Plane Coordinate System, Zone 6, NAD83 Datum (Feet), and Lambert Conformal Projection. All project measurements were made in feet.

ArcGIS 9.2 supports a personal geodatabase which has a $2 \mathrm{G}$ size limit and a file-based geodatabase format which has no size limit. The file-based geodatabase format was chosen for this project for its larger file capacity.

The file formats that support ArcGIS 9.2 include the MXD, shapefile, XML for metadata, and layer, a definition file. GPS data was captured in Excel's XLS format. Plant domain tables were created in the DBF format. The map, poster and brochure MXD included data in JPEG, GIF, EMF and PDF formats.

The client's preliminary data search to find existing garden data uncovered a non-digital hard copy plant inventory from a Word Perfect document compiled in November, 2000. This inventory was outdated, but included useful base information for the creation of plant feature attributes and domains. There was also a non-digital hard copy hand sketch of the garden bed boundaries.

City-wide GIS layers were made available through SanGIS, the City of San Diego's GIS data repository server, which included various base map data, such as roads and utilities, in the shapefile format. The 2005 color orthophotography was in TIF format with a built in world header file for spatial reference information. The 2005 lidar bare-earth data was in ASCII format and provided by the City of San Diego's Land Survey Section. The lidar data was processed to create a DEM. Newly created data included feature classes and layer files of plants and garden infrastructure features including garden beds, signs, boulders, trails and visitor points of interest (benches, kiosks, trash cans, bus stops, parking areas and boulder resting areas). Digital photography was taken in JPEG format.

All of the data types and sources were documented in the project's metadata files. 


\section{File Geodatabase}

The FGDB was chosen over the personal geodatabase format for its larger file capacity. This format was also chosen to accommodate for the city's recent upgrade to ArcGIS 9.2. The FGDB was designed in ArcCatalog and houses all of the project's GIS data and other supporting data, and creates and manages domains that are assigned to feature attributes. The FGDB manages vector data by allowing feature class groupings into feature data sets that share the same spatial extent, topology rules and spatial reference. The individual feature class determines the field types, domain selections and subtype creation and assigns domains to subtypes. Figure 13 illustrates the feature datasets and associated feature classes, defines the data formats, and assigned field data types. 
Garden Infrastructure Feature Dataset

\begin{tabular}{|l|}
\hline Garden Bed Feature Class (poly) \\
\hline bednumber (domain) (int) \\
\hline exhibit (text) \\
\hline soiltype (text) \\
\hline notes (text) \\
\hline imageid (text) \\
\hline imagelink (raster) \\
\hline
\end{tabular}

\begin{tabular}{|l|}
\hline Tourist Point Feature Class (pt) \\
\hline type (subtype) (int) \\
\hline material (domain) (text) \\
\hline diameter (float) \\
\hline length (float) \\
\hline width (float) \\
\hline height (float) \\
\hline notes (text) \\
\hline imageid (text) \\
\hline imagelink (raster) \\
\hline
\end{tabular}

\begin{tabular}{|l|}
\hline Irrigation Feature Class (pt) \\
\hline type (subtype) (int) \\
\hline size (float) \\
\hline height (float) \\
\hline coverage (float) \\
\hline condition (domain) (text) \\
\hline notes (text) \\
\hline imageid (text) \\
\hline imagelink (raster) \\
\hline
\end{tabular}

\begin{tabular}{|l|}
\hline Sign Feature Class (pt) \\
\hline height (float) \\
\hline material (domain) (text) \\
\hline notes (text) \\
\hline imageid (text) \\
\hline imagelink (raster) \\
\hline
\end{tabular}

\begin{tabular}{|l|}
\hline Bed F Boulder Feature Class (pt) \\
\hline height (float) \\
\hline width (float) \\
\hline material (domain) (text) \\
\hline notes (text) \\
\hline imageid (text) \\
\hline imagelink (raster) \\
\hline
\end{tabular}

\begin{tabular}{|l|}
\hline City Utilities Feature Class (pt) \\
\hline utilitytype (text) \\
\hline notes (text) \\
\hline imageid (text) \\
\hline imagelink (raster) \\
\hline
\end{tabular}

Plant Feature Dataset

\begin{tabular}{|l|}
\hline Plant Feature Class (pt) \\
\hline plantclass (subtype) (int) \\
\hline family (domain) (text) \\
\hline genusspecies (domain) (text) \\
\hline commonname (text) \\
\hline nativity (text) \\
\hline planttosee (domain) (int) \\
\hline planttoseeid (int) \\
\hline capturedate (date) \\
\hline capturemethod (domain) (text) \\
\hline rare (domain) \\
\hline condition (domain) \\
\hline notes (text) \\
\hline imageid (text) \\
\hline imagelink (raster) \\
\hline
\end{tabular}

\section{Garden Access Feature Dataset}

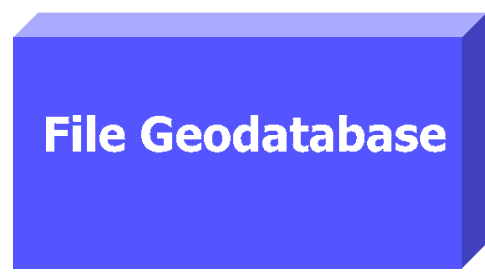

\section{Supporting Data (inside FGDB)}

Orthophotography 2005

mosaic and clip (tif)

\begin{tabular}{|l|}
\hline Bare-Earth Lidar 2005 \\
\hline (ascii) \\
\hline
\end{tabular}

\begin{tabular}{|l|}
\hline Trail Feature Class (line) \\
\hline type (subtype) (int) \\
\hline material (text) \\
\hline notes (text) \\
\hline
\end{tabular}

\begin{tabular}{|l|}
\hline Trail Network (edge/junction) \\
\hline type (subtype) (int) \\
\hline material (text) \\
\hline notes (text) \\
\hline
\end{tabular}

Figure 13. File geodatabase design diagram.

\section{Garden Photography (outside of FGDB) \\ Image (jpeg) \\ Image ID Number}




\subsection{Geodatabase Design}

The garden infrastructure dataset included the garden beds, which define the garden's boundaries for maintenance operations and exhibit planning. The physical features that make up or support the garden's infrastructure were the irrigation system components that deliver water from the city's water system into the garden, boulders that provided ground stability against erosion and interesting seating areas for visitors, and signs that warned or informed the visitors. The visitor points of interest were features that guided and informed the visitors and are the information kiosks, boulder seating areas that provided interesting seating and picnicking surfaces, entrances and exits, trash cans, and bus stops. The plant feature dataset was designated for plant features and grouped into plant type groupings. The transportation dataset is designated for the trail feature class and is grouped into the trail types. A raster dataset was created to seamlessly mosaic two orthophoto image tiles together that covered the extent of the garden. The mosaic was clipped to the project vicinity to decrease file size and the image refresh rate for use in ArcMap and ArcServer. The lidar raster DEM resided inside the FGDB, but not inside a dataset. The garden features digital photographs were kept outside of the FGDB but inside of the project directory. Information-rich attributes were assigned to each feature class to assist the garden staff in tracking, monitoring, querying, and managing the gardens assets (Table 1).

Table 1. Attribute table sample of the plant feature class.

\begin{tabular}{|c|c|c|c|c|c|c|c|}
\hline ImageID & GenusSpecies & CommonName & CaptureMethod & DataDate & POINT_X & POINT_Y & PlantClass1 \\
\hline R0010526 & Erythrina coralloides & Naked coral tree & Ricoh_GarminGPS & $4 / 6 / 2007$ & 6286203.613821 & 1847628.100332 & Single Tree \\
\hline R0010274 & Aloe bainessii & Tree aloe & Ricoh_GarminGPS & $4 / 6 / 2007$ & 6286275.350554 & 1847332.282682 & Single Tree \\
\hline R0010236 & Dasylirion quadrangulatum & Mexican grass tree & Ricoh_GarminGPS & $4 / 6 / 2007$ & 6286336.317952 & 1847308.434961 & Single Shrub \\
\hline R0010434 & Dracaena draco & Dragon tree & Ricoh_GarminGPS & $4 / 6 / 2007$ & 6286211.916298 & 1847869.97977 & Single Tree \\
\hline R0010428 & Fucreaea roezlii & $<$ Null $>$ & Ricoh_GarminGPS & $4 / 6 / 2007$ & 6286229.602942 & 1847831.522169 & Single Tree \\
\hline R0010361 & Yucca rostrata & Beaked yucca & Ricoh_GarminGPS & $4 / 6 / 2007$ & 6286228.020596 & 1847689.580196 & Single Tree \\
\hline R0010107 & Idria columnaris & Boojum tree & RicohGPS & $3 / 30 / 2007$ & 6286286.569692 & 1847661.413586 & Single Tree \\
\hline R0010518 & Alluaudia procera & Ocotillo & Ricoh_GarminGPS & $4 / 6 / 2007$ & 6286217.576719 & 1847598.27526 & Single Plant \\
\hline R0010085 & Brahea armata & Blue hesper & RicohGPS & $3 / 30 / 2007$ & 6286291.791466 & 1847604.2887 & Single Tree \\
\hline R0010054 & Lemaireocereus marginatus & Mexican fence post & RicohGPS & $3 / 30 / 2007$ & 6286321.857351 & 1847548.42956 & Single Shrub \\
\hline R0010030 & Yucca brevifolia & Joshua tree & RicohGPS & $3 / 30 / 2007$ & 6286314.123114 & 1847537.738636 & Single Tree \\
\hline R0010042 & Brachychiton rupestris & Bottle tree & RicohGPS & $3 / 30 / 2007$ & 6286285.689444 & 1847553.068002 & Varied Cluster \\
\hline DSCN6828 & Echinopsis grusonii & Golden barrel & Nikon_GarminGPS & $6 / 1 / 2007$ & 6286220.662343 & 1847525.623175 & Other \\
\hline DSCN6834 & Beaucarnea recurvata & $<$ Null $>$ & Casio_GarminGPS & $6 / 1 / 2007$ & 6286228.079979 & 1847433.151247 & Single Tree \\
\hline DSCN6836 & Euphorbia ingens & Candelabra tree & Casio_GarminGPS & $6 / 1 / 2007$ & 6286246.376531 & 1847439.08529 & Single Tree \\
\hline DSCN6826 & Caesalpinia cacalaco & Cascalote tree & Casio_GarminGPS & $6 / 1 / 2007$ & 6286365.304114 & 1847478.892625 & Single Tree \\
\hline R0010211 & Agave villmoriniana & Octopus agave & Ricoh_GarminGPS & $4 / 6 / 2007$ & 6286350.46917 & 1847346.860737 & Plant Cluster \\
\hline R0010278 & Euphorbia millii & Crown of thorns & Ricoh_GarminGPS & $4 / 6 / 2007$ & 6286180.113212 & 1847256.861245 & Plant Cluster \\
\hline R0010268 & Euphorbia tirucalli & Pencil tree & Ricoh_GarminGPS & $4 / 6 / 2007$ & 6286290.139894 & 1847302.108202 & Single Tree \\
\hline DSCN6824 & Aloe dichotoma & Quiver tree & Casio_GarminGPS & $6 / 1 / 2007$ & 6286440.221287 & 1847318.674114 & Single Tree \\
\hline
\end{tabular}

\subsection{Domains and Subtypes}

The plant inventory from November, 2000 provided a base list of plant family, genus and species, common names, and native origins. Individual Excel spreadsheets were created for each of the name types and imported into the FGDB using the Table-to-Domain tool, which creates a predefined selection of attributes for a given field, constraining the data choices to minimize data entry errors and ensured data integrity. This tool created the domains and was made available in the FDBD properties domain tab for management. The domains were assigned in the fields tab of the feature class properties and updated in the FGDB properties. New attributes would need to be added to existing domains, for example when a new plant genus and species was introduced into the garden. The 
original Excel spreadsheet was updated and reordered, and imported back into the FGDB using the Table-to-Domain tool and selecting the option to replace. The domains (Table 2) provide pull down lists of the pre-defined attributes for the user to select while editing a record or a group of records in an edit session. Domains could be assigned a range of values or coded values. The domains that were assigned numerical coded values were created for fields assigned as a short or long integer, allowing for faster sorting in the FGDB. It was determined unnecessary, and impractical, to create unique codes for individual plant taxonomy names. The coded values and descriptions for the plant taxonomy domains were created as text and to match in value, enabling these values to be accessed as pull-down selections in the attribute table (Figure 14).

Table 2. Subtypes.

\begin{tabular}{|c|c|}
\hline \multicolumn{2}{|c|}{ Data Capture Method } \\
\hline Code & Description \\
\hline 1 & Casio_GarminGPS \\
\hline 2 & FieldOrthoID \\
\hline 3 & HU Digitizing \\
\hline 4 & Ricoh_GarminGPS \\
\hline 5 & RicohGPS \\
\hline 6 & PDAGPS_ArcPad \\
\hline 7 & Nikon_GarminGPS \\
\hline
\end{tabular}

\begin{tabular}{|c|c|}
\hline \multicolumn{2}{|c|}{ Plant Condition } \\
\hline Code & Description \\
\hline 1 & Graffiti \\
\hline 2 & Physical Damag \\
\hline 3 & Theft \\
\hline 4 & Water Damage \\
\hline 5 & Dry \\
\hline 6 & Diseased \\
\hline 7 & Dead \\
\hline 8 & Good \\
\hline
\end{tabular}

Garden Bed

\begin{tabular}{|c|c|}
\hline Code & Description \\
\hline 1 & A \\
\hline 2 & B \\
\hline 3 & $\mathrm{C}$ \\
\hline 4 & $\mathrm{D}$ \\
\hline 5 & $\mathrm{E}$ \\
\hline 6 & F \\
\hline 7 & $\mathrm{G}$ \\
\hline 8 & $\mathrm{H}$ \\
\hline 9 & I \\
\hline 10 & $\mathrm{~J}$ \\
\hline 11 & $\mathrm{~K}$ \\
\hline 12 & $\mathrm{~L}$ \\
\hline
\end{tabular}

\begin{tabular}{ccc} 
Code & & Description \\
\cline { 1 - 1 } 1 & & Concrete \\
2 & & Other \\
3 & & Plastic \\
4 & & Rock \\
5 & & Steel \\
6 & Wood
\end{tabular}

\begin{tabular}{cc} 
Code & $\begin{array}{r}\text { Plants to See } \\
\text { Description }\end{array}$ \\
\hline 0 & no \\
1 & yes
\end{tabular}

\begin{tabular}{|c|c|}
\hline \multicolumn{2}{|c|}{ Rare Plant } \\
\hline Code & Description \\
\hline 0 & no \\
\hline 1 & yes \\
\hline
\end{tabular}




\begin{tabular}{|l|l|}
\hline \multicolumn{2}{|c|}{ Genus Species } \\
\hline Aloe dichotoma \\
\hline Aloe dichotoma & \\
\hline Aloe distans & \\
Aloe glauca & \\
Aloe greenii & \\
Aloe hybrid & \\
Aloe martolhii & \\
Aloe medishiana & \\
Aloe petricola & \\
Aloe plicatillis & \\
Aloe pubescens & \\
Aloe ramosissima & $\checkmark$ \\
\hline
\end{tabular}

Figure 14. Example of a predefined attribute selection.

Features were managed more efficiently by assigning a grouping category called a subtype in the FGDB (Table 3). Specific domains were assigned to each specific subtype, allowing for finer attribute choices that apply only to a specific subtype. Feature classes using subtypes are pre-categorized when displayed in the ArcMap table of contents (Arctur \& Zeiler, 2004). A subtype was created for the plant feature class to be grouped by plant type. This allowed for each plant type to have a unique set of domains that applied only to that plant type. For example, the tree plant type had a unique set of plant name domains to choose from that contained only tree names. For the purpose of this project, the subtype set up was initiated and all plant types refer to the same domains due to the lack of support to disseminate the plant names by plant type. This also applies for the subtypes created for the irrigation component types, trails, and visitor points of information. 
Table 3. Domains.

\begin{tabular}{ccc} 
Code & $\begin{array}{c}\text { Plant } \\
\text { Description }\end{array}$ & $\underline{\underline{\text { Code }}}$ \\
\hline 1 & Single Plant & 1 \\
2 & Single Shrub & 2 \\
3 & Single Tree & 3 \\
4 & Plant Cluster & 4 \\
5 & Shrub Cluster & 5 \\
6 & Tree Cluster & 6 \\
7 & Varied Cluster & 7 \\
8 & Ground Cover & \\
9 & Other &
\end{tabular}

\section{Irrigation Component}

Description

Drain

Flush Head

Head with Riser

Pop Up

Quick Coupler

Reachable Flex Head

Shut Off

\section{Trail}

$\begin{array}{cc}\text { Code } & \text { Description } \\ 1 & \text { Concrete Path } \\ 2 & \text { Concrete Sidewalk } \\ 3 & \text { Concrete Pedestrian Overpass } \\ 4 & \text { Decomposed Granite Trail }\end{array}$

\section{Code}

1

2

3

4

5

6

7
Visitor Points of Interest Description

Bench

Boulder Seating Area

Bus Stop

Entrance/Exit

Information Kiosk

Parking Area

Trash Can

\subsection{Metadata}

Metadata was created in XML format for each feature class, and supporting data could be accessed in ArcCatalog. A compiled listing of metadata for all project data was created in XLS format and kept outside of the FGBD. 


\section{Data Compilation and Integration}

Project data originated from different sources, was captured using different methods, and was brought into the FGDB using different import and conversion tools. Data was created by using heads up digitizing, field identification with orthophotography, GPS, and by taking digital pictures. The data capturing methods varied due to equipment availability and operability, and software functionality. The data sets had varied spatial accuracy. Different methods, procedures, and tools were used to create feature attributes before and after integration into the FGDB.

\subsection{Digitizing}

The garden bed boundaries were clearly identified in the high resolution color orthophotography (quarter-foot pixel resolution). A polygon feature class was created in ArcMap using heads-up digitizing (Figure 15). The existing hand sketch of garden boundaries was used as a guide, along with marked up boundary line edits and bed names provided by the client. Domains were created for bed name and soil type. This feature class was created within the garden infrastructure feature data set in ArcCatalog. This is the benchmark creation for this feature class, which was created by digitizing along clearly identified features in highly accurate orthophotography, therefore, the accuracy is estimated to be to +/-one foot.

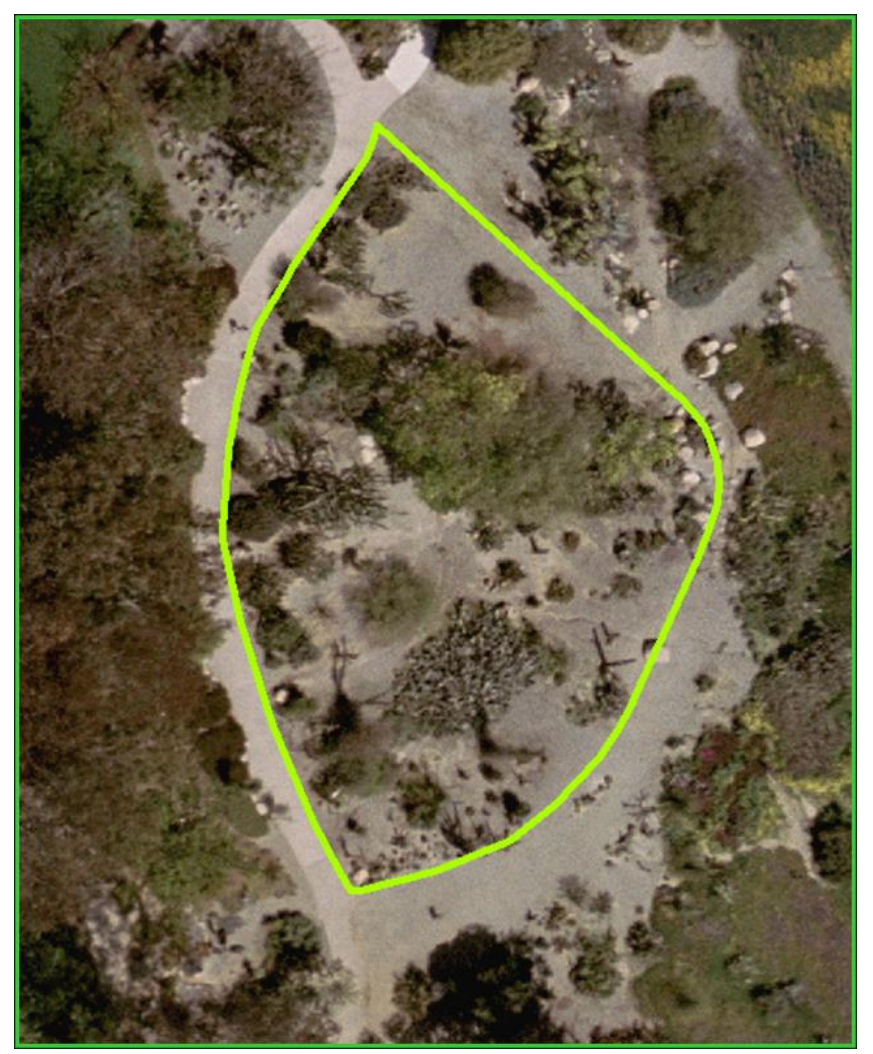

Figure 15. Heads-up digitized garden bed. 
The concrete walkway trails were also clearly identified in the orthophotography and a line feature class was created using heads up digitizing in ArcMap (Figure 16). The attributes were created as the individual trails were digitized. A subtype was created to group the trails by surface material and trail use. This feature class was created within the garden access feature data set in ArcCatalog. The accuracy was estimated to be $+/$ - one foot since the walkway widths range from 3 to 9 feet and the centerlines were estimated for digitizing.

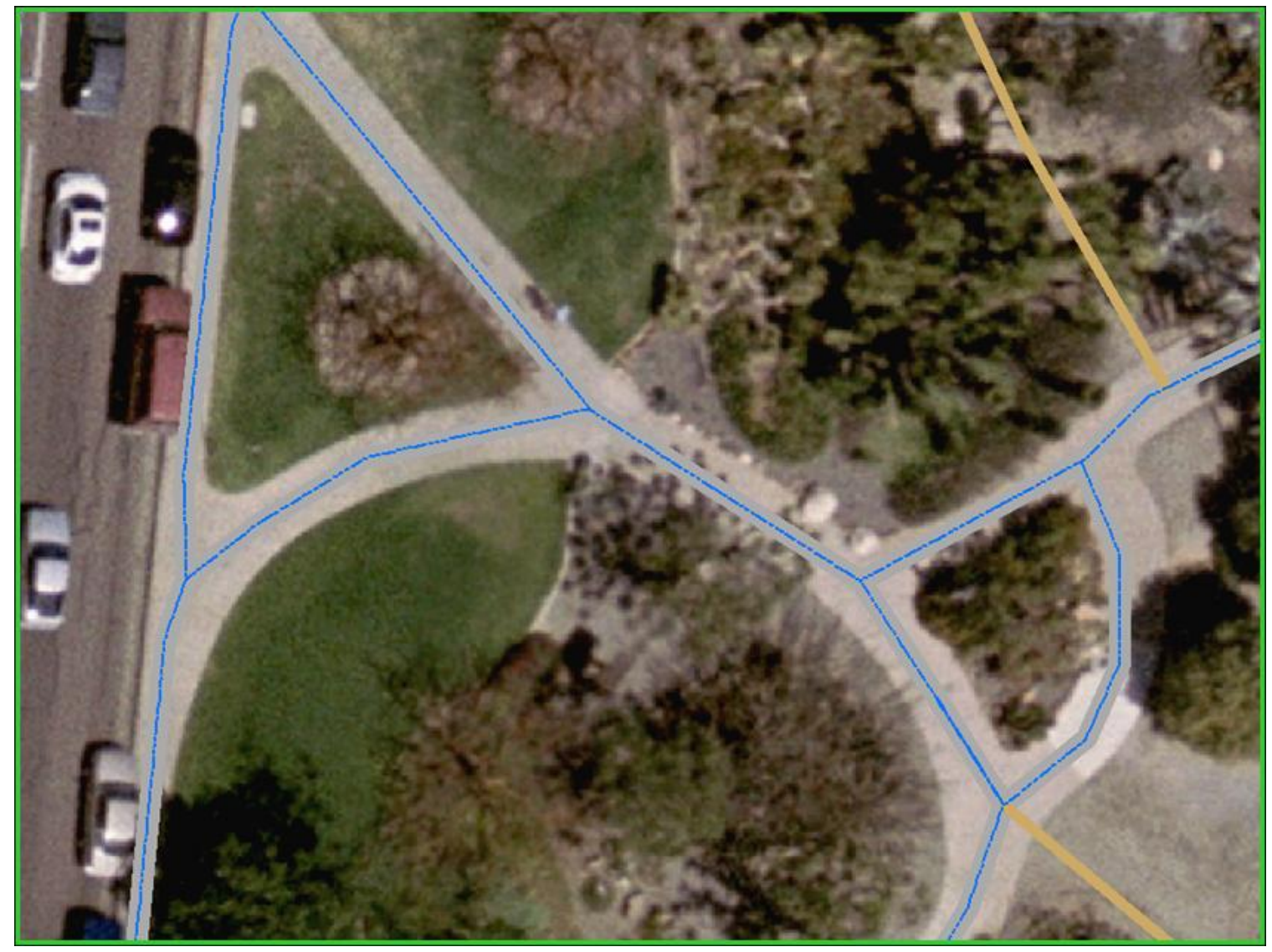

Figure 16. Heads-up digitized trail. 


\subsection{Field-to-Photo Identification}

The irrigation components were identified and located on printed orthophotography using field verification and referencing at the garden (Figure 17). The feature locations were then identified in ArcMap and corresponding locations were estimated and digitized on the orthophotography using heads up digitizing, resulting in a point-feature class. The attributes were determined and noted in the field by a maintenance worker, and the domains were created for component type, dimension, coverage and condition.

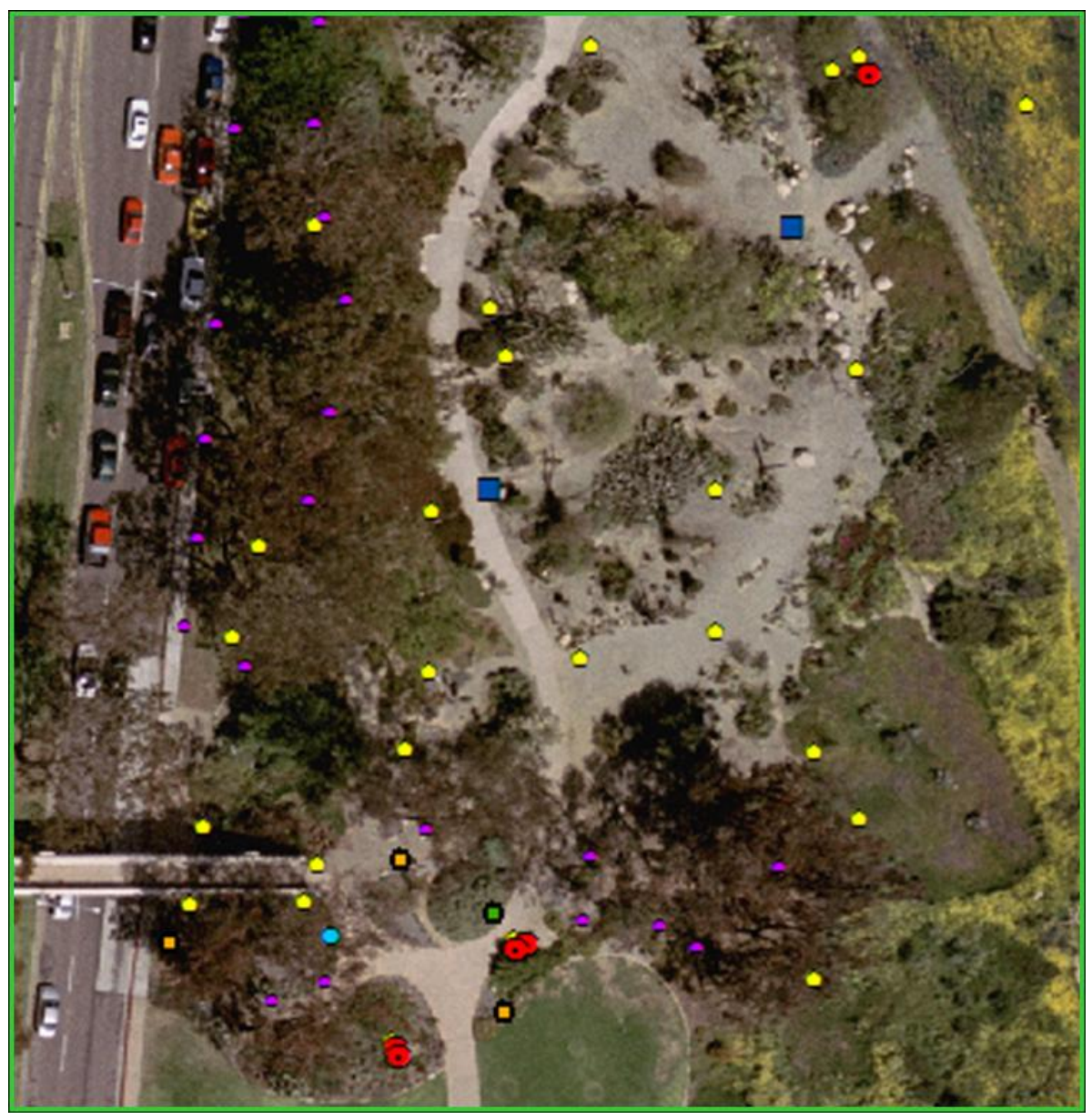

Figure 17. Irrigation components created by field-to-photo identification.

\subsection{GPS}

Various GPS equipment and data capturing methods were used to create new data for the garden's plants and infrastructure features. All coordinates were collected in geographic coordinates and World Geodetic System 1984 (WGS84). Domains were created to select a GPS capture method and feature type, and used to separate the records into separate feature classes. Capture dates were documented for each GPS data capture session. All GPS points correspond to a digital photograph number. 


\subsubsection{PDA with ArcPad/GPS}

The decomposed granite (DG) trails and boulders were located in the field using a personal data assistant (PDA) with ArcPad 7.0 with a built-in GPS, allowing for the modification of existing feature classes and new attribute entry in the field. The feature classes were created prior to field collection in ArcCatalog, and loaded into ArcPad as shapefiles in the ArcMap interface. The loaded shapefiles included the necessary spatial reference information for GPS collection. The decomposed granite trails were collected along the centerline using point streaming, which collects a point location every five seconds and connects the points, making a line feature. The boulder points represent the approximate center of the feature and the dimension attributes were manually entered. The feature classes were uploaded to ArcMap, replacing the original feature classes with the modified feature classes.

\subsubsection{GPS Camera}

Approximately 200 plant and visitor points of interest locations (Figure 18) and digital photographs were collected simultaneously using a Ricoh GPS camera. The photographs were taken from the most advantageous angle and perspective and the coordinates were collected over the approximate center of the feature. The camera had a built-in GPS receiver that embeds geographic coordinates into the digital image in an XIF format. XIF extraction tools were not available for project use, so the image ID number and X and Y coordinates were read-off and manually entered into an Excel spreadsheet. ArcMap's add XY data tool created an event layer from the spreadsheets XY coordinates, and then the event layer was exported as a shapefile. The shapefile was then imported into the plant feature dataset as a feature class, and domain fields were added for attribute selection.

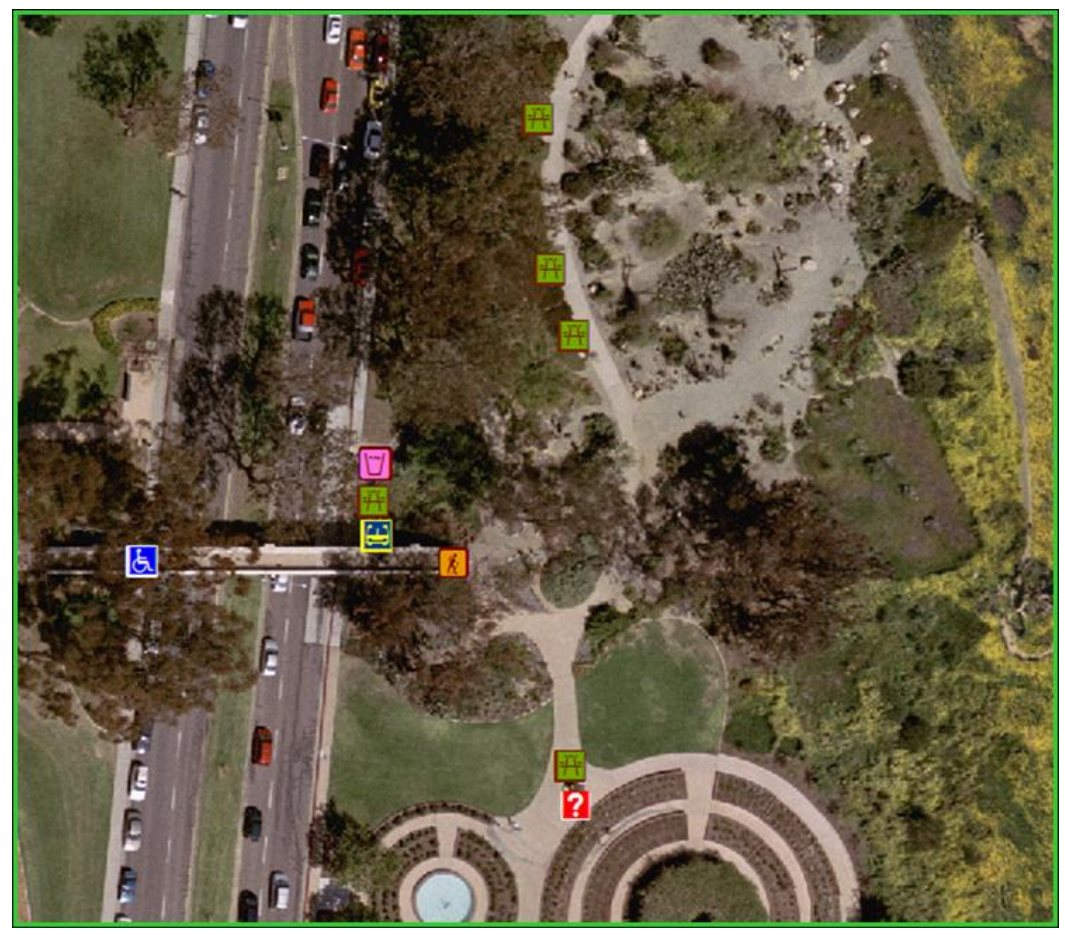

Figure 18. Visitor points of interest captured using a GPS camera. 


\subsubsection{Digital Camera with Hand-held GPS}

Approximately 500 plant, sign and visitor points of interest locations and digital photographs were collected on different dates using various digital cameras (Ricoh, Casio and Canon) with a hand-held Garmin GPSMap 60CSX (see Figure 19). The GPS collected data over the approximate center of a feature and a digital photograph was taken from the most advantageous angle and perspective.

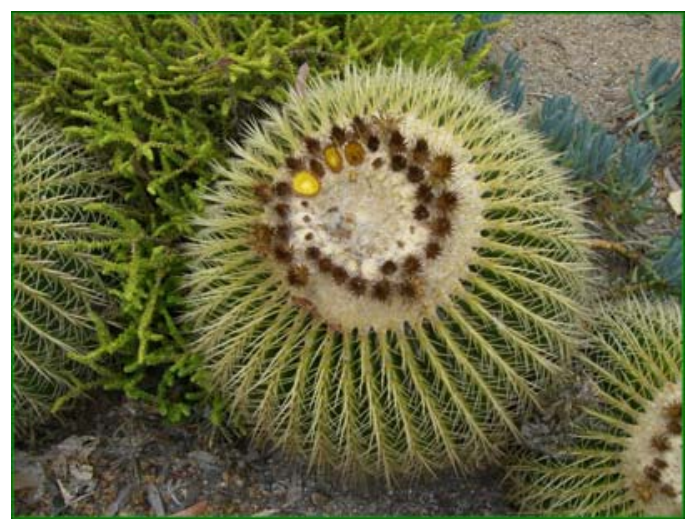

Figure 19. Digital photograph of a garden plant.

\subsection{Digital Photographs}

A digital photograph was taken for each plant, visitor point of interest, and sign feature location that was captured using a GPS receiver. Overview photographs were taken for the garden beds, and sample photographs for irrigation and trail features. A log was kept in the field to associate the digital camera photograph number with the associated GPS point. A raster field type was created for each feature class, and each feature record was hyperlinked to the corresponding photograph called a "raster link" (Figure 20).

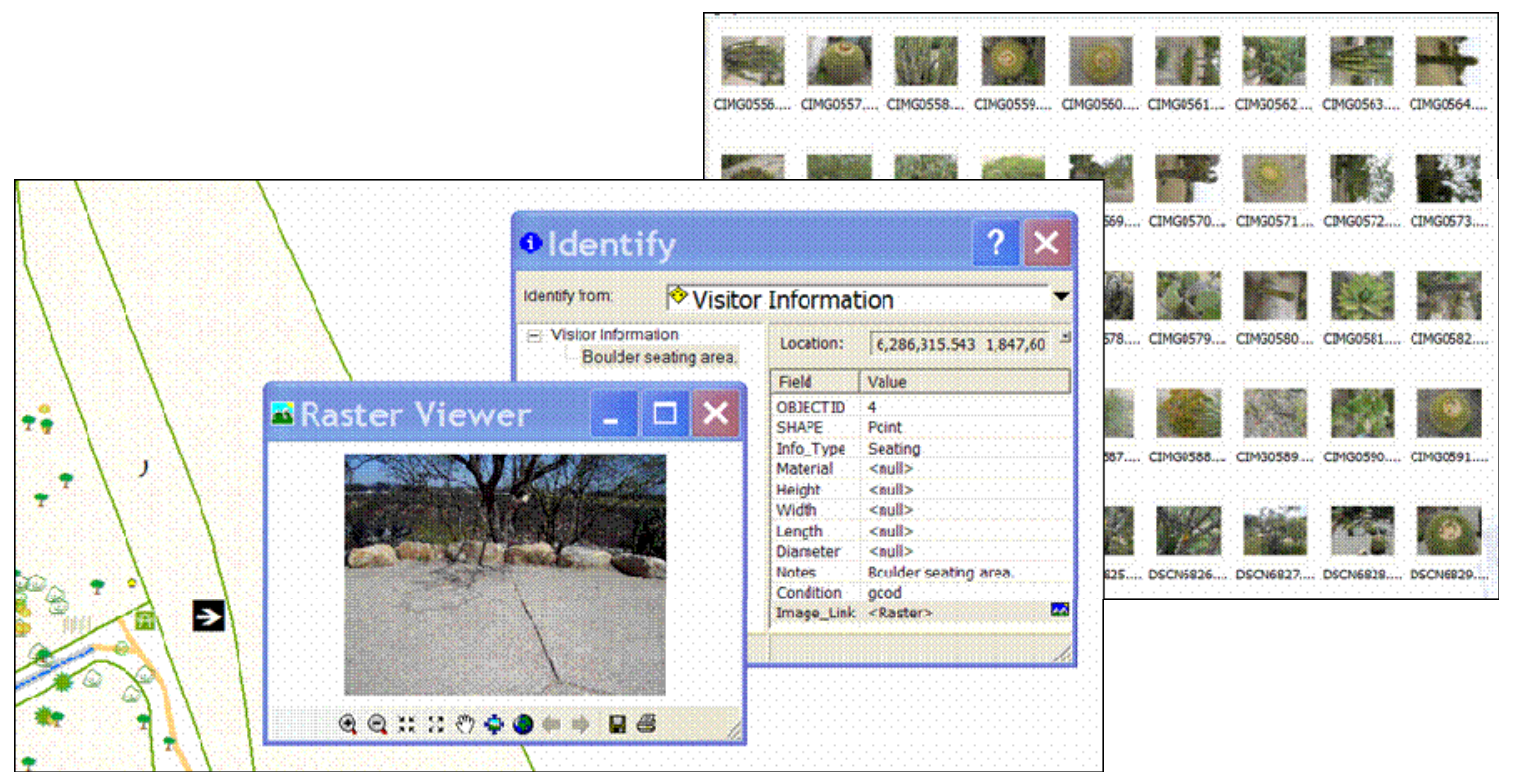

Figure 20. Image hyper-linking. 
The photographs were useful for providing the garden staff with time-stamped images for detecting change over time. Attribute assigning for most of the captured plants was done remotely, by viewing the digital photograph and referring to internet resources and reference books to help determining a plant's family name, genus/species, common name, native origin, the appearance of disease, watering issues, and the incidence of vandalism. The digital photographs were analyzed for evidence of vandalism (Figure 21), and tracked in the feature class tables.

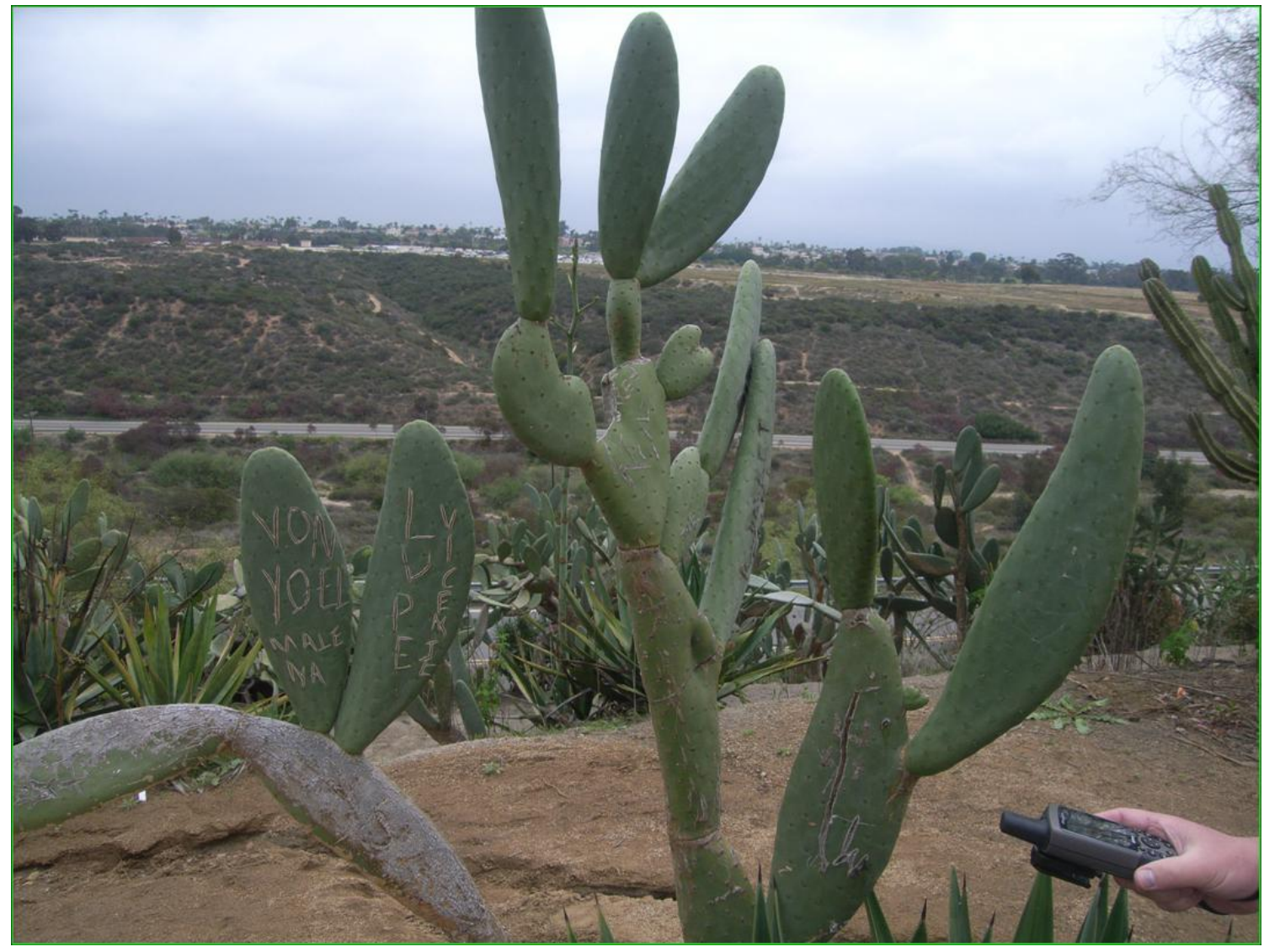

Figure 21. Plant feature captured using a hand-held GPS receiver.

This inventory provided the garden staff with a benchmark of incident locations to plan for preventative measures such as roping off vulnerable plants, relocating them to a less traveled area of the garden, or moving them to the park nursery for rejuvenation. The garden staff planned to make periodical photo updates to monitor the condition in rare, diseased or vandalized plants.

\subsection{Plant Identification}

The plants were identified by viewing the hyper-linked photographs and selecting plant nomenclature domains for the record attributes. The client and the garden staff identified the plant grouping type, family name, genus/species, and condition. Once the plant nomenclature was identified, the common name and native origin was researched on the Internet, and vandalism/graffiti incidences were determined from viewing the photographs (which did not require domain experts). 


\subsection{Data Accuracy and Revision}

Each data capture method had varying degrees of accuracy. The accuracy for the first data capture session using the hand-held Garmin GPS receiver was approximately +/-16 feet. All other data capture sessions using the hand-held Garmin GPS receiver were approximately +/- 10 feet. The accuracy for the data captured using a PDA with ArcPad/GPS receiver and the Ricoh GPS camera and receiver was approximately +/- 10 feet. The accuracy for the data created using heads-up digitizing with the city's 3-inch pixel orthophotography was approximately $+/-1$ foot, due the high pixel resolution and clarity of the orthophotography. The accuracy for the field-to-photo identification process was +/- 10 feet, due to location estimating in areas with high vegetation canopies that obstructed ground features below them. The compiled accuracy results met the client's project expectations.

Feature locations that appeared grossly out of place due to the GPS accuracy and/or precision were revised in ArcMap. For example, plant features that fell on the concrete sidewalks were moved inside the nearest garden bed boundary, and were later fieldverified for correct locations.

The accuracy for one data capture session that created 400 points using the hand-held GPS receiver was compromised due to the oversight of the display setting of the GPS unit. The unit was set to record precise coordinate values at 0.00000001 decimal degrees, but set to display coordinates after rounding to the nearest 0.001 decimal minute. The rounding of this dataset created plant locations with duplicate coordinate values. Figure 22 illustrates the resulting regular grid-like pattern from the rounded coordinate values.

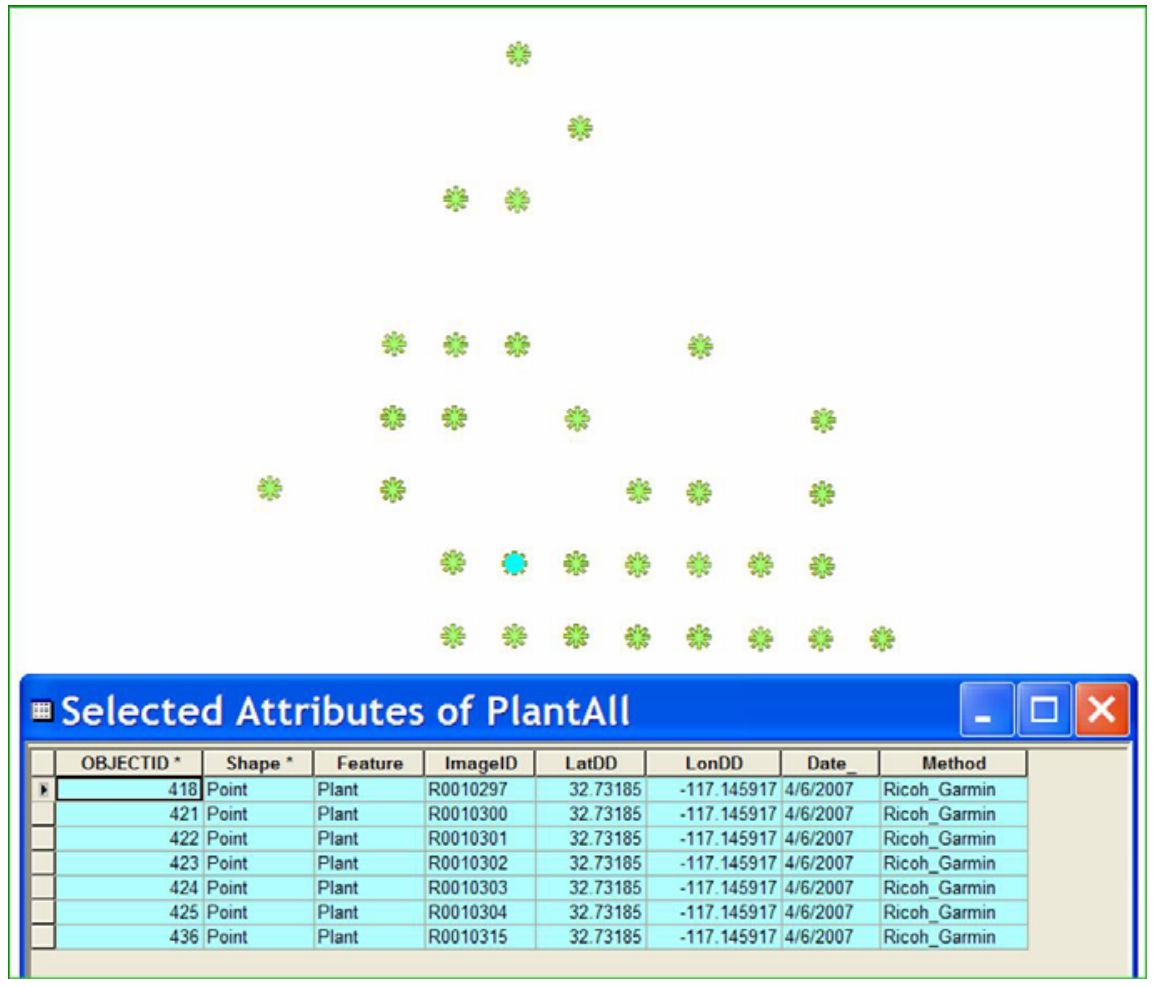

Figure 22. Example of a regular grid-like pattern of overlapping points. 
These grids measured five feet between adjacent points in the east and west direction, and measured six feet between the adjacent points in the north and south direction. These measurements are consistent with measuring distances for .001 decimal minute at 32 degrees north latitude and 117 degrees west longitude, the garden's geographic coordinates (Strahler, Alan \& Strahler Arthur, 2000). The data accuracy for this GPS capture session was estimated to be $+/-16$ feet by adding 6 feet (the higher measurement between grids) to the +/- 10 feet of accuracy for subsequent GPS capture sessions.

This data precision issue was avoided for subsequent GPS capture sessions by:

- Setting the GPS unit to display coordinate values as they are recorded in 0.00000001 decimal degrees without automatic rounding.

- Capturing the data recordings as Way-Points, storing the coordinate values in precise 0.00000001 decimal degrees in a spreadsheet or table format to be imported into a GIS for feature and attribute creation.

The overlapping points were manually dispersed in ArcMap at a scale of 1:240 (Figure 23). The digital plant photographs were used to estimate better locations for these points. These edited locations resulted in discrete symbolization of the points. The overall data accuracies of the project data met the client's expectations.

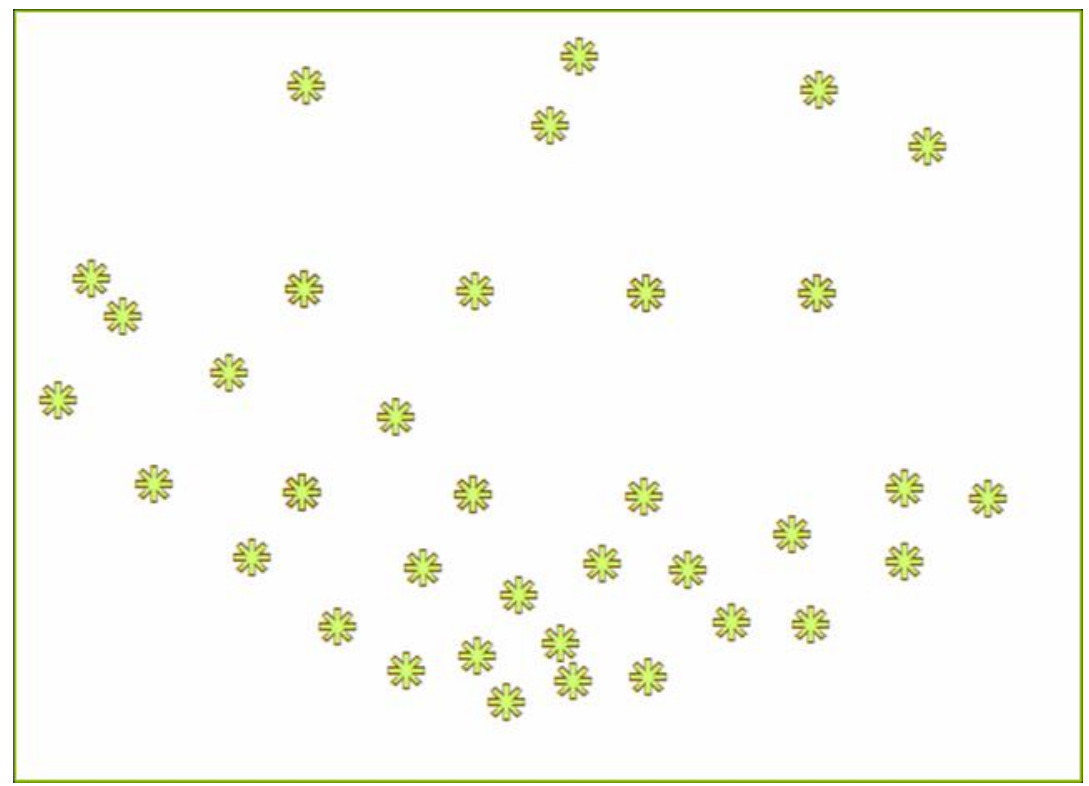

Figure 23. Example after manually dispersing overlapping points. 


\section{Information Kiosk Map and Brochure}

An informative kiosk map was created and displayed inside the Desert Garden's information kiosk and the Balboa Park's visitor center (Figure 24). This map displays the locations, photographs, and descriptions of twenty interesting plants that were selected by the garden staff as excellent representations of the garden. The city was given permission to duplicate and distribute the printed map. All plant and photo data was collected by Gina Durizzi and can be redistributed freely. 


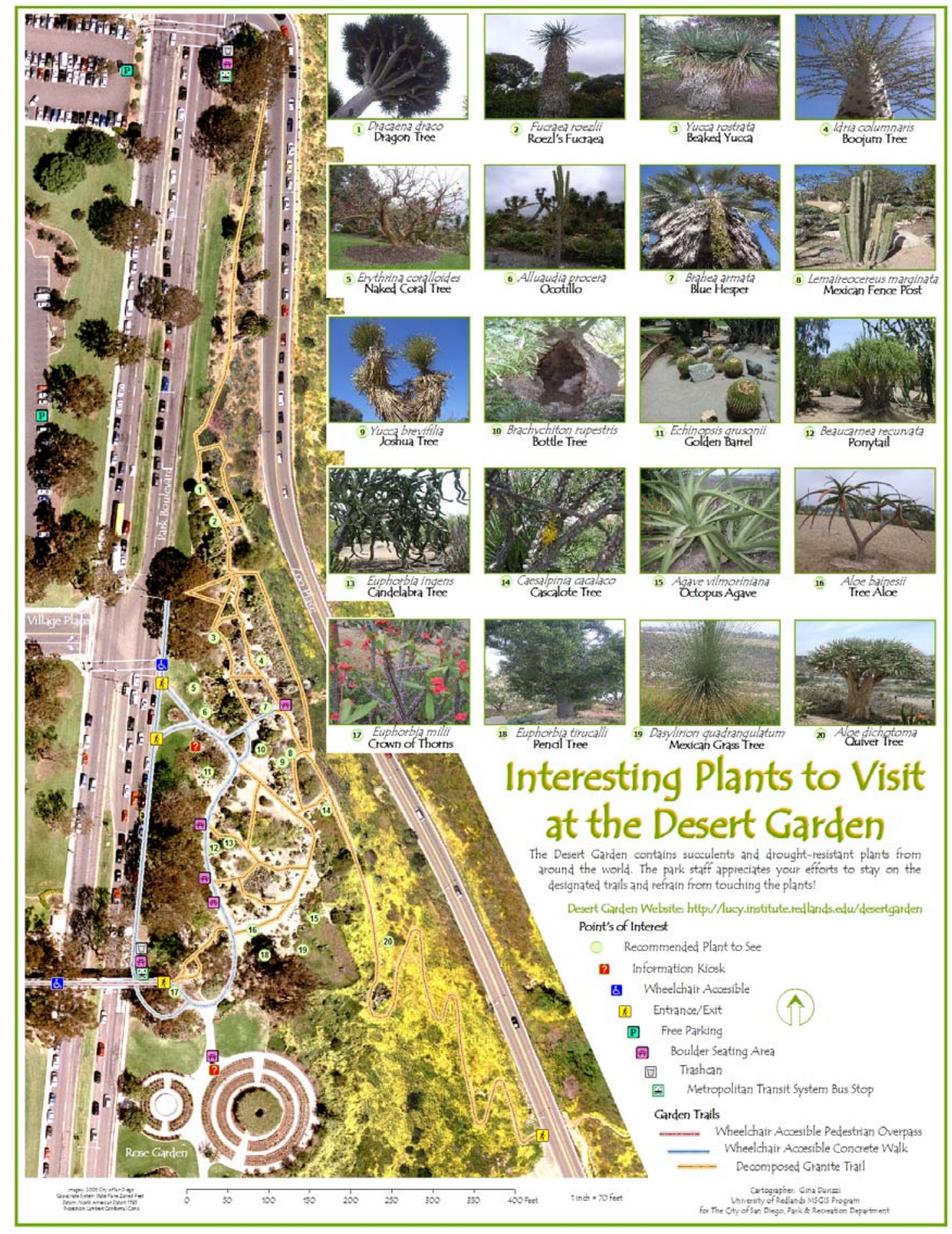

Figure 24. Information kiosk map. 
Wheelchair accessibility, trail routes, boulder resting areas, parking areas, information kiosks, trash cans, bus stops, and entrances and exits were also symbolized (Figure 25) and overlaid on high resolution orthophotography.

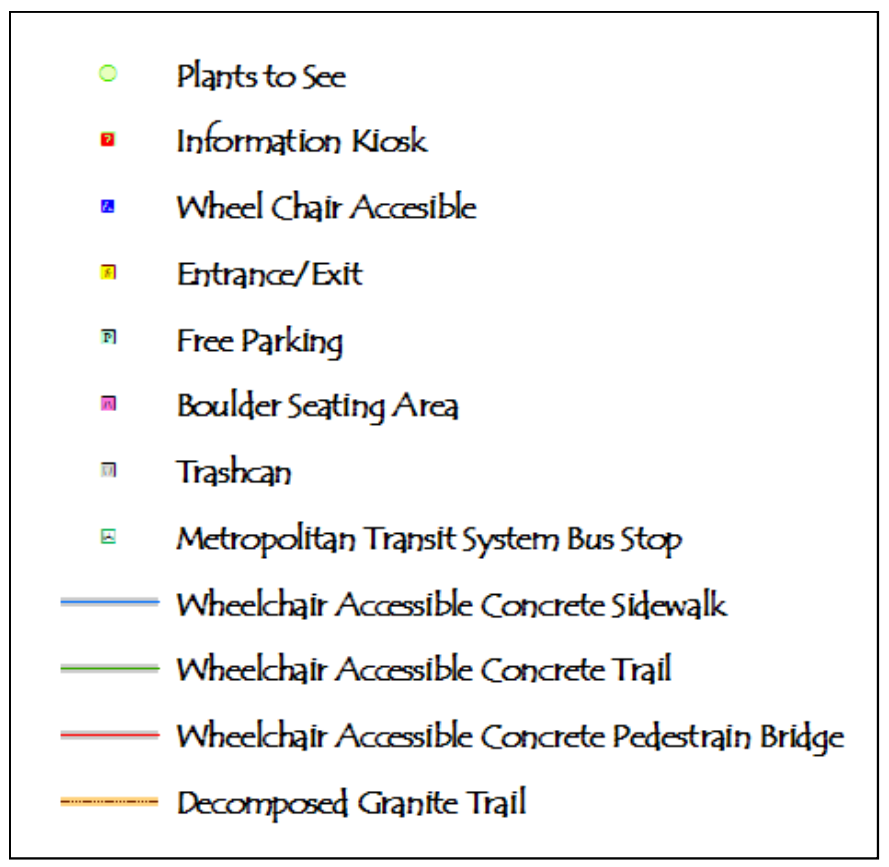

Figure 25. Legend for the information kiosk map and brochure. 
A brochure was also created based on the information kiosk map, and made available at the Balboa Park's visitor center for distribution to park visitors as a supplemental guide and garden souvenir (Figure 26). A visitor could use the brochure as a guide to navigate through the garden via the illustrated trails and walkways, and locate and identify the featured twenty plants, thus making optimal use of their time in the garden. The city was given permission to duplicate and distribute the printed brochure with plant and photo data collected by Gina Durizzi.
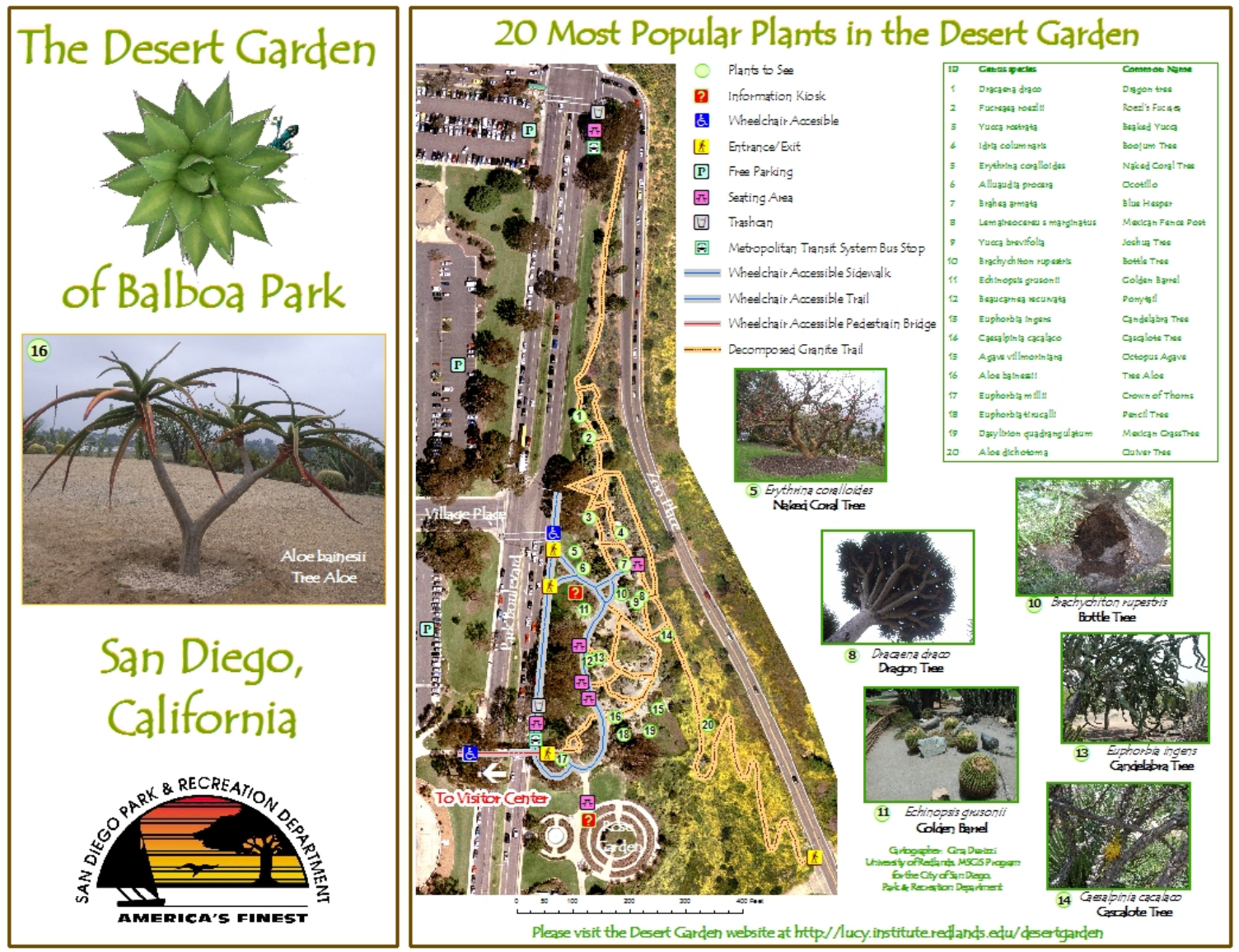

Figure 26. Brochure for the Balboa Park's visitor center. 


\section{Web-GIS Service}

An interactive mapping website was created to promote twenty interesting garden plants recommended by the park staff for visitors to view (Figure 27).

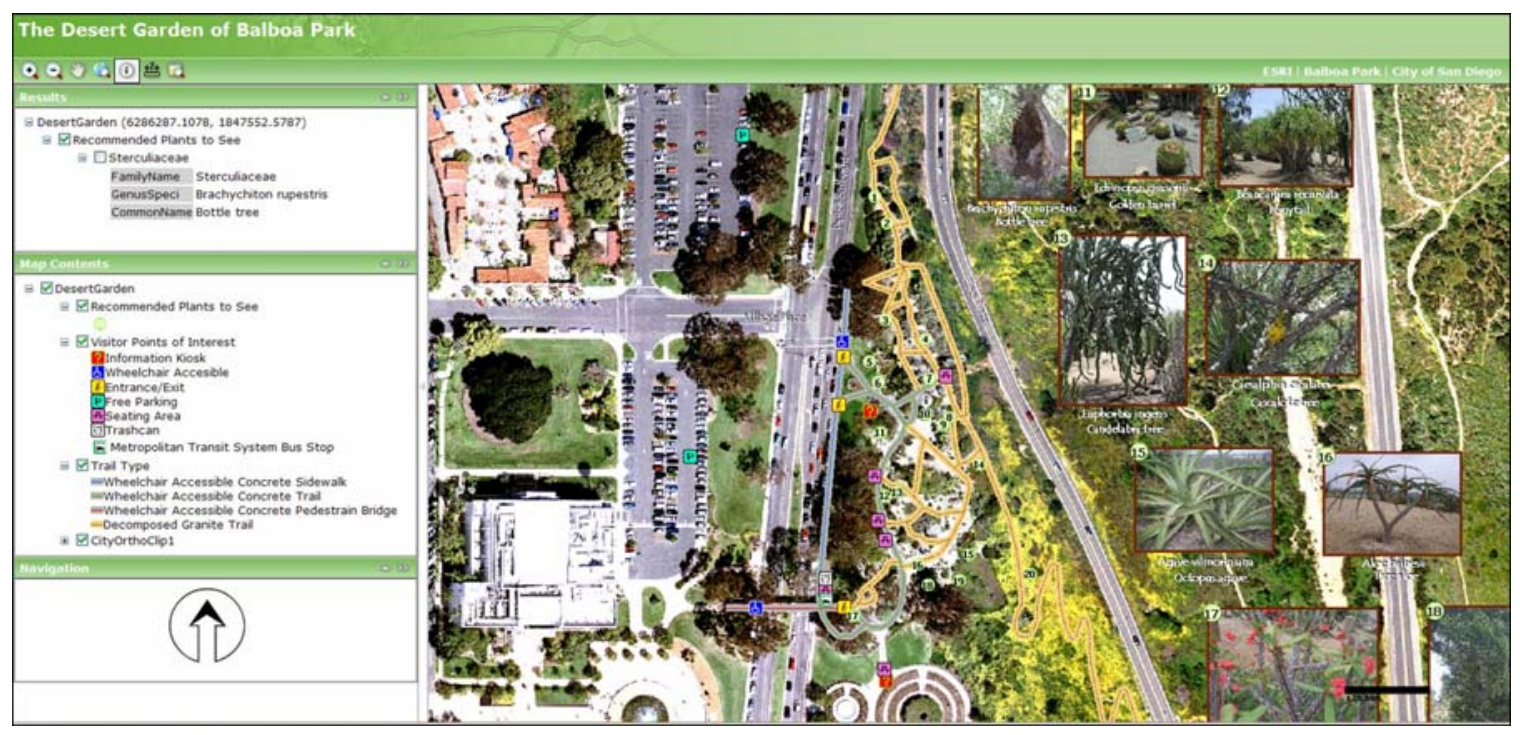

Figure 27. Desert Garden web-GIS site.

The website was based on the garden's kiosk map so that visitors can interact and view the garden's featured plants, visitor points of interest, trails, orthophotography, and photographs. Park enthusiasts could plan their visits and become familiar with the available visitor resources. Those with special transportation needs could view the wheelchair accessible trails and how they network with the rest of Balboa Park. Hikers could also view the trail network in and out of the garden, and locations of the boulder resting areas. Bus stop locations and routes were also available for planning a trip to the garden. There were hyperlinks to the City of San Diego's official website and a Balboa Park website.

ArcServer 9.2 was used to share the garden's resources with the public on the web. The information kiosk Map MXD was configured and published on the web through ArcServer Manager, where the MXD and specific layers and attributes were selected for viewing. This website allowed the public to interact with the garden's kiosk map by using standard ArcGIS tool bar to zoom in, zoom out, pan, zoom to full extent, identify, measure, and magnify. The user also has the ability to turn on and turn off the garden layers which include the 20 Plants to See, visitor information points of interest, trails, and the orthophotography. There was no out-of-the-box image hyper linking option available in ArcServer 9.2, therefore plant photographs and plant name text blocks were inserted directly into the MDX. This method allowed for the 20 static plant images and corresponding text to be viewable in the web application. This website was hosted by the University of Redlands on the Redlands Institute server, and will reside there until the City of San Diego officially implements ArcGIS 9.2 and ArcServer 9.2 city-wide. At that time, the information kiosk MXD would be reconfigured and hosted by the City's web coordinator on the City's official website. A web hyper-link was created for the 
public to access the Desert Garden website from the City of San Diego's Park and Recreation web page, until official implementation takes place by the city (Figure 28). The Web application's set-up instructions are available in Appendix A of this document.

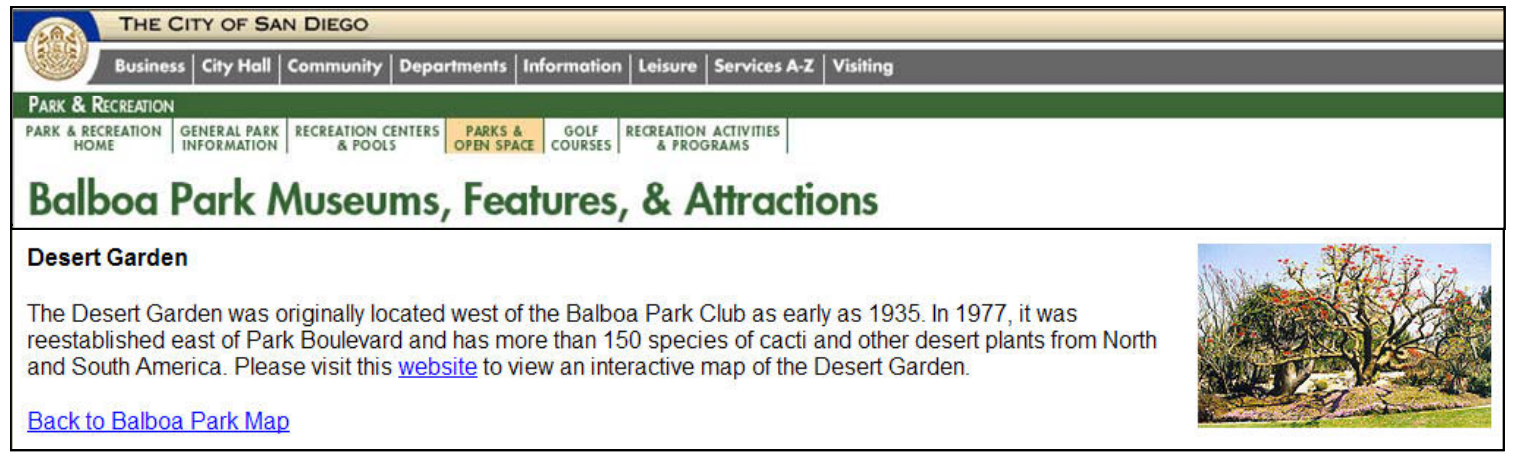

Figure 28. Hyper-link to the Desert Garden website. 


\section{3-D Lidar Bare-Earth Surface Map}

The City of San Diego 2005 lidar project delivered city-wide tiles of 5 foot resolution lidar data. The lidar data is a point cloud of elevation and coordinate readings. This data was available in ASCII format with an elevation, X coordinate and Y coordinate field representing the ground surface or bare-earth, with man-made and vegetation features removed.

To represent this data as a surface, a DEM was created from the ASCII file by first creating a feature class out of the point file using the ASCII-to-3D tool. Next, an empty triangular irregular network (TIN) was created using the Create Tin tool. The new point feature class was the input for creating a TIN using the Edit TIN tool. The output TIN was then creating into a raster using the TIN-to-Raster tool. The final product was a 3-D bare-earth DEM of the garden vicinity.

The client requested a map of the 3D bare-earth surface to visualize the garden without man-made features and vegetation (see Figure 29). This map provided a benchmark of the garden's bare-earth surface for 2005 that could be compared to future lidar and past 1999 data for change detection analysis. This 3-D surface map provides a visual aid for planning new garden exhibits, extending the trail network, and making additions to their irrigation system. This data could be further processed by the Park and Recreation Department's GIS coordinator to generate slopes for surface analysis. 


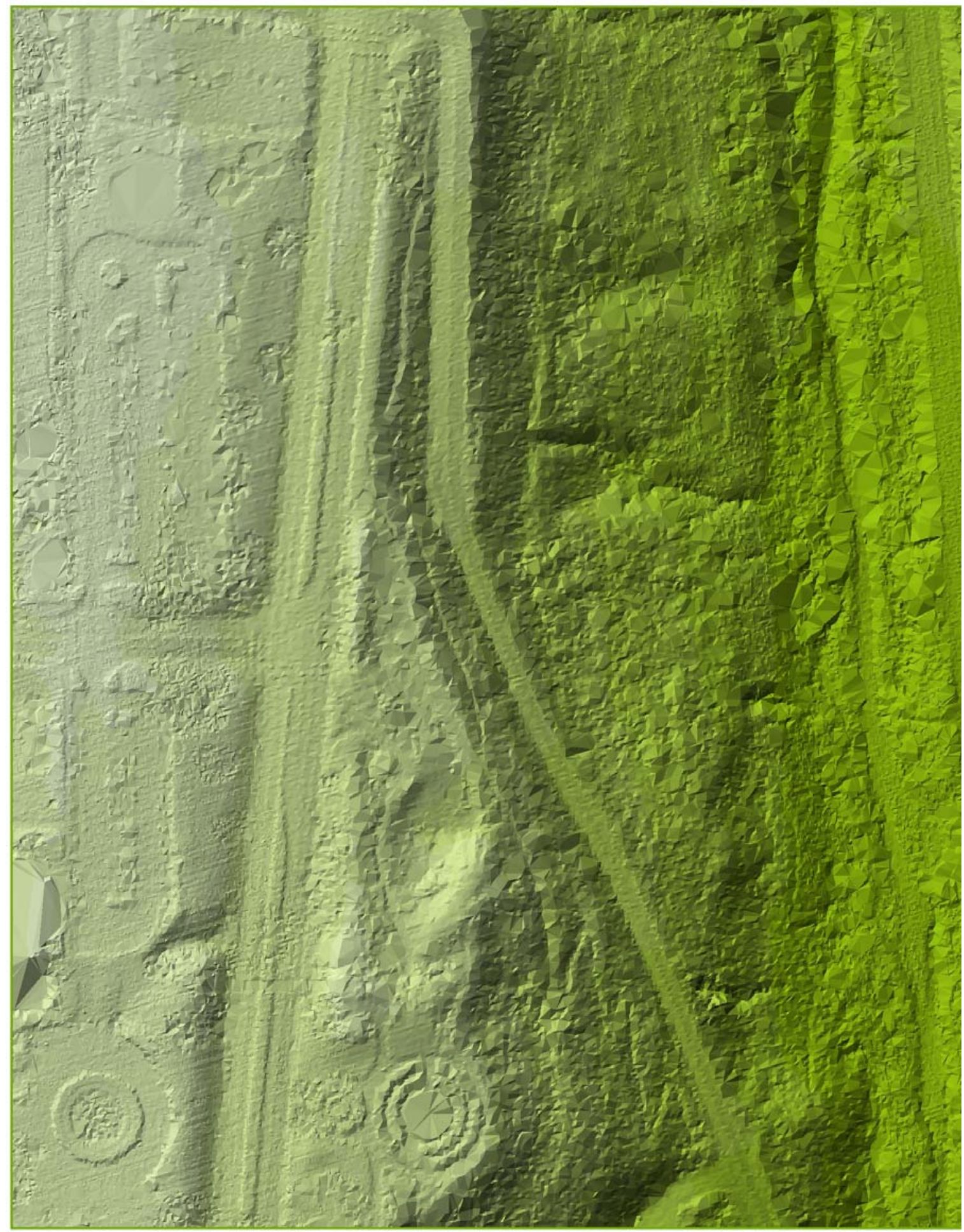

Figure 29. 3-D bare-earth surface map generated from lidar DEM. 


\section{ArcGIS Interface for City Personnel}

The user interfaces for this GIS were designed from commercial-off-the-shelf ArcGIS 9.2 and provide out-of-the-box functionality with no customization. The client requested this design for easier management and maintenance by the city's GIS staff. This design qualifies for regular maintenance and support through the city's ESRI license agreement, which does not cover issues related to customization. A higher level of skill is required to maintain customized code than to configure for commercial-off-the-shelf applications. Customized codes could become unusable and or unstable after software upgrades.

The FGDB is managed in ArcCatalog (Figure 30) and edits, queries, reports, and maps are created in ArcMap. The MXD document was maintained in ArcMap and used to publish the web-GIS service. The web-GIS service was configured and managed in ArcServer Manager.

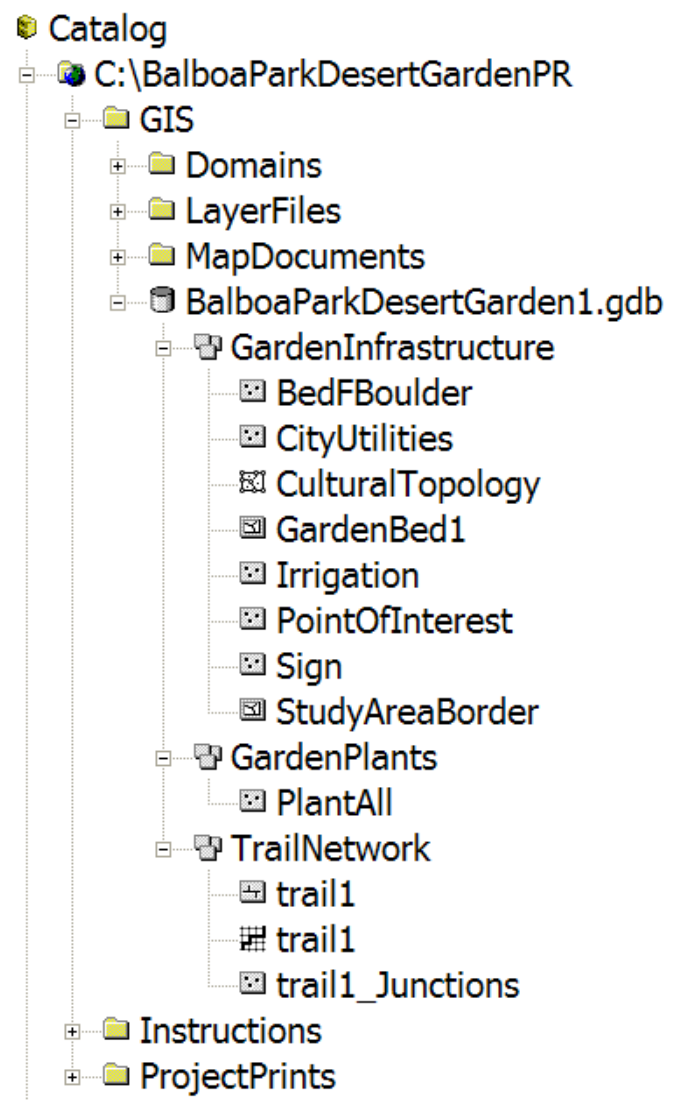

Figure 30. ArcCatalog user interface. 
A DesertGardenWorkspace.mxd (Figure 31) was created for displaying, creating and editing features and their attributes, measuring, querying, reporting, creating map layouts and printing maps. The GIS Coordinator set permissions to authorize only select city personnel to access the FGDB, to avoid the loss of data or data corruption. Routine backups were also set-up and scheduled by the GIS Coordinator.

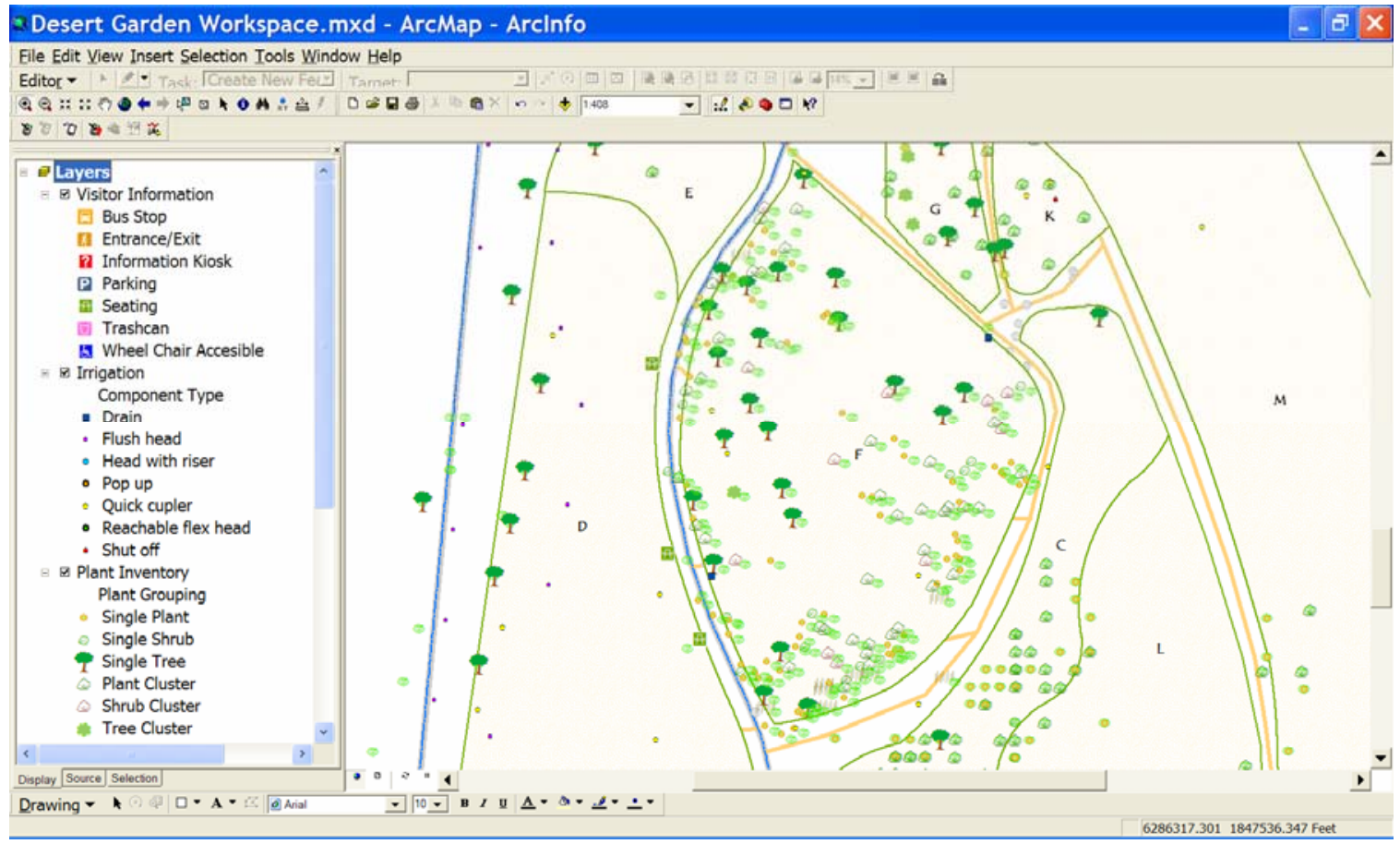

Figure 31. ArcMap user interface. 


\section{Project Workflow Poster}

Figure 32 illustrates an E size or 34” by 44” poster that was created to display the general MIP workflow processes.

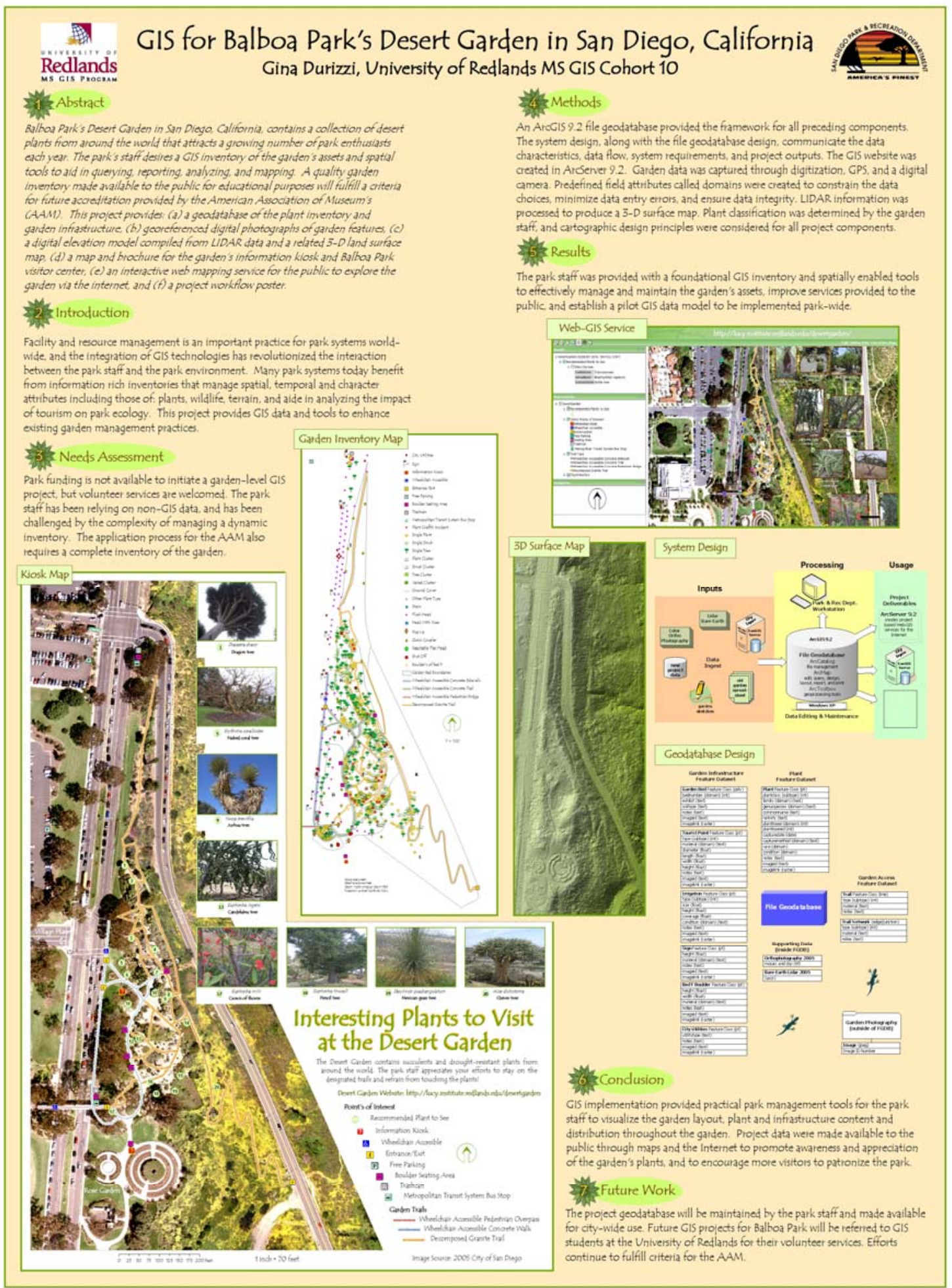

Figure 32. Project poster. 


\section{Conclusions and Recommendations}

The implementation of GIS into the workflow of the Park and Recreation Department has improved many aspects of park facility management since 1996. The park staff used GIS to track maintenance events for city parks, utilize city-wide GIS data, manage park boundaries, plan for new park sites, and aid in special events planning. Garden-level implementation of GIS provided the staff with spatially-enabled tools to display, edit, query, report, and mapping of the garden's features. This garden inventory established a benchmark of the garden's assets, aided in increasing the efficiency in maintenance practices, assisted in exhibit planning and design, enhanced visitor services, and introduced a routine workflow incorporating GIS to manage the gardens assets. A wellmaintained and working FGDB would allow the data model and data workflow to be introduced to other park facilities within the city. This project contributed to the city's coordination efforts to create, share, display, and store GIS data for city-wide use and made garden information available to the public.

\subsection{Results}

The project deliverables implemented into the Park and Recreation Department's GIS provided a foundational GIS inventory to manage the Desert Garden assets. The garden staff was provided with garden-level GIS data to contribute to the established Park and Recreation Department's GIS and city-wide GIS. The project provided a functioning data model and workflow to track routine changes in the park's plants and infrastructure and manage the garden's assets. Tracking and monitoring the condition of the garden's assets would allow the garden staff to budget and make decisions about future infrastructure repairs, plant replacements and procurement, vandalism prevention and garden bed expansion. The garden staff intends to provide timely data to the GIS coordinator to maintain and expand the foundational GIS inventory provided for this project. The GIS coordinator was requested to fulfill all Desert Garden related GIS requests, mainly to display, query, analyze, report and map, until sufficient training and a functioning GIS workstation is available for the garden staff.

\subsection{Data Problems}

There were many clusters of mixed plants arranged in dense concentrations, making it impractical to collect discrete points for each individual plant. This was not necessarily a significant problem due to the client understanding the project accuracy expectations, but it does warrant recognition.

The data accuracy was compromised for one GPS session due to an oversight in the settings of the hand-held GPS receiver unit, resulting in the rounding of the coordinate values to the nearest 0.001 decimal minute. The rounding of this dataset created plant locations with duplicate coordinate values that displayed a regular grid-like pattern. The overlapping points were manually dispersed in ArcMap at a scale of 1:240 and the digital plant photographs were used to estimate better plant locations. These edited locations resulted in discrete symbolization of the points. 
This data precision issue was avoided for subsequent GPS capture sessions by settings the data values to be recorded and displayed at the precision of 0.00000001 decimal degrees. Another setting option was to capture the data recordings as Way-Points to store the coordinate values in precise 0.00000001 decimal degrees in a spreadsheet or table format to be imported into a GIS for feature and attribute creation. The overall data accuracies of the project data met the client's expectations.

Heads-up digitizing and the field-to-photo identification method were most accurate in areas without obstruction caused by vegetation and slope. Some irrigation feature locations were estimated in high-vegetation areas.

Approximately 30 of the plant locations collected from GPS receivers were identified as being in the concrete paths or in the street right-of-way. These had to be identified and moved to the correct garden bed and verified in the field. Finding the correct garden bed to assign the plant was challenging in areas where many garden bed boundaries come together, adding extra time to the project for field verification and referencing the digital plant photographs.

GPS capture was challenging in the southeast portion of the garden due to the degree of slope and unstable ground cover. The steep slopes with decomposed granite ground cover made it extremely difficult and dangerous for establishing GPS positions of the columnar cacti. The plants were vulnerable to being stepped on or knocked over, and the field person was vulnerable to being pricked by the cactus. The steep slope obstructed portions of the satellite constellations at given times of the day, limiting the chances of receiving good positional information from the GPS receiver. Field-to-photo identification was not an option for this area because the columnar cacti were planted after the orthophotography was taken in 2005.

\subsection{Opportunities for Analysis}

The following are opportunities for spatial and attribute analysis that can be performed by the Park and Recreation Department's GIS staff using the project's completed inventory data:

- Spatial distribution and analysis of plants by native origin for planning thematic garden bed exhibits.

- Spatial distribution and analysis of vandalism locations to plan for prevention and relocation of affected plants.

- Monitoring and analysis for determining best locations for rare and valuable plants.

- Needs assessment, analysis and area calculations for materials assessment including fertilizer, soil, sand, decomposed granite, and boulders.

- Condition assessment and analysis of infrastructure and plants for fiscal planning.

- Temporal analysis and change detection with city lidar data sets to determine and monitor areas with erosion problems, especially in the sloped southeast portion of the garden.

- Slope and aspect creation for usable slope analysis.

- Monitoring and analysis of watering schedules and plant conditions for water conservation.

- Monitoring and analysis of diseased plants for prevention and management. 


\subsection{Future Recommendations for the Desert Garden}

The FGDB structure should be maintained by the GIS coordinator and adhered to as per the city's GIS standards. All future activity in the garden should be updated in the GIS and include a hyperlinked digital photograph. Future activities should be tracked and documented for plants, include new plantings, plant removal, plant relocation, vandalism and disease. Infrastructure maintenance, upkeep and staff information should also be tracked and documented. New feature locations should be collected using GPS, digitizing from current city orthophotography, or field-to-orthophoto identification. Attribute domains should be updated as needed and used consistently to assign record attributes.

An Access table is recommended to be built and joined to the plant feature class to track the to-and-from movement as plants are moved within the garden, or to-and-from the nursery. The relationship of the table should be a one-to-many relationship, tracking multiple locations for one plant during its life cycle. For example, a plant may originate from the park nursery, then be moved to garden bed A, moved to garden bed B, sent back to the nursery for treatment, and moved back to garden bed $\mathrm{B}$.

The city has plans to capture lidar data on an annual basis. These datasets can be used for temporal analysis and change detection for surface related issues such as erosion, drainage and flooding. The city's existing orthophotography from 1991, 1999 and 2005 can also be used for the purpose of temporal analysis and change detection via image analysis and classification.

The city’s GIS program should continue providing ESRI product licensing and support for the garden staff and software training, as permitted by the Park and Recreation Department budget. It is recommended that the garden staff be trained via ESRI's virtual campus and participate in instructor-led courses covering topics in FGDB management, ArcMap editing, querying, analysis, reporting and map design, ArcServer set-up and configuration. If funding is an issue, training and software grants are offered by ESRI to Botanical Gardens and Zoological Parks to support GIS applications towards plant conservation, research, management, and public education (application deadline is June 30, 2008) (Spatial News, 2007). ArcServer is expected to be implemented city-wide in the future, and ArcServer 9.3 will have out-of-the-box printing and image hyper-linking functionality which would enhance the website greatly by adding the capability to view digital photographs of the features plants in the garden.

The Park and Recreation Department may want to explore the opportunity to invest in the BG-Map software application, a botanical garden specific data collection and documentation system to use along with GPS to integrate into the project data model created for gardens. This system is becoming a botanical garden standard and is used for collecting plant data in world-class garden collections.

The deliverables for this project did not include training or a procedure manual. All garden-level GIS requests were left to the GIS coordinator to fulfill until the garden staff is trained to a level where they can fulfill their own requests. 


\section{Reference List}

American Association of Museums. (n.d.). AAM accreditation program. Retrieved July 14, 2007 from http://aam-us.org/museumresources/accred/index.cfm

ArcNorth News. (2002). Managing botanic gardens using GIS (Vol. 5, No.4, 2002). Retrieved July 14, 2007 from www.esri.com/industries/libraries/success-stories/pdfs/arc_north_02royal_ gardens.pdf

Arctur, D., \& Zeiler, M. (2004). Designing geodatabases. Redlands: ESRI Press.

Armstrong, L., \& Henry, M. (Eds.). (2004). Mapping the future of America's national parks. Redlands: ESRI Press.

Balboa Park. (n.d.). Balboa Park Official Website. Retrieved July 7, 2007, from http://www.balboapark.org

Cannistra, J., \& Raber, B. R. (2005). Lidar guidebook: Concepts, project design, and practical applications., Park Ridge: URISA.

CityWorks. (2007, June 30). San Diego CityWorks. Retrieved July $7^{\text {th }}$, 2007, from http://citymap.sandiego.gov/imf/sites/ciptpub/CIPGISIntro.jsp

Garmin. (2000). GPS guide for beginners. Retrieved July 14, 2007, from http://www8.garmin.com/aboutGPS/manual.html

Glissmann-Gough, S. (2005). Managing plant collections using GPS/GIS in the Royal Botanic Gardens Melbourne (RBGM). Paper presented at the 2005 ESRI International User Conference. Retrieved September $29^{\text {th }}$, 2006, from http://gis2.esri.com/library/userconf/proc05/papers/pap1833.pdf

Goodchild, M.F., Longley, P.A., Maguire, D.J., \& Rhind, D.W. (2005). Geographic Information Systems and Science, (2nd ed.). West Sussex: John Wiley \& Sons Ltd.

Gower, J., Moat, J., \& Morley, J. (2000) A virtual tour of the Princess of Wales Conservatory, Royal Botanical Gardens, Kew. Paper presented at the 2000 GIS Research UK 2000 Conference. Retrieved July 7, 2007, from http://www.kew.org/gis/papers/GISVis.pdf

Hewett, M. (2005). Automating feature extraction with the ArcGIS spatial analyst extension. Paper presented at the 2005 ESRI International User Conference. Retrieved October 4, 2006, from http://gis2.esri.com/library/userconf/proc05/papers/pap2109.pdf 
Jensen, D., \& Stonich, T. (2005). Park \& recreation information system- Integrated ArcIMS application. Paper presented at the 2005 ESRI International User Conference. Retrieved September 29, 2006 from http://gis.esri.com/library/userconf/proc05/papers/pap1272.pdf

Jeter, M., \& Ratchinsky, K. (2005) GIS for botanical garden management and educational programming. Paper presented at the 2003 ESRI International User Conference. Retrieved July 7, 2007 from http:/gis.esri.com/library/userconf/proc03/p0311.pdf

Mauricycle La Tuque Department, (n.d.). Mauricycle La Tuque. Retrieved July 13, 2007 from http://www.tourismehsm.qc.ca/mauricycle/index.php

Mounts Botanical Garden, (n.d.). Plants and gardens. Retrieved July 14, 2007 from http://www.gisweb.co.palm-beach.fl.us

Odion, D. (Eds.). (1988) The Guide to the Santa Barbara Botanical Garden. Santa Barbara: Santa Barbara Botanical Garden.

Puplava, K., \& Sirois, P. (Eds.). (2001). Trees and gardens of Balboa Park. San Diego: Tecolote Press.

Sappington, N. (Eds.). (2006). ESRI map book Volume 21. Redlands: ESRI Press.

Scott Arboretum of Swathmore College, (May 7, 2001). BG-map feature article. Retrieved July 7, 2007, from http://www.bg-map.com/feature/sct_inst.html\#about

Sherman, S. (2005) Delivering world class service: Integrating GIS and municipal asset management. Paper presented at the 2005 ESRI International User Conference. Retrieved September 29, 2006, from http://gis.esri.com/library/userconf/proc05/papers/pap1096.pdf

Spatial News. (July 11, 2007). ESRI offers GIS software and training grants to botanical gardens and zoological parks. Retrieved July 14, 2007 from http://spatialnews.geocomm.com/dailnews/2007/jul/11/news6.html

Strahler, Alan, \& Strahler, Arthur. (2000). Introducing physical geography, $\left(2^{\text {nd }} e d.\right)$. New York: John Wiley \& Sons, Inc. 


\section{Appendix A: Web Application Set-up Instructions}

The following are step-by-step instructions are for creating the MIPs interactive website using ArcServer 9.2 and serving the website on the University of Redland's lucy server. The website DGWeb1.mxd (not DGWeb1x which was used for the purpose creating these instructions only) and hyper-linked digital photographs are available on the MIP project data DVD.

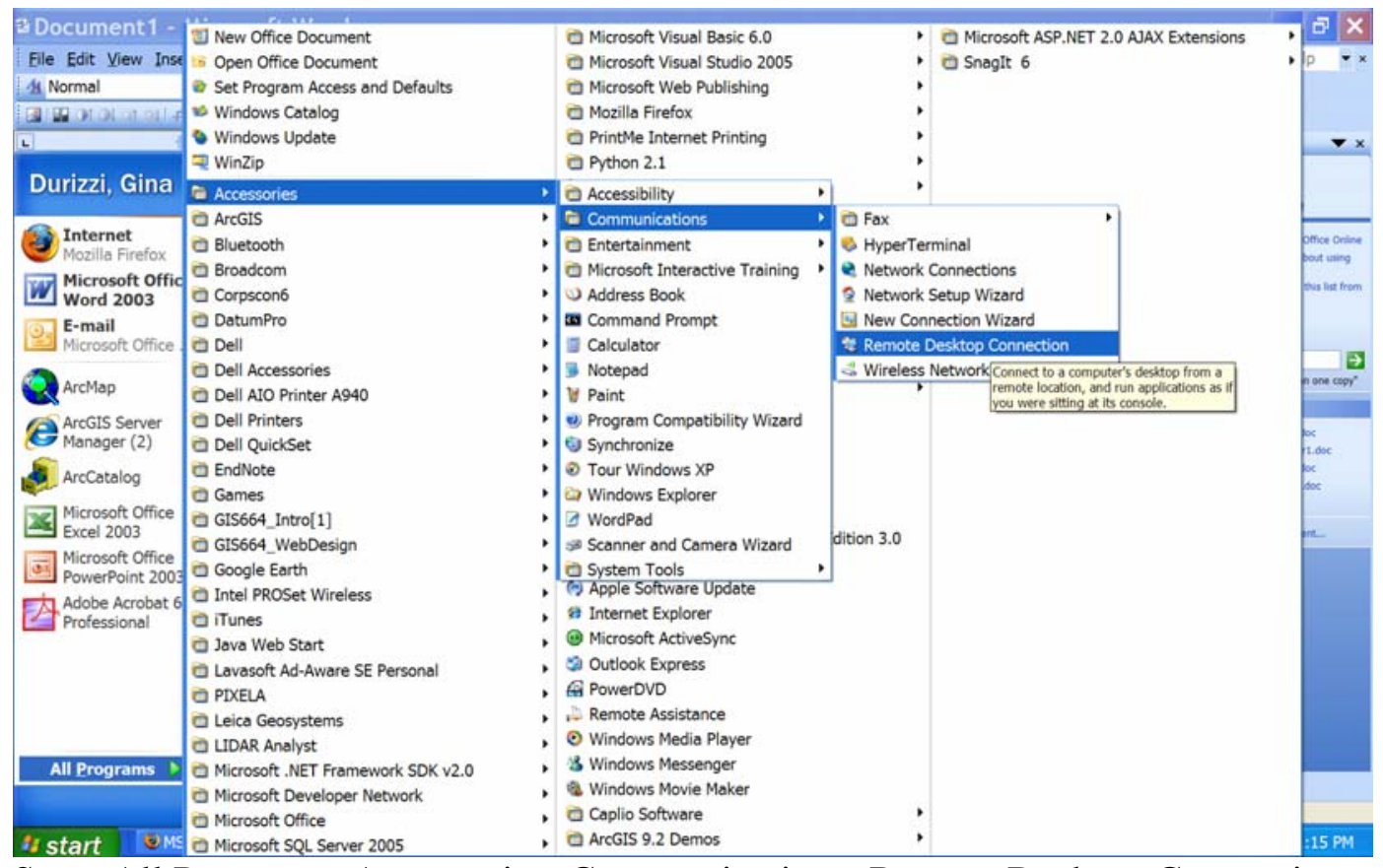

Start, All Programs, Accessories, Communications, Remote Desktop Connection to connect to the University of Redlands lucy server.
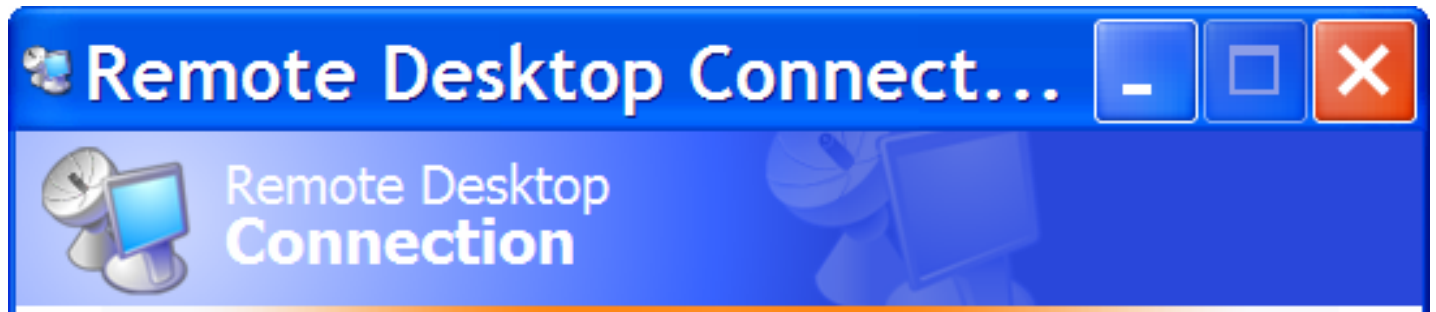

Computer:
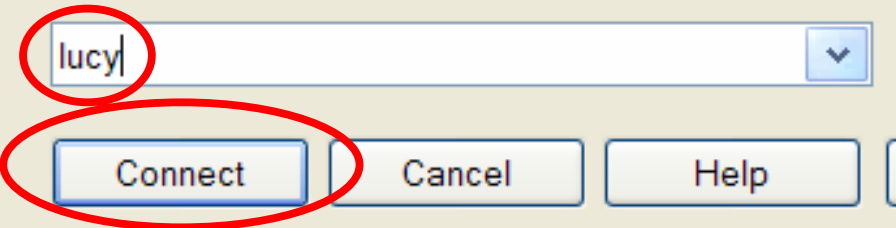

\section{Options $\gg$}

Enter lucy for the computer name. 


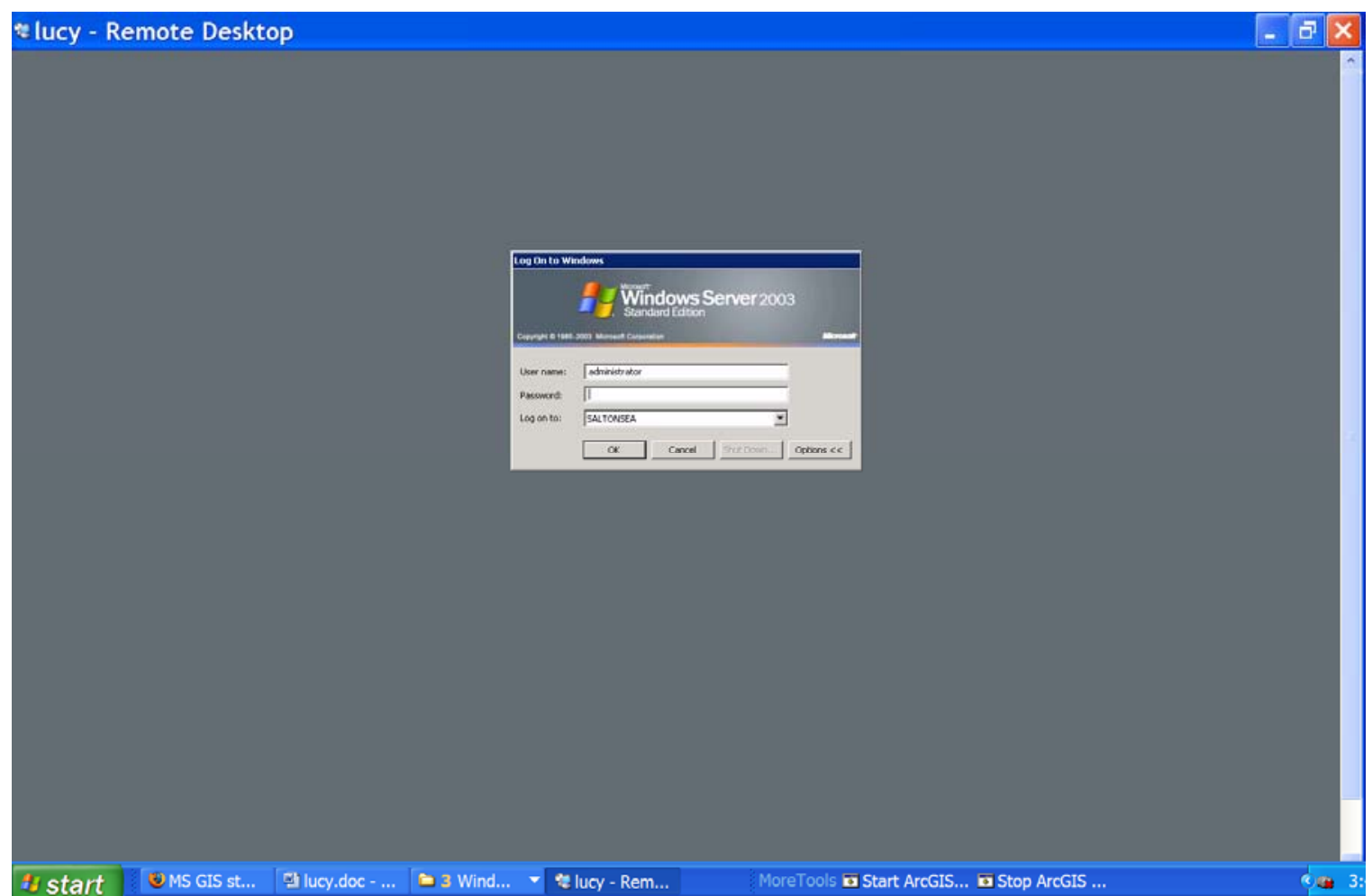

Consult with your IT department for proper login specifications.

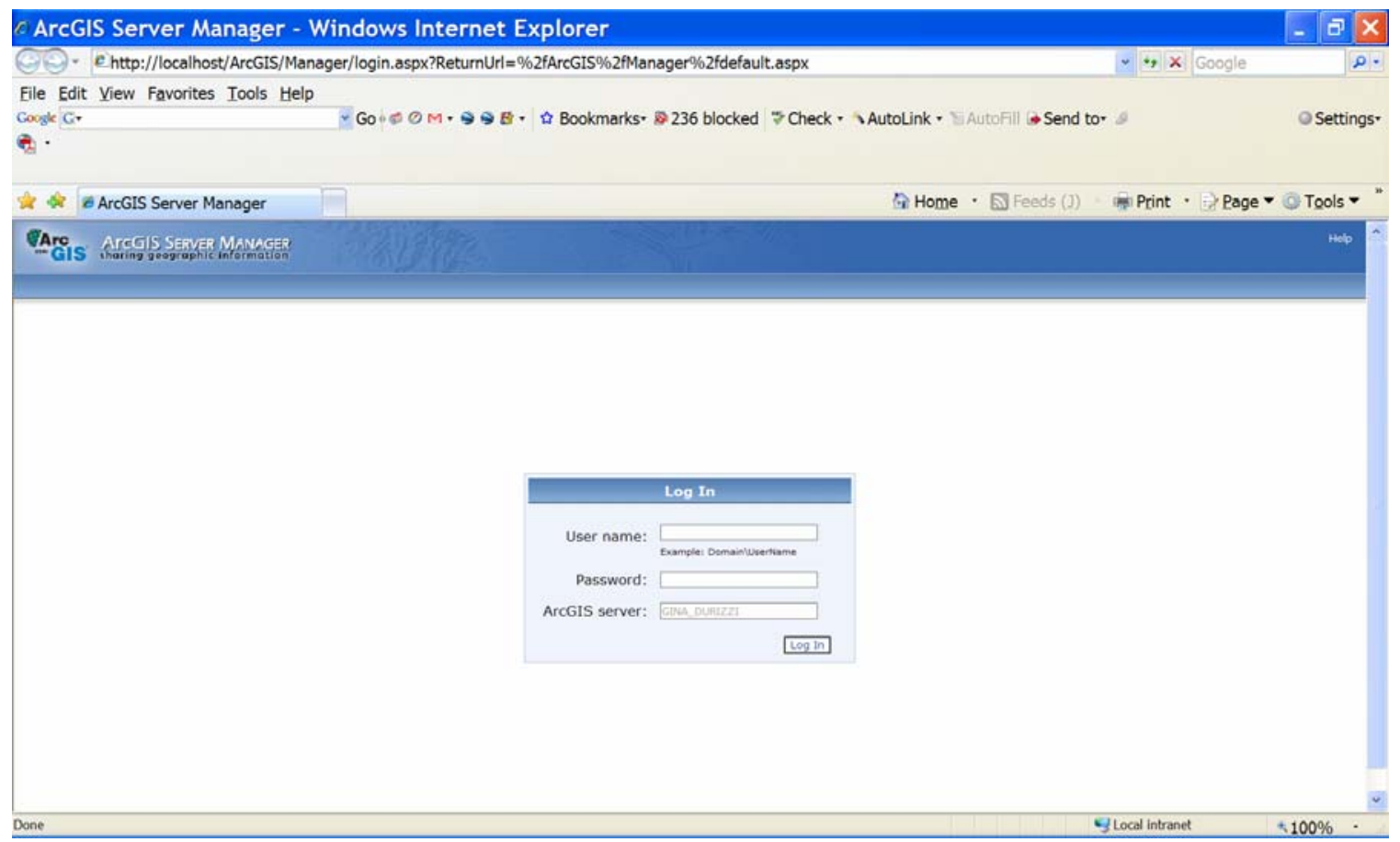

Login for ArcGIS Server Manager. This login will depend on the user. 


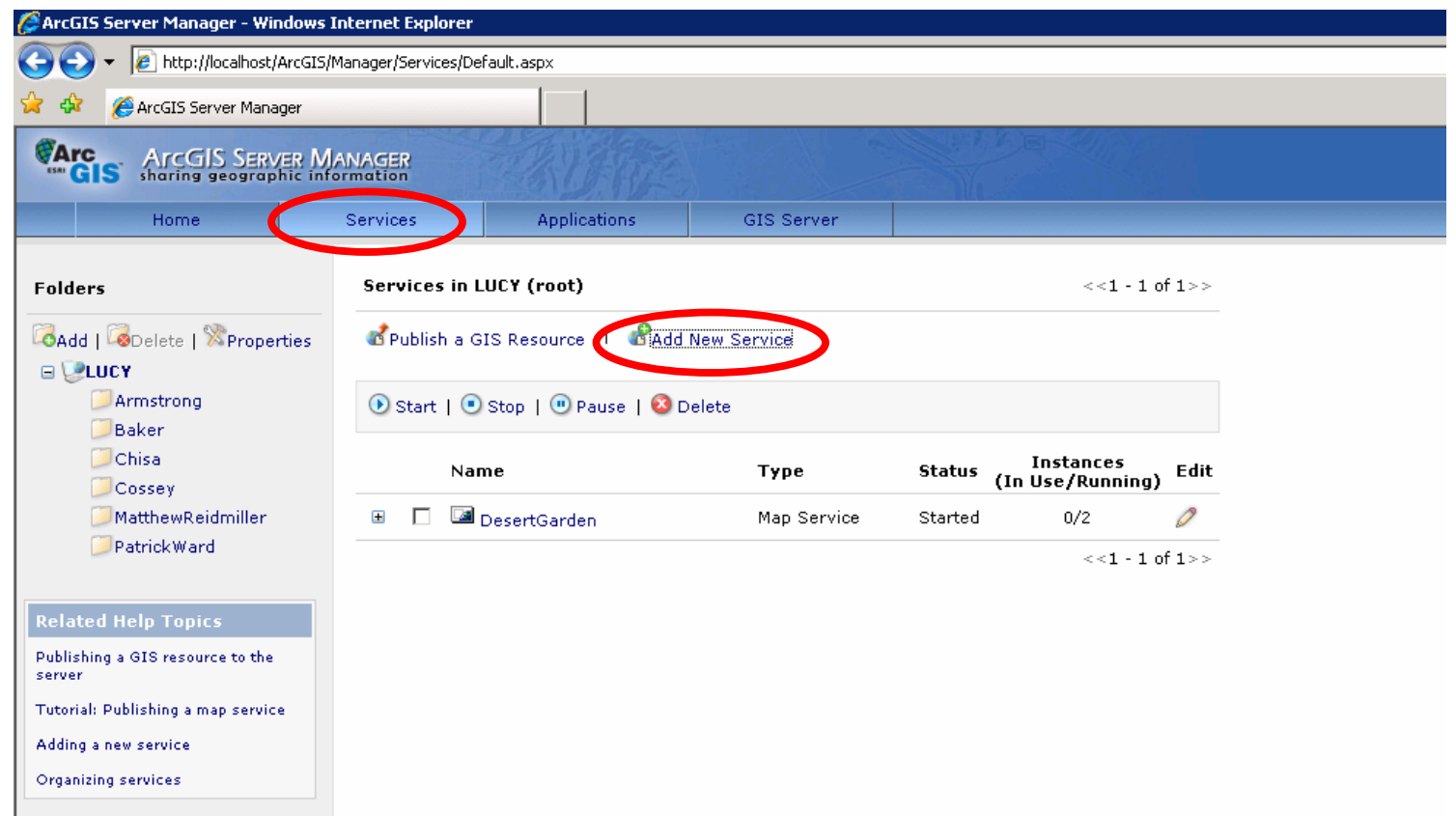

To add a new service, select the Services tab and select Add New Service.

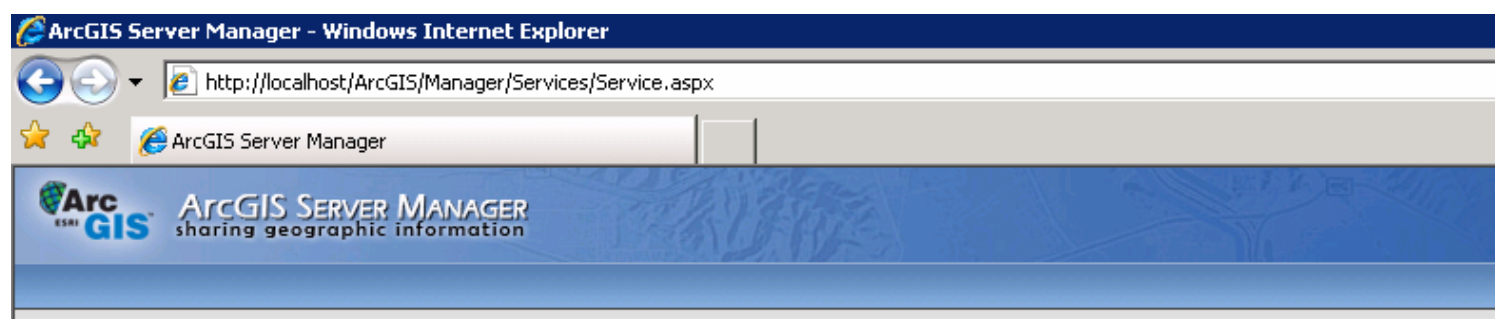

Add New Service

This wizard lets you add a new cerwion to the GIS server.

Name:

DesertGardenx|

Type:

Map Service $\quad$ -

Description:

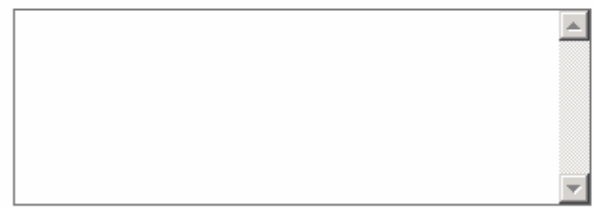

Startup Type:

Automatic $=$

Name the service (no spaces- keep it simple), click Next. 


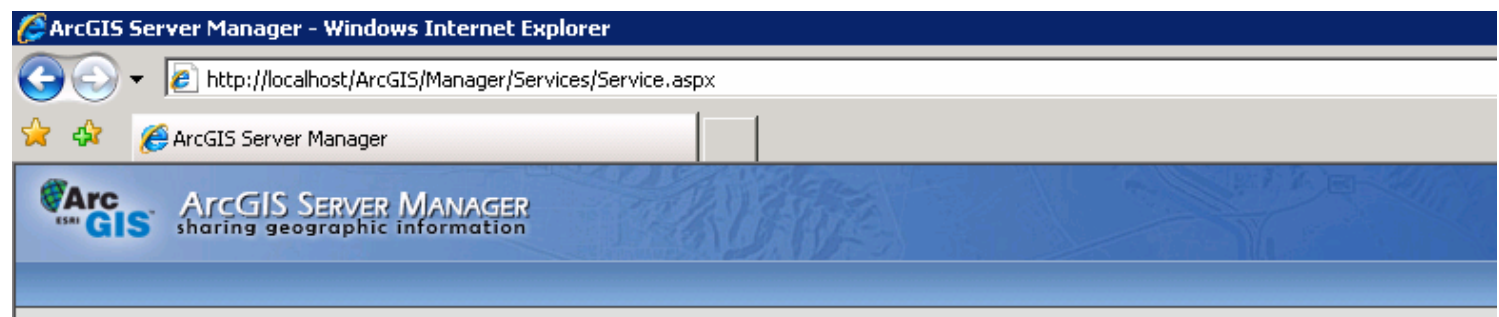

\section{Add New Service}

Map Document:

\LUCYStudents \gina_durizzi\BalboaParkDesertGarden\GIS\MapDocu

Type in the location of the resource. If you want to browse to a location.

smandrives appear in the list.

Data Frame:

Active Data Frame $\quad$ Change...

Output Directory:

c: \arcgisserver \arcgisoutput

$\pm$

Virtual Output Directory:

Supported Image Return Type:

http://lucy/arcgisoutput

MIME + URL

Specify cache directory

Server Cache Directory:

None

$\nabla$

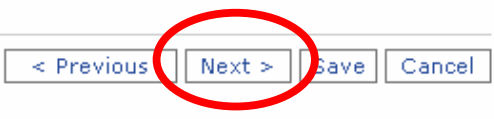

Select the map document (MXD) to be used for the web application, click Next.

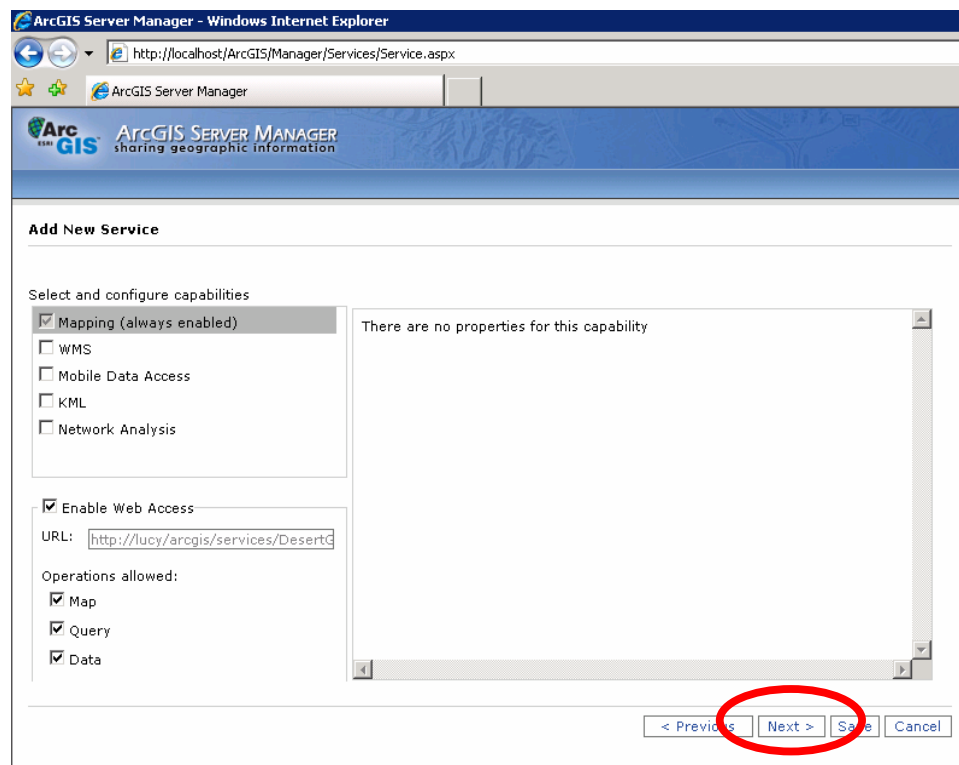

Use default selections, next. 


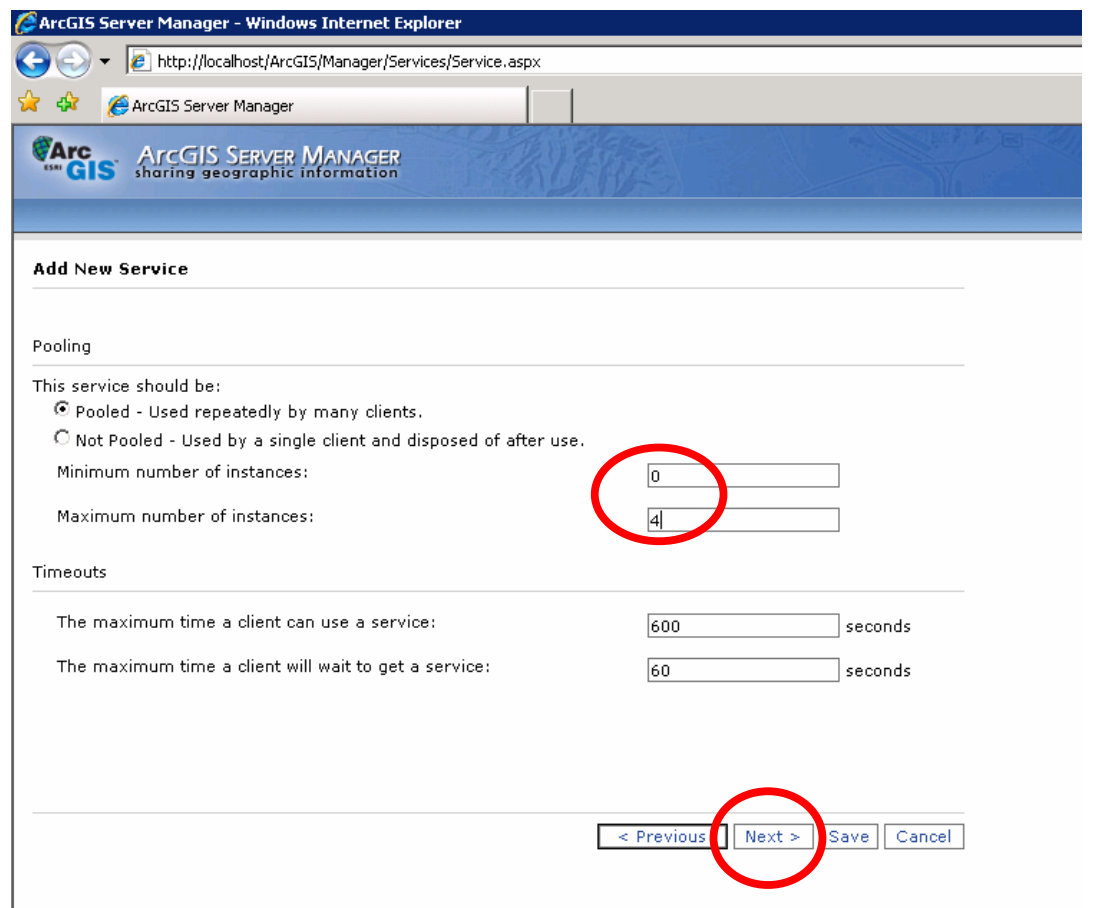

Set the Minimum number of instances to 0 . Set the Maximum number of instances to 4 . Click Next.

\section{CArcGIS Server Manager - Windows Internet Explore}

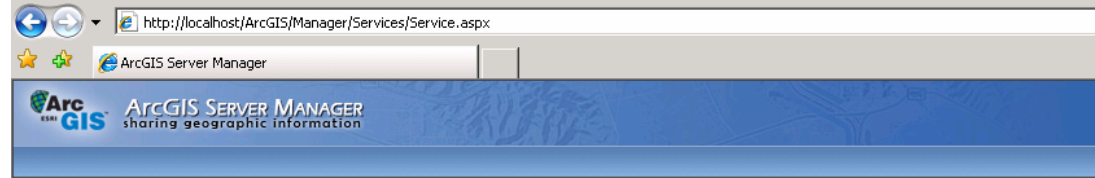

Add New Service

Services run in processes on the host machines.

Run instances of this configuration:

In a separate process for each instance (high isolation)

Recycling shuts down the process and restarts it at regular intervals to help maintain performance and

stability.

Recycle this configuration every:

Starting at:

24

hour(s).

12:00 AM
(e.g. 12:00 AM)

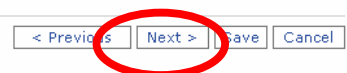

Use default selections, click Next. 


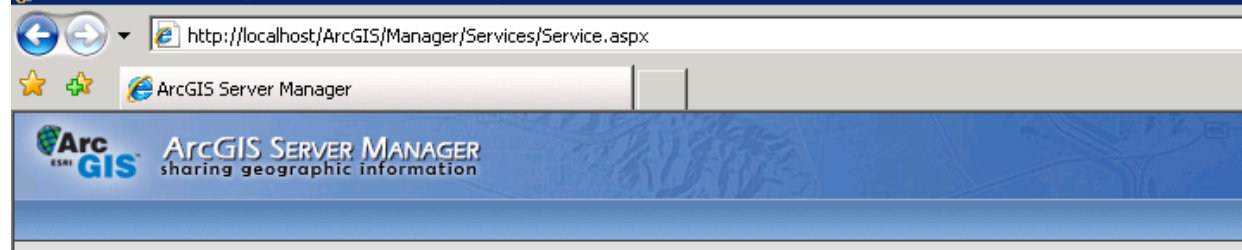

\section{Add New Service}

You are about to create the following ArcGIS Service:

General:

Name: DesertGardenx

Type: Map Service

Description:

Startup Type: Automatic

MaxRecordCount: 500

MaxBufferCount: 100

MaxImagewidth: 2048

MaxImage Height: 2048

MaxImage Height: 2048

OutputDir: c: Varcgisserver

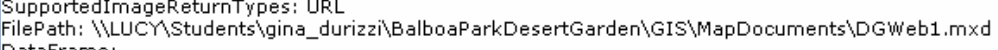

VirtualoutputDir: http://lucy/arcgisoutput

SOMC.arhapir:
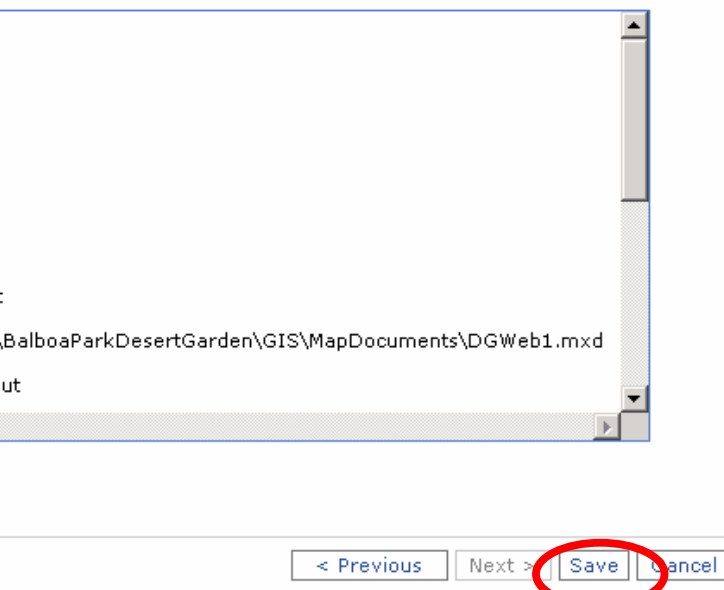

\section{Click Save}

\section{CArcGiS Server Manager - Windows Internet Explorer}

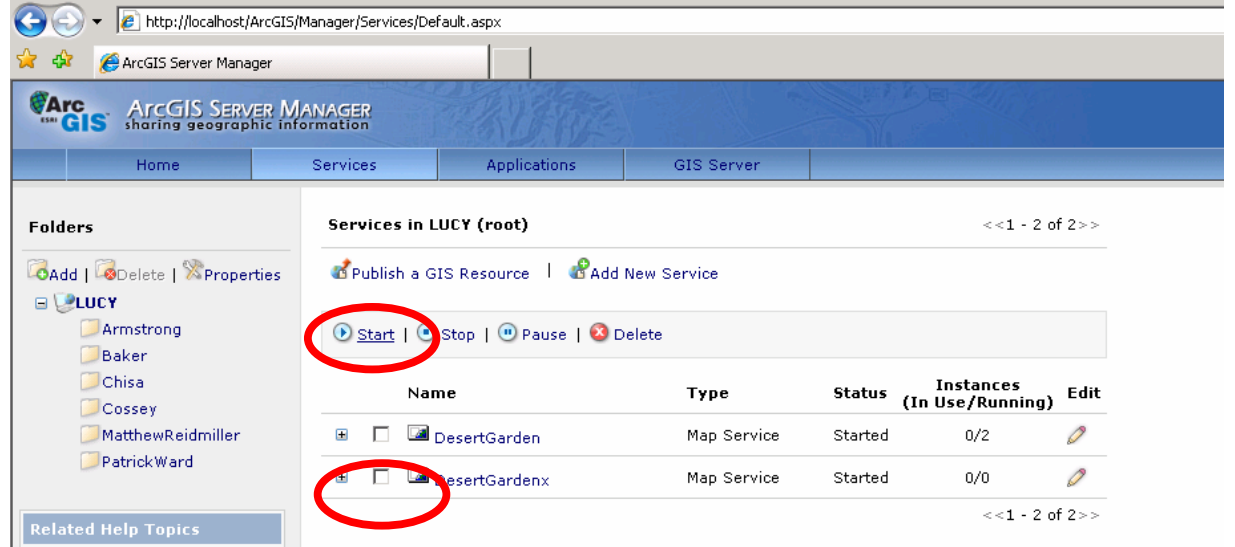

Publishing a GIS resource to the

server

Tutorial: Publishing a map service

Adding a new service

Organizing services

To start the service, check the service and click Start. 


\section{EArcGIS Server Manager - Windows Internet Explore}

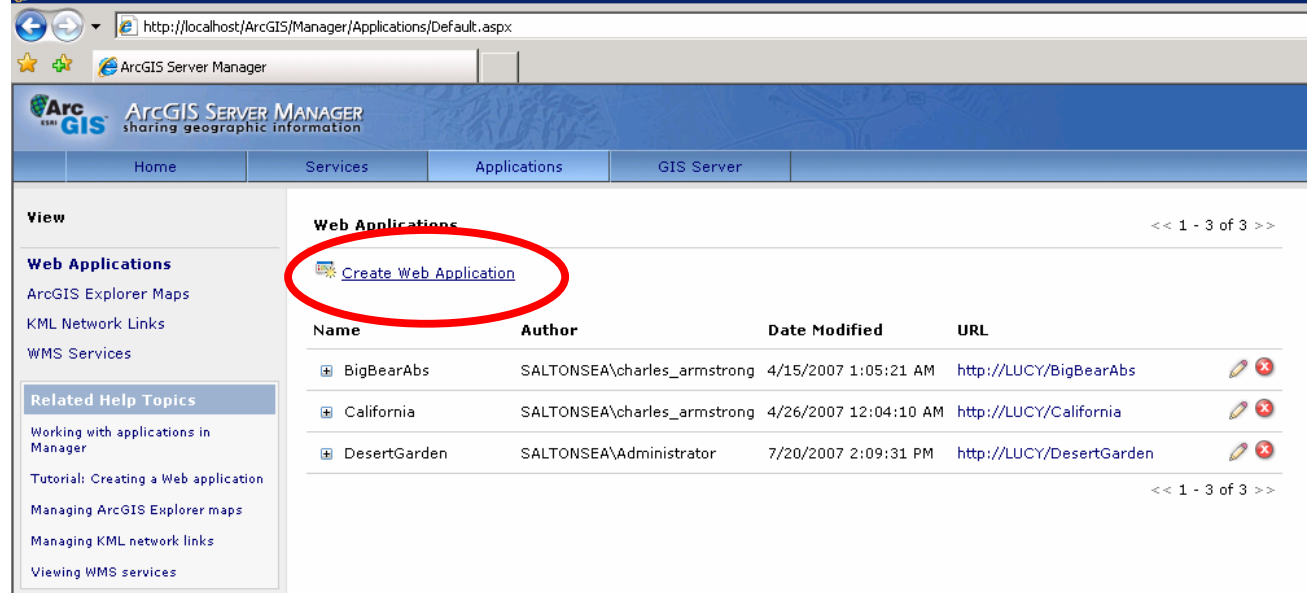

\section{Select, Create Web Application}

\section{EArcGIS Server Manager - Windows Internet Explorer}

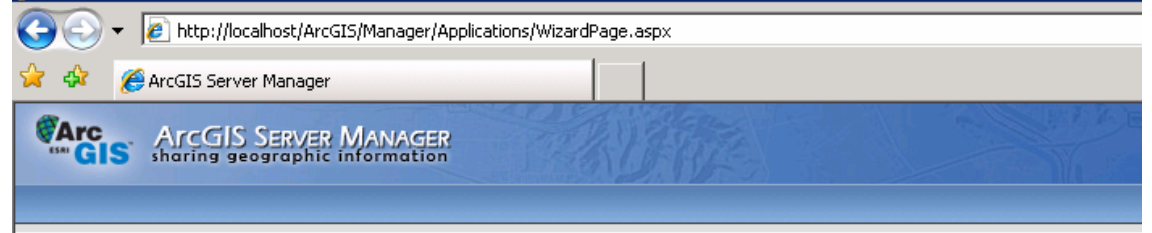

\section{Web Applications}

Specify the name of the application you want to create and the host (web server machine) it will run on.

Host:

Name:

Description:
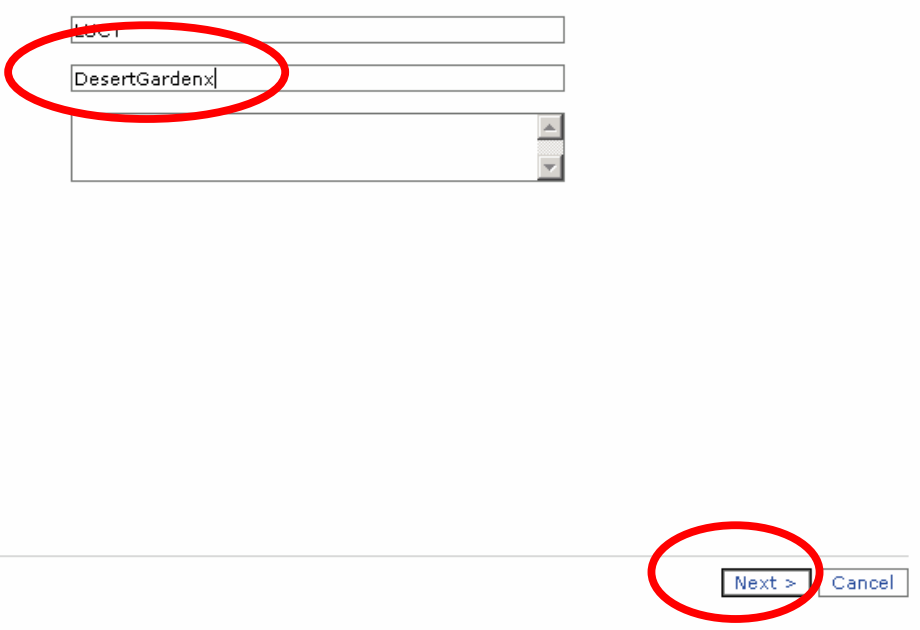

Name the web application and add description as necessary. Click Next. 

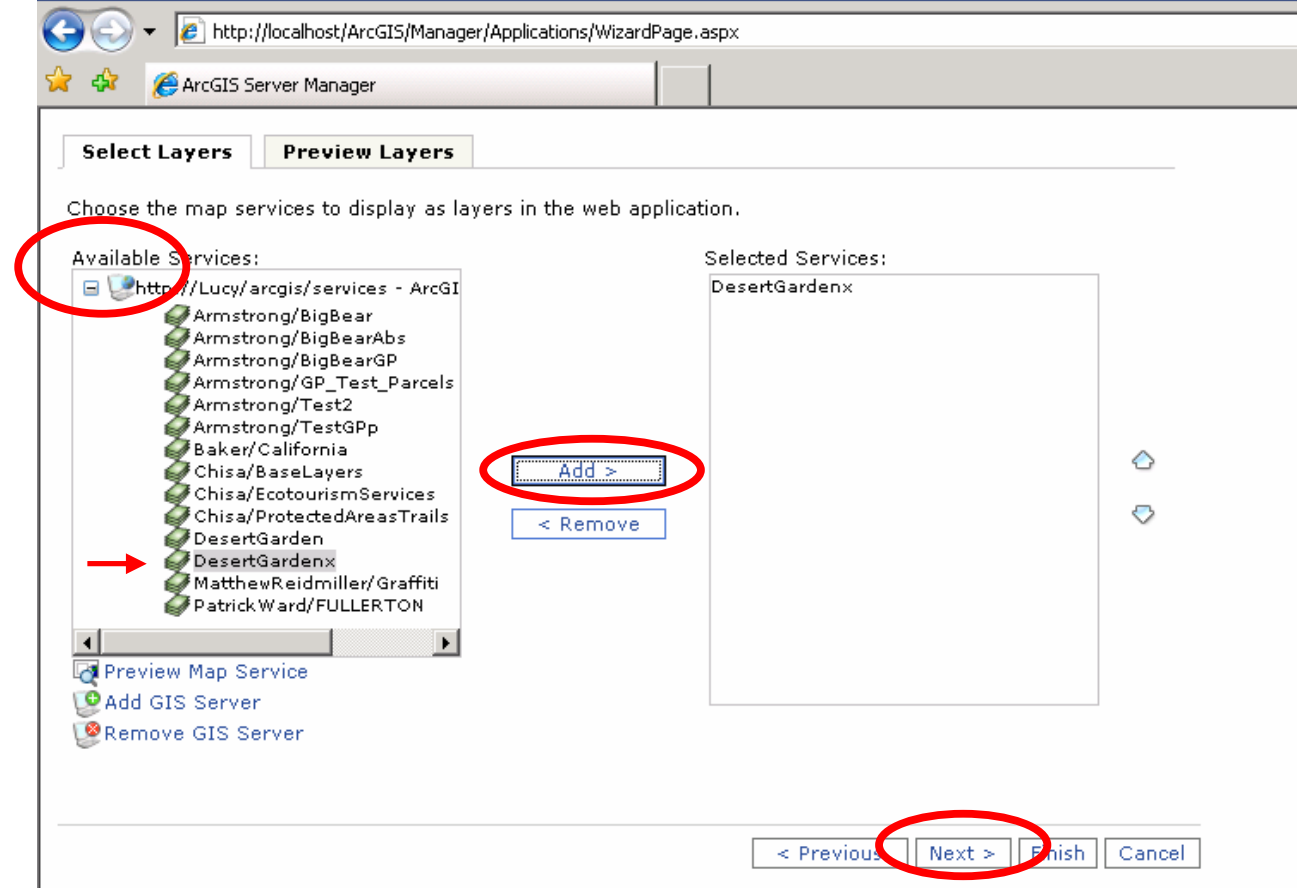

From Available Services, expand and select the service you just created and select Add to move the item to the Selected Services. Click Next.

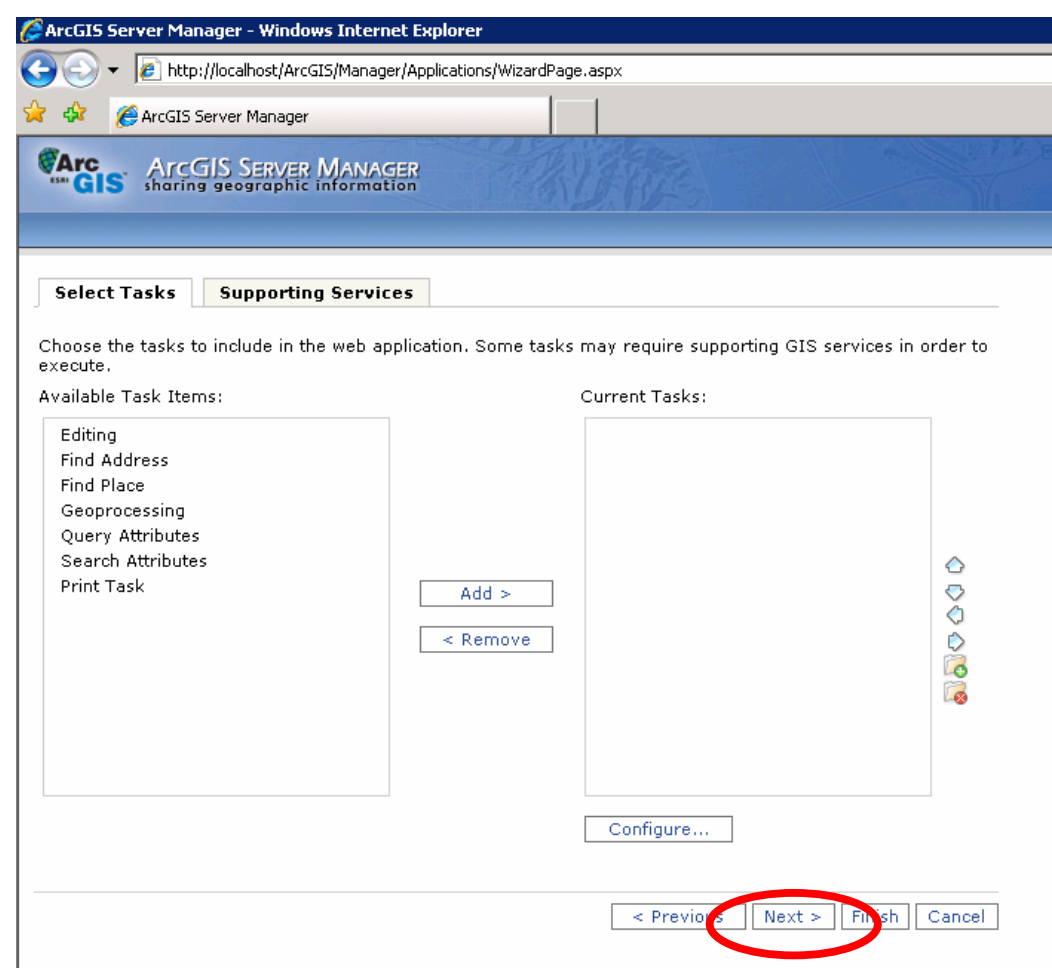

Use default settings, click Next. 


\section{EArcGIS Server Manager - Windows Internet Explorer}

(3) - e http://localhost/ArcGIS/Manager/Applications/WizardPage.aspx

is the ArcGis Server Manager

PArc ArCGIS SERVER MANAGER

Set Page Propertie

Title text:

Theme:

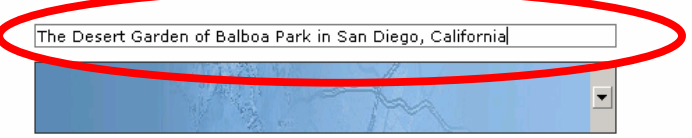

Web page links:

\begin{tabular}{|lll|}
\hline Name & URL \\
\hline ESRI & http://www.esri.com & \\
ESRI Support Center & http://support.esri.com & 8 \\
Help & Help/Default.htm & 8 \\
\hline Add Link & &
\end{tabular}

He Help/Default.htm

Enter title to be shown on web application.

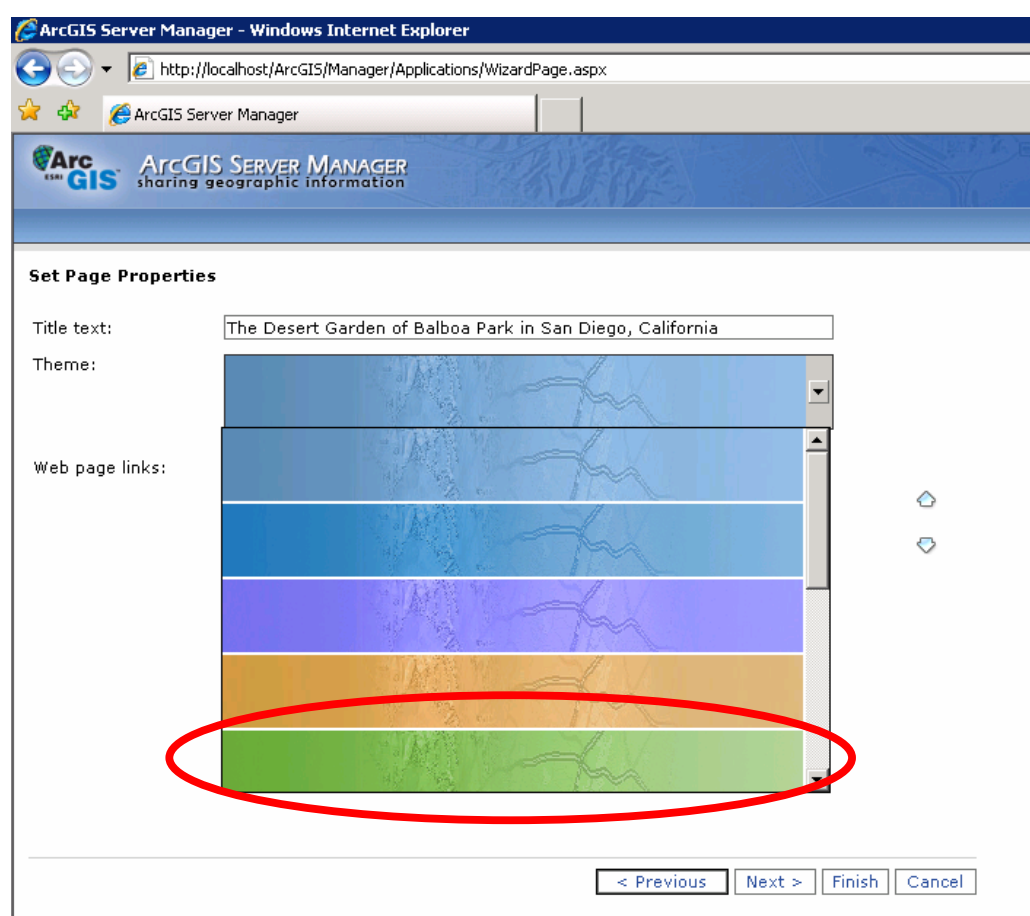

Select a theme color (light green). 


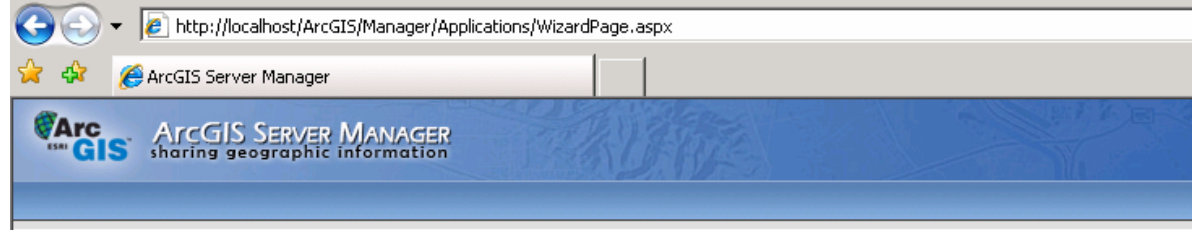

Set Page Properties

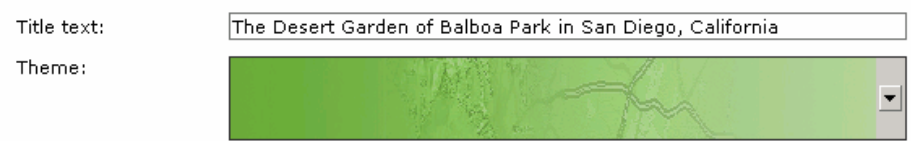

Web page links:

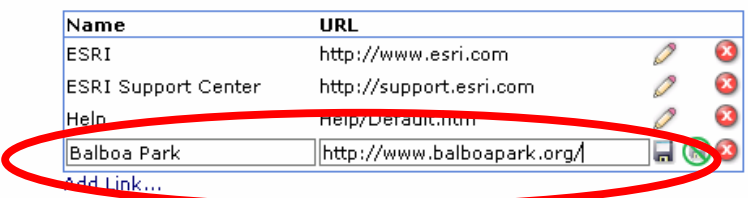

To add a web page link, select Add link..., enter web page name and URL, click the Save icon.

\section{EArcGIS Server Manager - Windows Internet Explorer}

(3) - http://localhost/ArcGIS/Manager/Applications/WizardPage.aspx

is the ArcGis Server Manager

\section{Harc AIS ArCGIS SERVER MANAGER}

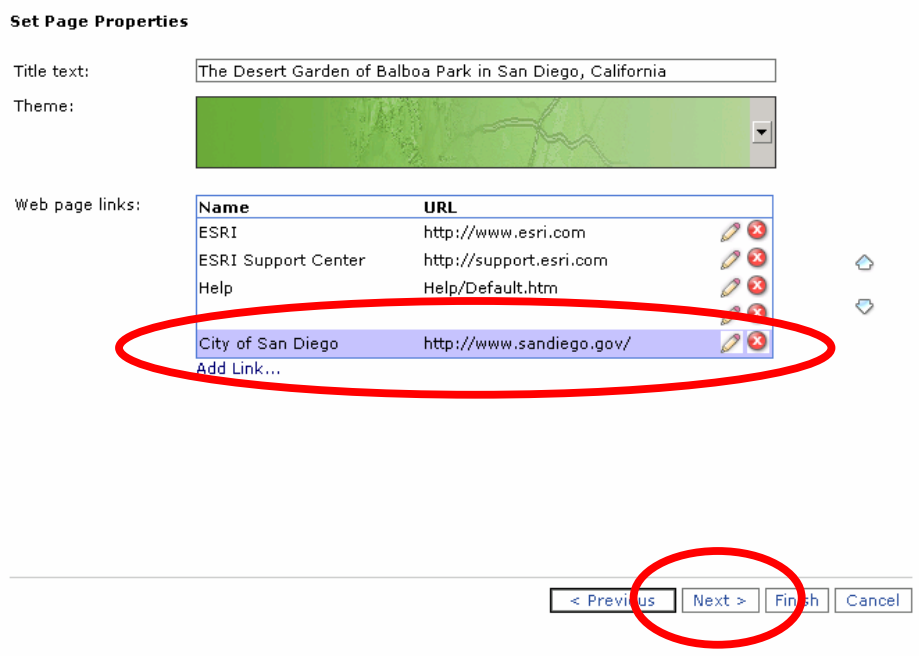

To add a second web page link, add link, enter web page name and URL, click the Save icon. Click Next. 


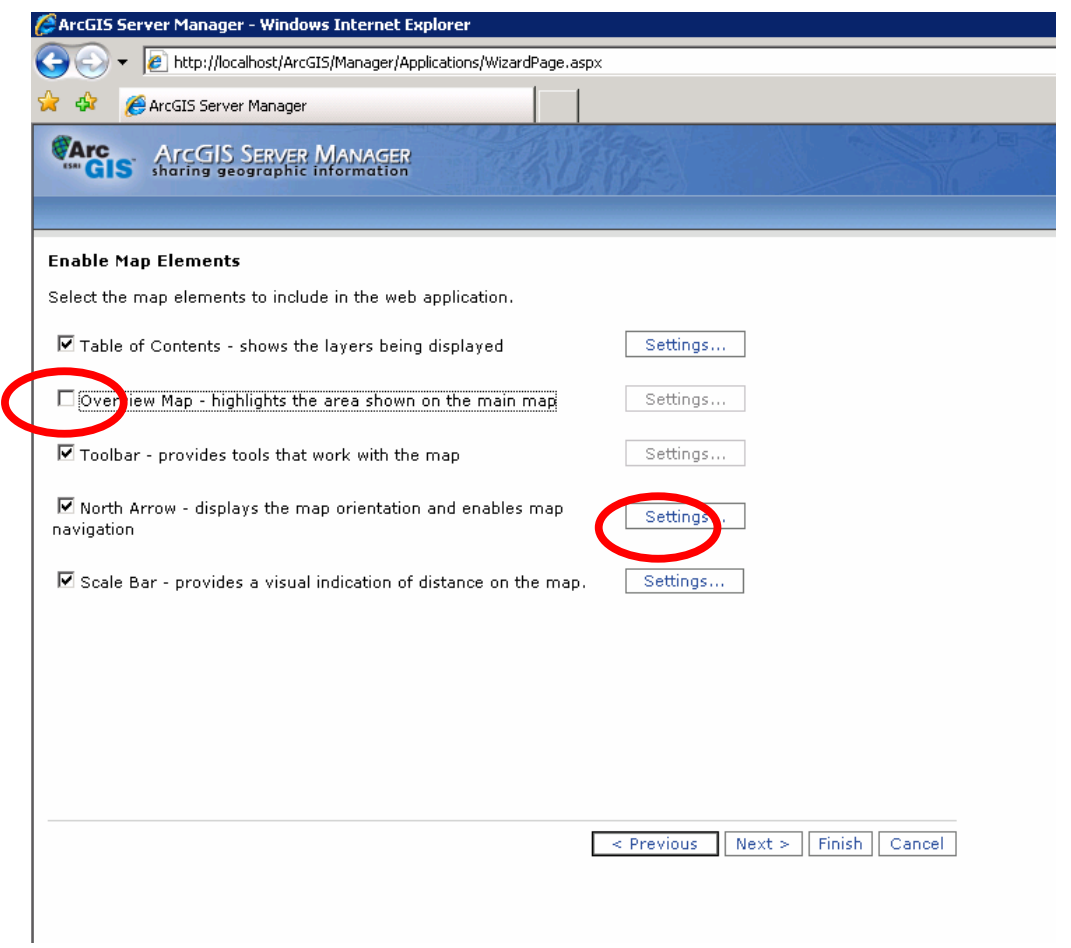

Uncheck the option for an Overview Map, click Settings... for North Arrow.

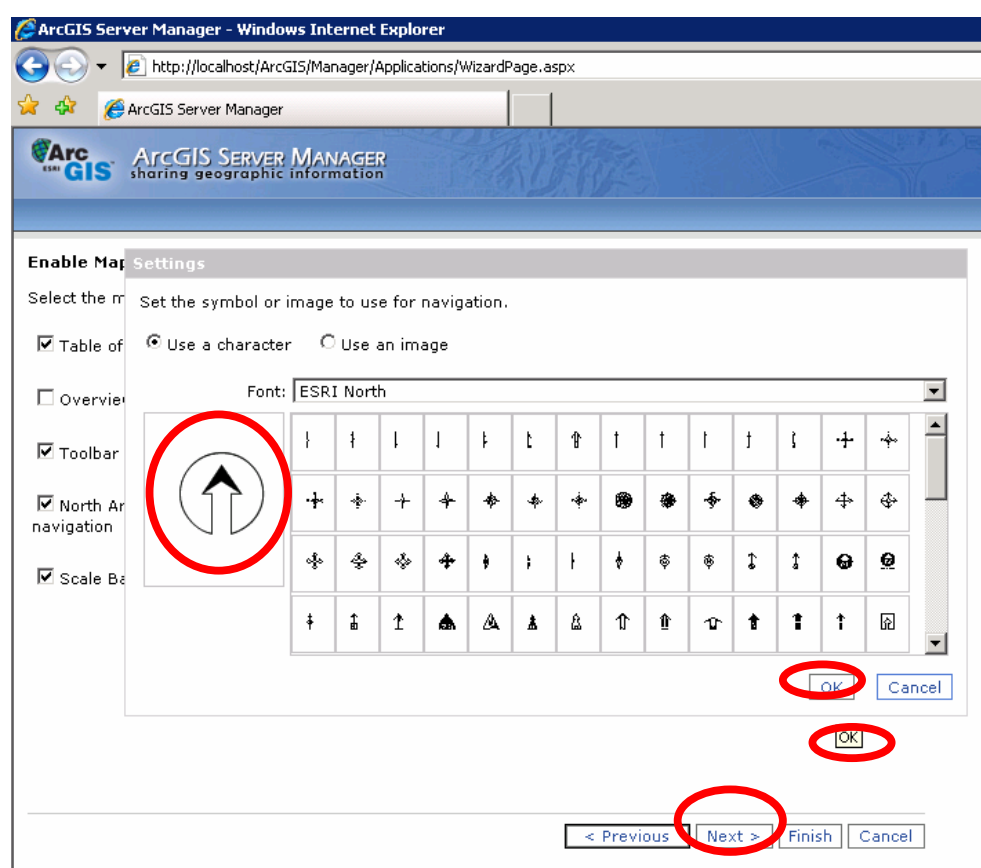

Select the north arrow from the fifth row, second column, OK, OK. Click Next 


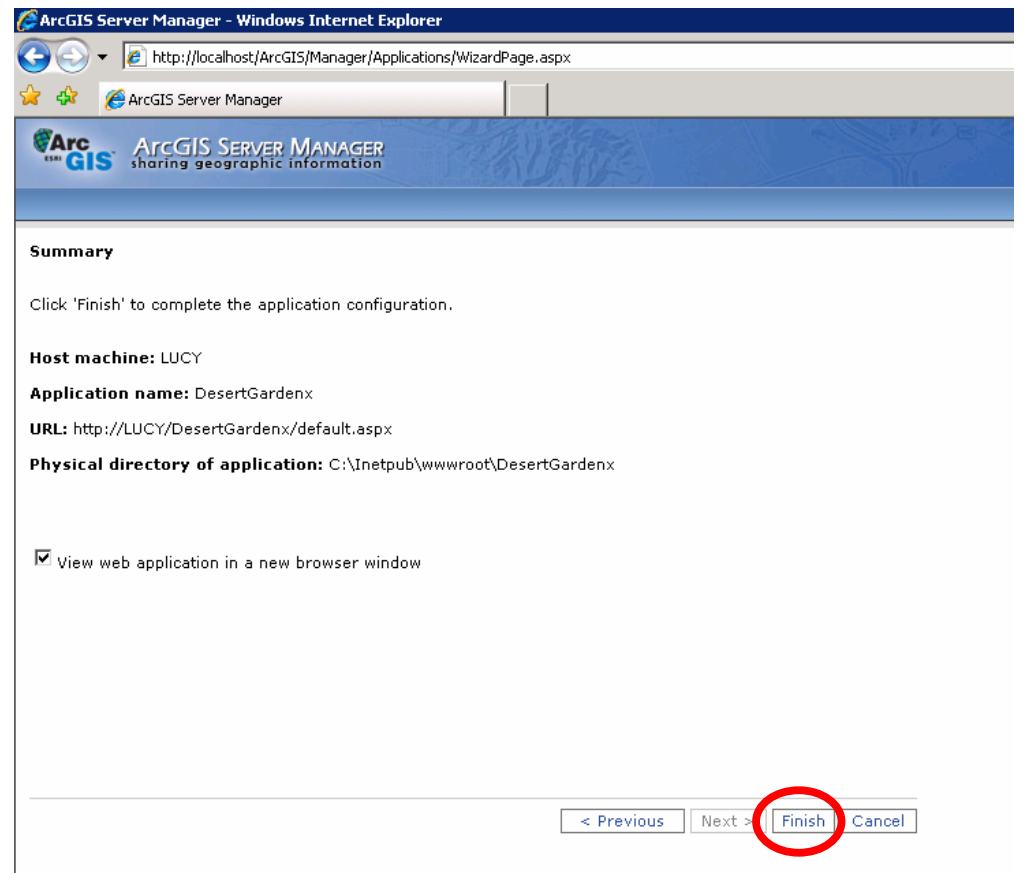

This is a summary. Click Finish.

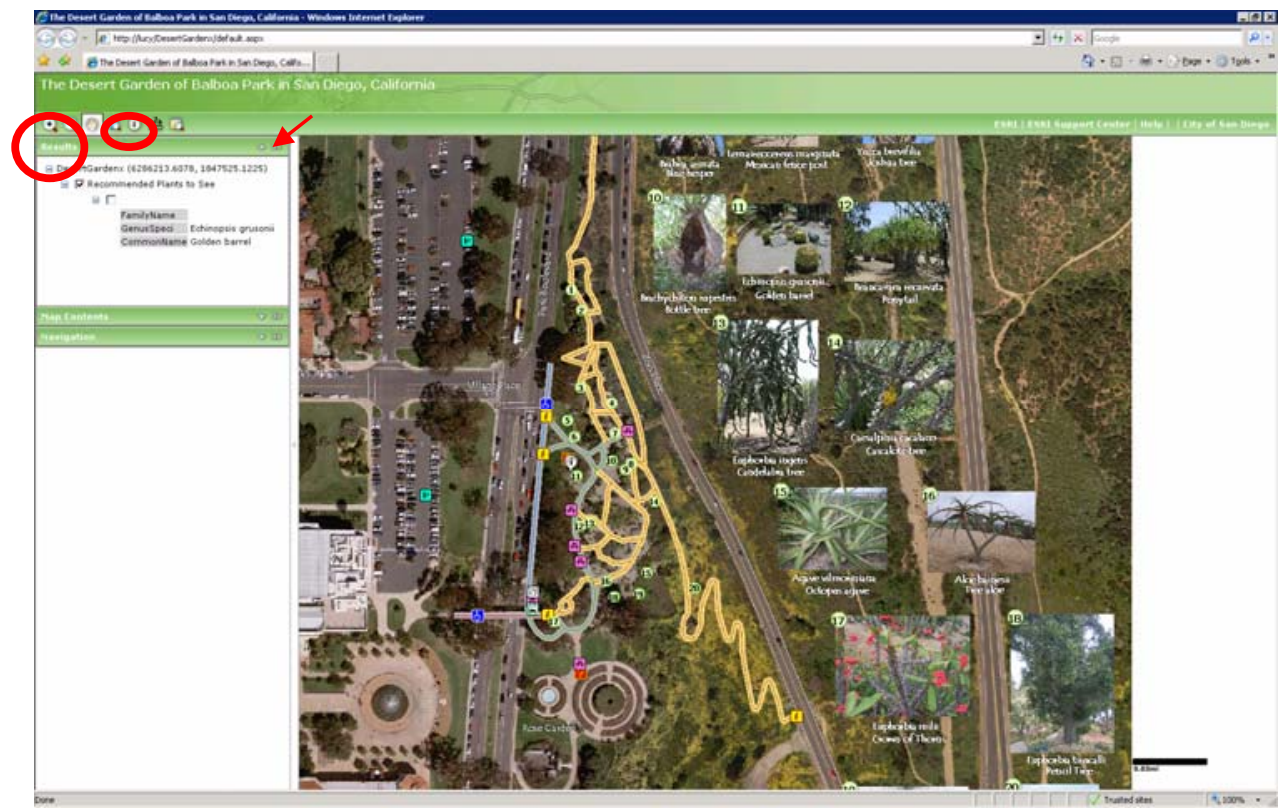

The website will open automatically.

Functionality:

Click the I identify button to select a feature to identify.

The results will display in the Results box.

Open the Results box to open.

You will need to expand the pull down to see your selection. 


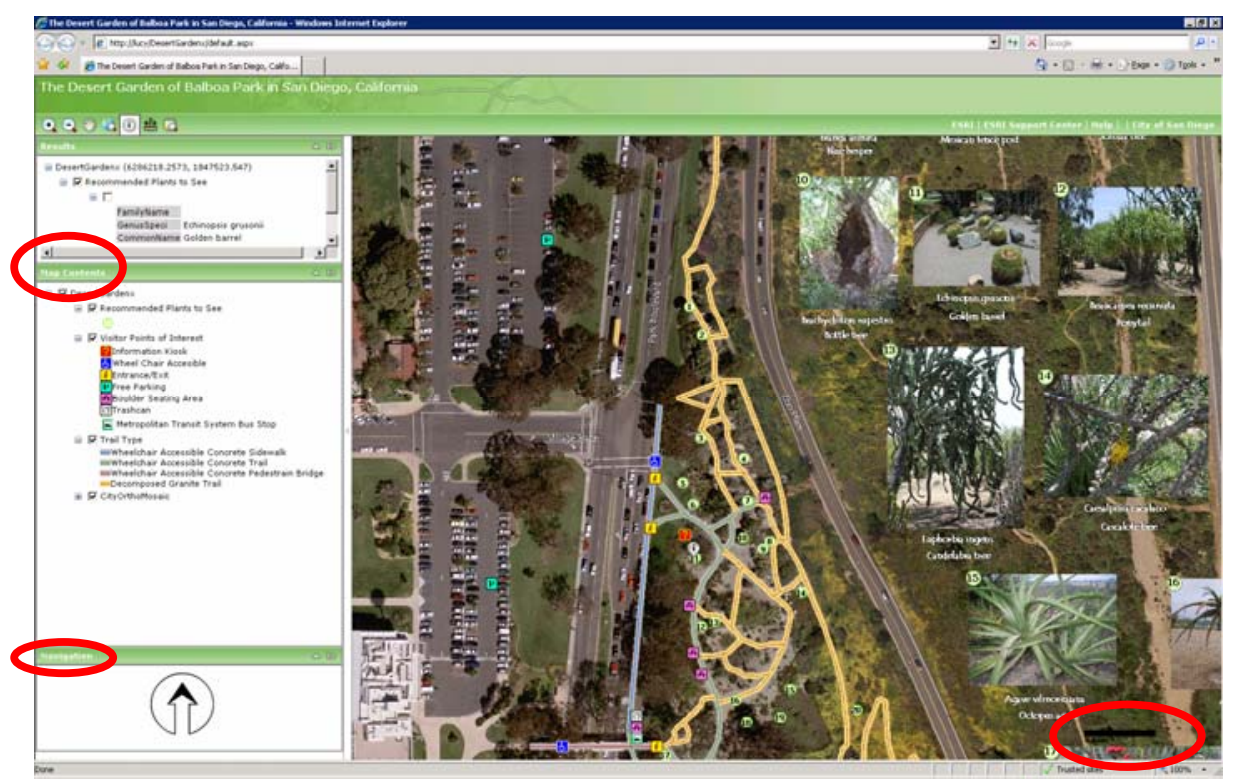

To view the Map Contents (layers), open the Map Contents box.

To use the navigation north arrow, open the navigation box.

The dynamic scale bar is located at the bottom right corner of the website.

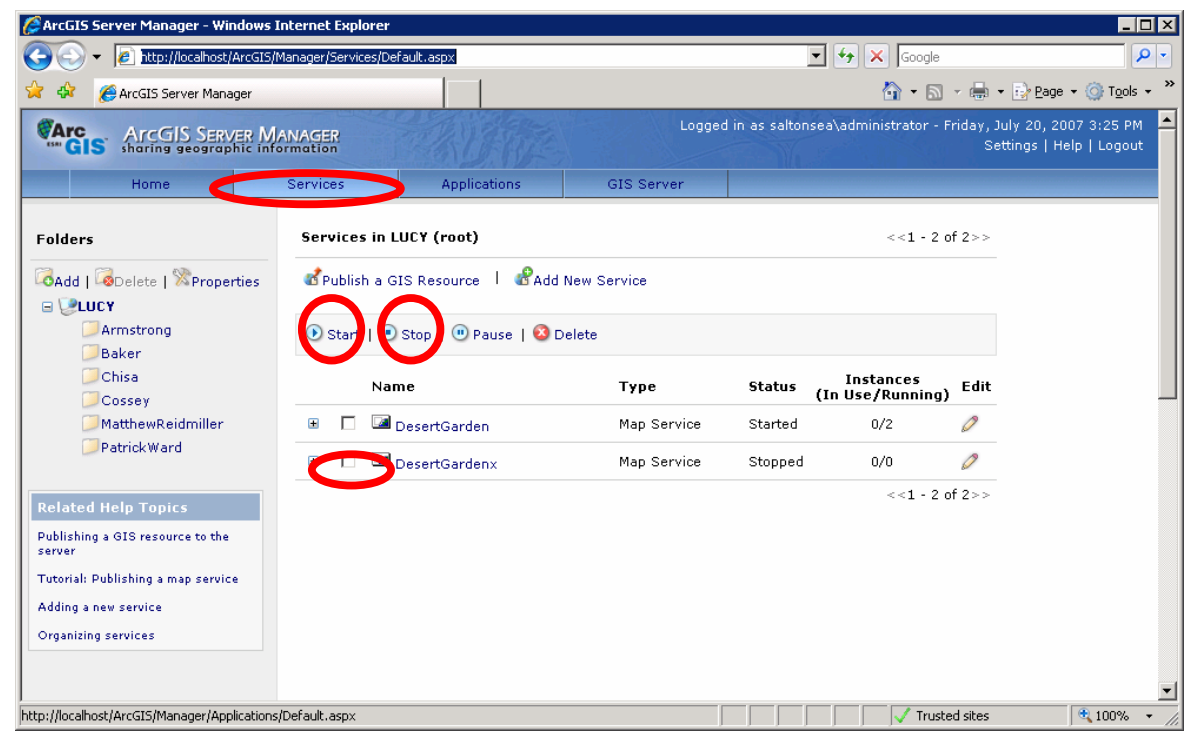

To make changes to the MXD:

Select the Services tab, check the service and click Stop to stop the service.

Open project MXD and make changes.

To update the service with new changes made to the project MXD, go back to ArcGIS Server Manager, select the Services tab, and check the service and click Start to start the service.

To delete a service, check the service and click Delete. 


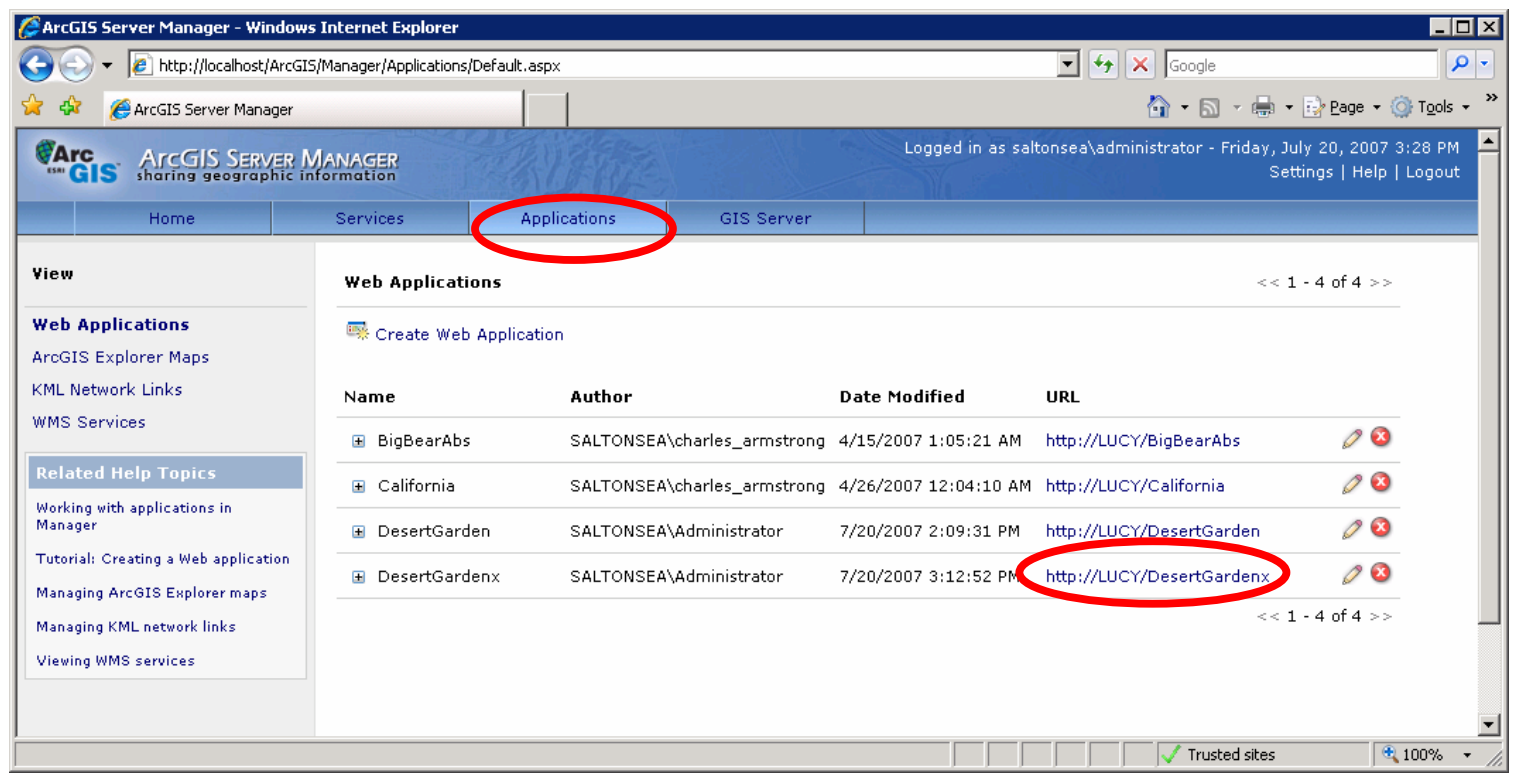

Select the Applications tab, select the URL to open the web application.

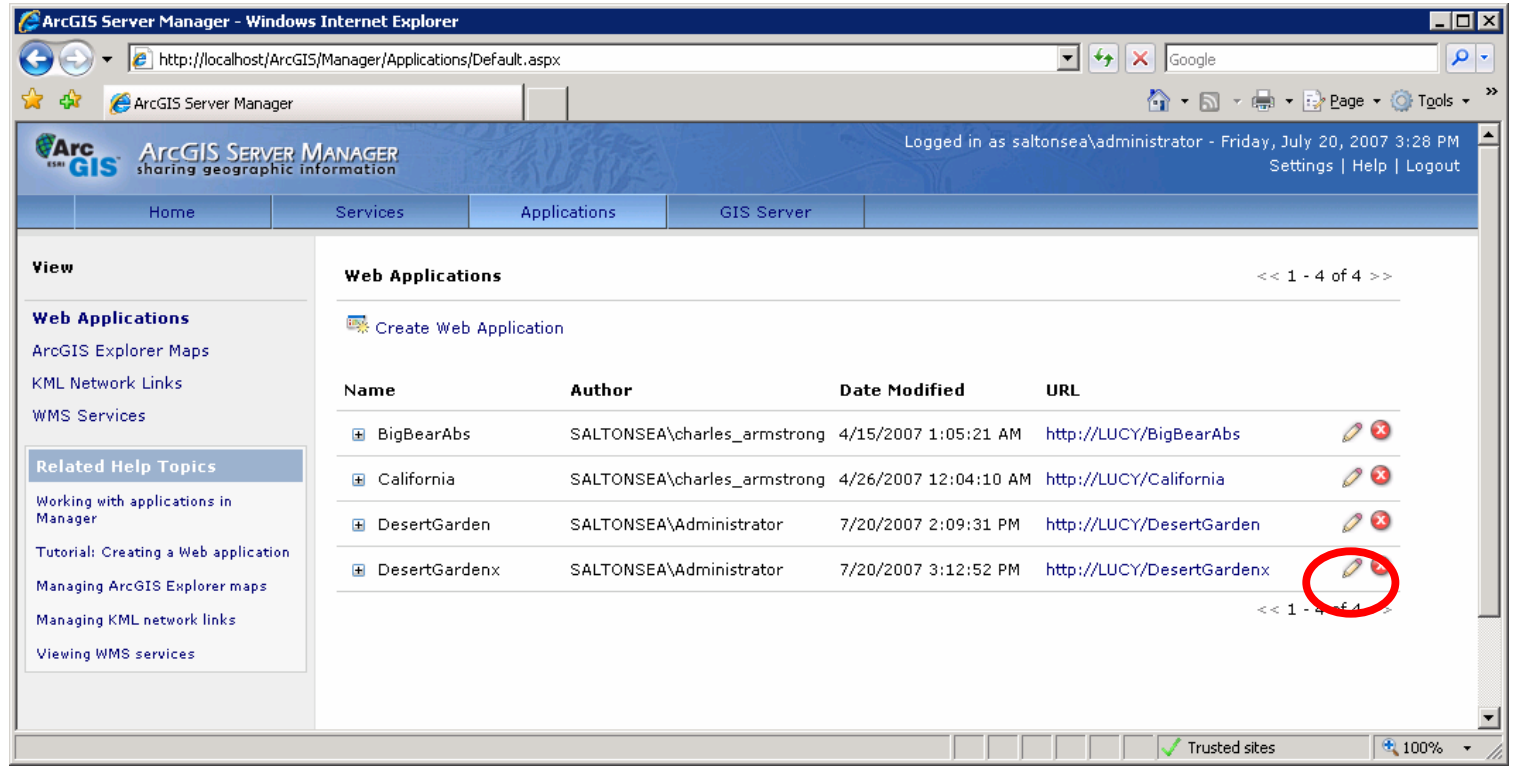

Select the Applications tab, click the Edit icon (pencil) for the web application to make edits.

Click the Delete icon to delete a web application if necessary. 